\title{
Statelessness in the United States:
}

\section{A Study to Estimate and Profile the US Stateless Population}
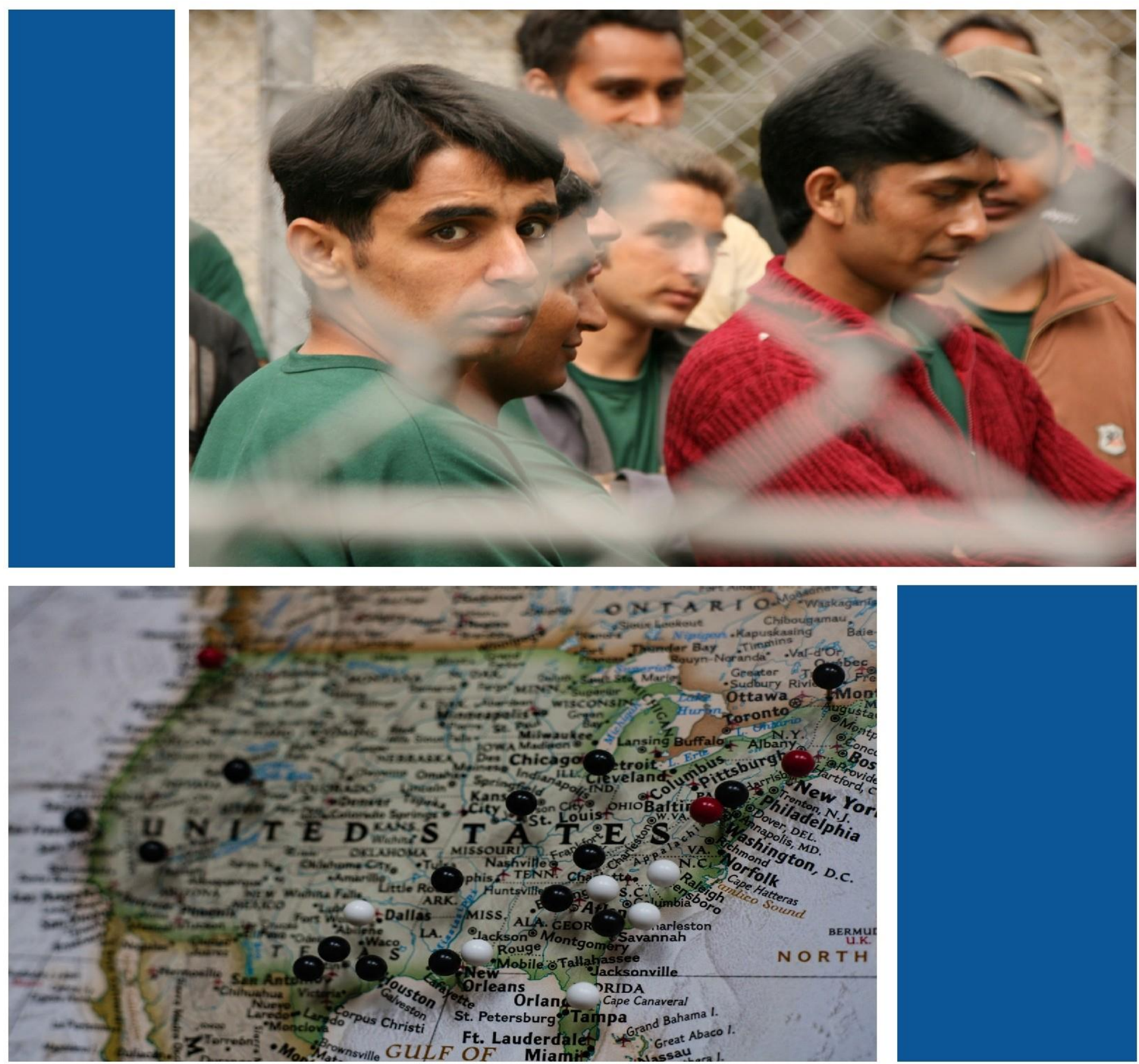

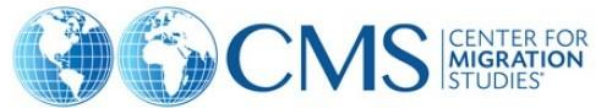


(C) 2020 Center for Migration Studies of New York (CMS).

All Rights Reserved.

Cover photo credits:

Top photo: Mykola Komarovskyy / Shutterstock.com

Bottom photo: Joey Csunyo / Unsplash.com

No part of this publication may be reproduced or transmitted in any form by any means, electronic or print, including photocopy, or any information storage retrieval system, without the permission of CMS.

Suggested Citation:

Kerwin, Donald, Daniela Alulema, Michael Nicholson and Robert Warren. 2020. Stateless in the United States: A Study to Estimate and Profile the US Stateless Population. CMS Report, January. New York: CMS.

For more information, visit www.cmsny.org. 


\section{Statelessness in the United States: A Study to Estimate and Profile the US Stateless Population}

\section{A report by the Center for Migration Studies}

January 2020 


\section{Acknowledgements}

This project would not have been possible without the initiative, genius and participation of a broad community of individuals and institutions. To start, the authors wish to thank the following members of the project advisory group who lent their invaluable expertise and guidance to the study's design: Heather Alexander of Tilburg University, Laura Bingham of Open Society Justice Initiative, Karina Clough of United Stateless, Ivonne Garza of the Inter-American Commission of Human Rights, Catherine Harrington of Women's Refugee Commission, Nikolai Levasov of United Stateless, Chris Nash of the European Network on Statelessness, Francisco Quintana of the Americas Network on Statelessness, Bryan Roberts of the Institute for Defense Analyses, Katherine Southwick of the George Mason University's School of Conflict Analysis and Resolution, and Vicky Virgin from the NYC Mayor's Office for Economic Opportunity.

The study also benefitted significantly from feedback on the initial profiles of potentially stateless populations in the United States by Heather Alexander, David Baluarte of Washington and Lee University School of Law, Catherine Harrington, and Nikolai Levasov. The authors also wish to thank Dr. Jamie Winders of Syracuse University, Meredith Linsky of the American Bar Association, Jeanne Atkinson formerly of the Catholic Legal Immigration Network, Inc, and Mark von Sternberg of Catholic Charities Community Services of the Archdiocese of New York for their trenchant input on the organizational online survey.

The authors also thank Elizabeth Davis of Syracuse University for her superb work during the Institutional Review Board application process and, in particular, for her contributions to creating the organizational online survey, conducting interviews with stateless persons, and assisting in the development of the interview instrument. We also thank Dr. Jamie Winders for her overall guidance and support on the study.

The authors also wish to acknowledge the excellent work of former CMS interns, including Jacqueline Altamirano, Christina Auguste, Meagan Beckmeyer, Hayk Esaghoulyan, Marike Heesch, Samantha Kunin, Lucy McAuliffe and Nikhita Mendis, who assisted with transcriptions and outreach to organizations and service providers during the project's data collection stage. They are also grateful to Jeffrey Sharlein, who served as a consultant in the early stages of the project, working on profiles of populations with potentially stateless members or persons potentially at risk of statelessness.

The authors also thank the community-based organizations and legal service providers that provided their knowledge of statelessness with us by participating in the project's online survey. Above all, the authors wish to express their profound gratitude to the stateless individuals who shared their stories, challenges and aspirations in the hope that this would lead a greater understanding of and commitment to responding to this problem in an effective and humane way and in accordance with international law. 


\section{Table of Contents}

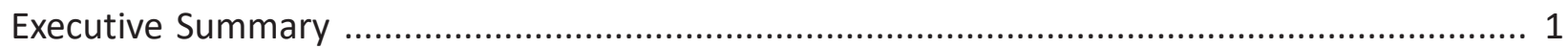

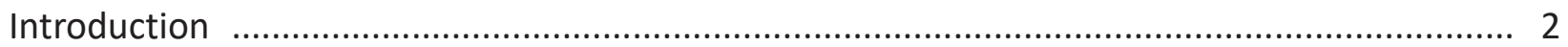

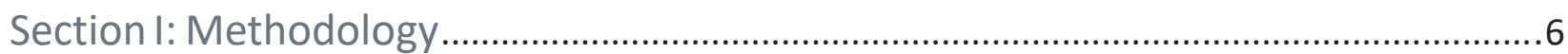

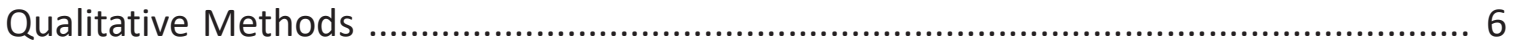

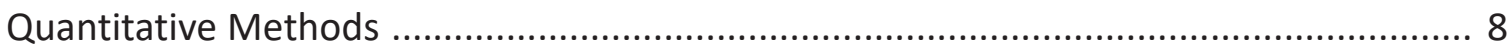

Section II: Causes of Statelessness, the US Legal Context, and Profiles of Potentially Stateless US Residents orThose Potentiallyat Risk ofStatelessness ................................9

The US Legal Context ..................................................................................................11

Profiles of Populations That Are Potentially Stateless or Potentially at

Risk of Statelessness in the United States ............................................................... 14

Europe and Eurasia .................................................................................... 15

The Middle East and North Africa ............................................................ 19

Asia and the South Pacific ............................................................................. 23

Sub-Saharan Africa ................................................................................. 30

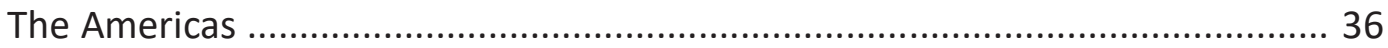

Additional Considerations .............................................................................. 37

Section III: Estimates of Those Who are Potentially Stateless or Potentially At Risk

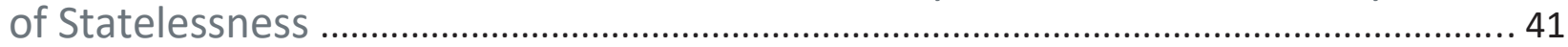

Sources of Data and Tentative Estimates of US Stateless Populations .............................. 41

American Community Survey ......................................................................... 41

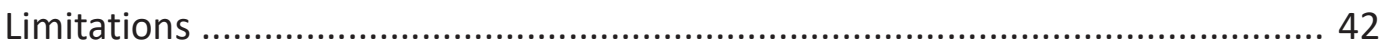

Provisional Estimates of Persons who are Potentially Stateless

or Potentially at Risk of Statelessness in the United States ................................. 43

Demographic and Labor Force Characteristics of Populations

That Are Potentially Stateless or Potentially at Risk of Statelessness ................ 53

Potentially Omitted Groups .............................................................................. 59

Refugee- and Immigration-Related Administrative Data on the Stateless .............60

Worldwide Refugee Admissions Processing System (WRAPS) ...........................6 61

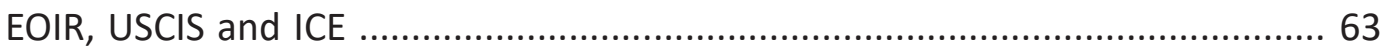

Section IV: Challenges Confronting US Stateless Persons ....................................... 68

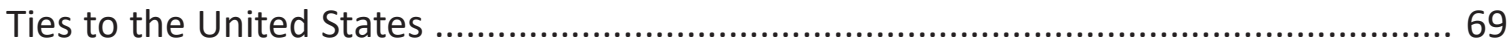

Challenges Facing Stateless Persons without Lawful Status ........................................ 70

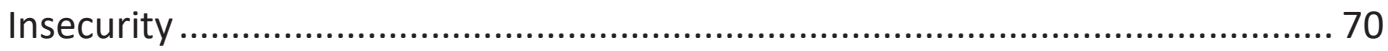

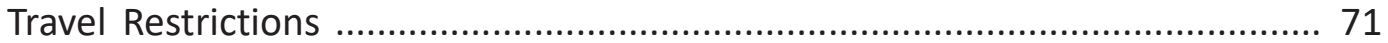

Employment Consequences ………....................................................... 71

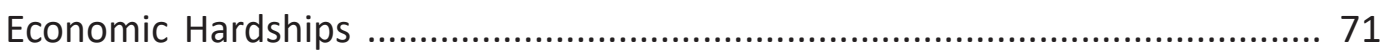

ICE Order of Supervision Requirements ...................................................... 72

Effects on Personal and Work Relationships ................................................... 72 


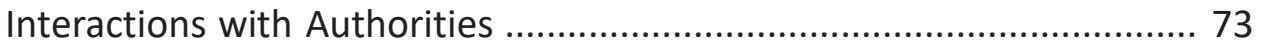

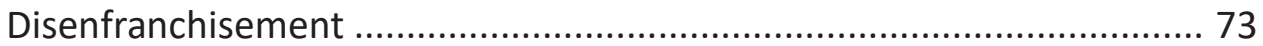

Psychological Stress ........................................................................ 73

Challenges Facing Refugees and Lawful Permanent Residents ........................ 74

Barriers to Adjustment of Status or Naturalization ................................ 74

Travel Restrictions ..................................................................... 74

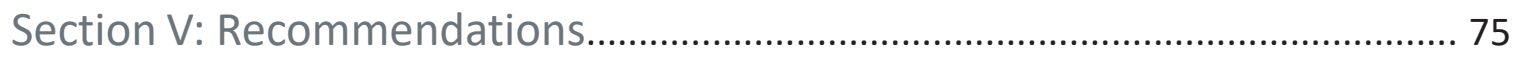

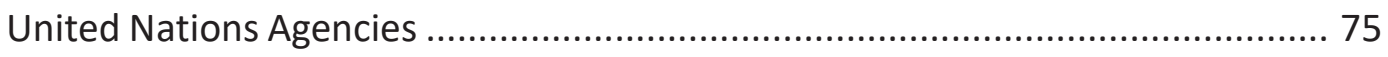

The US Congress, the Administration, and State and Local Governments .......... 75

US Civil Society Institutions and CBOs ........................................................... 76

Recommendations for the Improved Identification of Stateless

Populations in the United States .................................................................. 77

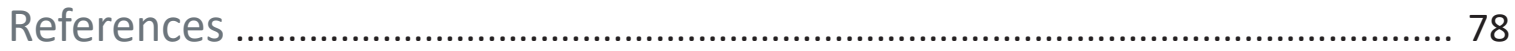

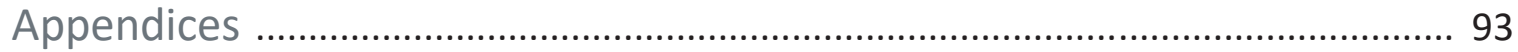

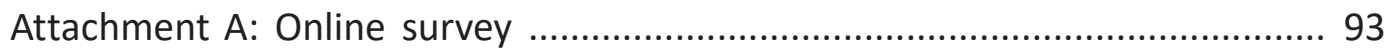

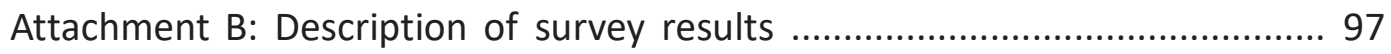

Attachment C: Interview questionnaire .................................................. 98

Attachment D: Annual numbers of persons in deportation proceedings of selected nationalities by outcome and custody status ................................. 101

Attachment E: Annual numbers of asylum decisions by nationality and court decision

Attachment F: Annual figures of affirmative asylum applications filed and cases completed from 2011 to 2016 


\title{
Statelessness in the United States: A Study to Estimate and Profile the US Stateless Population
}

\author{
Donald Kerwin, Daniela Alulema, Michael Nicholson, and Robert Warren
}

"I question my very existence, my very essence of being human. We don't want to live or die as ghosts."

Stateless person from the former Soviet Union

"Stateless means having no hope, being kind of empty. Because sometimes your body is moving but there is nothing to tell about yourself."

Stateless person from Ethiopia

\section{Executive Summary}

In October 2017, the Center for Migration Studies of New York (CMS) initiated a study to map the stateless population in the United States (US). This study sought to:

- Develop a methodology to estimate the US stateless population;

- Provide provisional estimates and profiles of persons who are potentially stateless or potentially at risk of statelessness in the United States;

- Create a research methodology that encouraged stateless persons to come forward and to join a growing network of persons committed to educating the public on and pursuing solutions to this problem; and,

- Establish an empirical basis for public and private stakeholders to develop services, programs, and policy interventions to prevent and reduce statelessness (UNHCR 2014g, 6), and to safeguard the rights of stateless persons (UNHCR 2014d).

This report describes a unique methodology to produce estimates and set forth the characteristics of US residents who are potentially stateless or potentially at risk of statelessness. The methodology relies on American Community Survey (ACS) data from the US Census Bureau, supplemented by very limited administrative data on stateless refugees and asylum-seekers. ${ }^{1}$

As part of the study, CMS developed extensive, well-documented profiles of non-US citizen residents who are potentially stateless or potentially at risk of statelessness. It then used these profiles to query ACS data in order to develop provisional estimates and determine the characteristics of these populations. 
The report finds that the population in the United States that is potentially stateless or potentially at risk of statelessness is larger and more diverse than previously assumed, albeit with the caveat that severe data limitations make it impossible to provide precise estimates of this population. Stateless determinations require individual screening, which the study could not undertake. Individuals deemed potentially stateless or potentially at risk of statelessness in this report may in fact have been able to secure nationality in their home countries or in third countries. They may also be on a path to citizenship in the United States, although nobody in CMS's estimates had yet to obtain US citizenship.

According to CMS's analysis, roughly 218,000 US residents are potentially stateless or potentially at risk of statelessness. These groups live in all 50 states, ${ }^{2}$ with the largest populations in California $(20,600)$, New York $(18,500)$, Texas $(15,200)$, Ohio $(13,200)$, Minnesota $(11,200)$, Illinois $(8,600)$, Pennsylvania $(8,200)$, Wisconsin (7,300), Georgia $(6,600)$, and Virginia $(6,500)$ (Chart 2).

The report recommends ways to improve data collection and, thus, to develop better estimates in the future. It also lifts up the voices and challenges of stateless persons, and outlines steps to reduce statelessness and to safeguard the rights of stateless persons in the United States. As it stands, the paucity of reliable federal data on the stateless, the lack of a designated path to legal status for them under US law, and the indifference of government agencies contribute to the vulnerability and isolation of these populations.

\section{Introduction}

The 1954 Convention Relating to the Status of Stateless Persons ["the 1954 Convention"] defines a "stateless person" as "a person who is not considered as a national by any State under the operation of its law." ${ }^{3}$ This definition - which has acquired customary law status according to the International Law Commission (ILC 2006, 36) - refers to the de jure stateless (those stateless by law), in contrast to the de facto stateless, a term not defined by treaty or international instrument (UNHCR 2014g, 5). ${ }^{4}$ The 1954 Convention also enumerates obligations and responsibilities of Contracting States and stateless persons, and the rights of the stateless. ${ }^{5}$

The 1961 Convention on the Reduction of Statelessness ["the 1961 Convention"] seeks to prevent statelessness by establishing "international norms relating to nationality" and, thus, to reduce statelessness over time. ${ }^{6}$ In particular, it requires states "to grant citizenship to children born on their territory, or born to their nationals abroad, who would otherwise be stateless." ${ }^{\prime \prime}$ It also prohibits "the withdrawal of citizenship from States' nationals - either through loss, renunciation, or deprivation of nationality - when doing so would result in statelessness." 8 The 1961 Convention was drafted with the understanding that states "maintain the right to elaborate the content of

2 CMS derived these estimates from the American Community Survey

3 Convention Relating to the Status of Stateless Persons, art. 1(1), Sept. 28, 1954, 360 U.N.T.S. 117.

4 A UNHCR publication sets forth a working definition of the de facto stateless as "persons outside the country of their nationality who are unable or, for valid reasons, are unwilling to avail themselves of the protection of that country" (Massey 2010, 61).

5 In particular, the 1954 Convention provides for free access to courts of law, work, entrepreneurship, housing, elementary education, labor rights, choice of place of residence, free movement within the contracting country, identity papers, travel documents, assimilation and naturalization.

6 Convention on the Reduction of Statelessness, Introductory Note, Aug. 30, 1961, 989 U.N.T.S. 175.

7 Id.

8 Id. 
their nationality laws," but must comply with international human rights standards. ${ }^{9}$

In the United States, the term nationality refers to a person "owing permanent allegiance" to the country, whether a citizen or a non-citizen. ${ }^{10}$ Beyond US citizens, the term mostly applies to persons born in outlying US possessions, particularly America Samoa and Swains Island. ${ }^{11}$

For the purposes of this study, CMS applies the internationally recognized definition of a stateless person reflected in Article 1 of the 1954 Convention: "a person who is not considered as a national by any State under the operation of its law." The term persons "at risk of statelessness" term denotes those with "difficulties furnishing relevant proof to establish their nationality" and who are therefore "at risk of not being considered nationals by a State" (UN 2011, 5). ${ }^{12}$ As noted in this report, due to serious insufficiencies in available data on either of these populations in the United States, the study is unable to identify with precision the number of people who meet these definitions, and it is not always possible to distinguish between the two populations. As such, the CMS report refers broadly to populations who are "potentially stateless or potentially at risk of statelessness."

CMS's estimates of US residents who are potentially stateless or potentially at risk of statelessness include persons who may have gained nationality in their country of origin or in a third country. However, its estimates do not include US citizens. Some stateless persons may ultimately become US citizens, but as the United Nations High Commissioner for Refugees (UNHCR) Handbook on Protection of Stateless Persons provides, "statelessness determinations are not "predictive exercises" regarding who may or may not become a citizen, and stateless persons may be "partway through a process of acquiring nationality" (UNHCR 2014g, 20).

UNHCR has commissioned several stateless mapping exercises for other nations. ${ }^{13}$ This study differs from those UNHCR studies due to a range of factors. With perhaps one exception (the United Kingdom), these other states lack the diversity of the US foreign-born population and of residents who are potentially stateless or potentially at risk of statelessness. Moreover, the overwhelming majority of these studies do not seek to estimate the nation's stateless population. In addition, they rely on tools to identify the stateless-like local or central population registriesthat are not available and not likely to be available in the United States. ${ }^{14}$

US administrative data on immigrants and refugees may be useful in identifying some categories

9 Id.

10 Immigration and Nationality Act (INA) §101(a)(22).

11 INA $\S 308$ sets forth the categories of US nationals who are not US citizens at birth, including persons born in an "outlying possession of the United States on or after the date of formal acquisition of such possession."

12 The UN provides that "[n]ecessary forms of proof [to establish nationality] may either relate to the question of whether a person is a national (for instance a national identity document or passport), or to the legal requirements which a person needs to meet in order to be considered a national. Such requirements generally refer to links a person has with the State" (UN 2011, 5-6). Difficulties in establishing nationality can result from inadequate "birth registration, civil registration and other documentation systems" and ineffective "public administration in this regard" (ibid., 6).

13 UNHCR is the UN agency mandated by the UN General Assembly, through a series of resolutions, with the task of preventing and reducing statelessness and protecting stateless persons around the world. See e.g., U.N. General Assembly Resolution A/RES/50/152 at If 14 (1995) (indicating that UNHCR's statutory international protection function includes efforts on behalf of stateless persons); see also A/RES/61/137 In 4 (urging continued UNHCR efforts "in regard to identifying stateless persons, preventing and reducing statelessness, and protecting stateless persons"). 14 They also rely on census and administrative data sources akin to US data sources. 
of stateless persons, but has severe limitations. Federal immigration datasets track "nationality," but may or may not include a dropdown for statelessness. The "nationality" variable typically lists persons of "unknown" nationality, a designation that includes, but is not exclusive to those who are potentially stateless or potentially at risk of statelessness. In addition, the federal government has restricted the public's access to relevant federal datasets and to systems manuals that could explain codes, variables, and data entry procedures. Furthermore, immigration- and refugeerelated data would cover only those stateless persons (not all) who come to the attention of federal officials. Nor does this data yield complete or reliable estimates of those known to federal officials.

Based on these data limitations, CMS opted to make the US Census Bureau's American Community Survey (ACS) data the centerpiece of its profiles of populations that are potentially stateless or potentially at risk of statelessness in the United States. Among possible data sources, the ACS provides the most detailed demographic, social and economic data, and it covers the widest number and array of US residents who are potentially stateless or potentially at risk of statelessness. CMS supplemented the ACS with administrative data on refugee and immigrant populations encountered by federal officials.

The ACS covers roughly one percent of the US population. Each year, it gathers detailed data - including for non-naturalized foreign-born persons - for all states and for cities, counties, metropolitan statistical areas, and Public Use Microdata Areas (PUMAs), a Census-defined geographic area of 100,000 people or more.

CMS queried ACS data on foreign-born non-citizens using characteristics from the profiles of stateless groups from around the world whose members are or may be in the United States. It developed these profiles based on UNHCR reports, government and academic literature, survey responses, and interviews with stateless persons. Based on the ACS data, CMS estimates that there were 198,000 non-US citizens among the 2017 US resident population that fit its profiles of potentially stateless persons or those potentially at risk of statelessness. ${ }^{15}$ However, some profiles included variables - such as some ethnicities, languages and countries of origin-that are not available through the ACS, thus precluding estimates for these populations based on the ACS.

To complement its ACS estimates, CMS secured data from the US Department of State's (DOS') Worldwide Refugee Admissions Processing System (WRAPS), a database that tracks the admission of refugees for resettlement. WRAPS does not permit the calculation of estimates for all groups for which CMS compiled ACS-based estimates, but it does permit estimates from some populations for which ACS estimates were zero or could not be calculated. CMS's analysis of WRAPS data revealed an estimated 117,370 refugees that fit the profiles of potentially stateless persons or those potentially at risk of statelessness, including 20,320 from profiles for which ACS estimates were zero or not possible to produce.

Adding CMS's ACS estimates and its WRAPS estimates-for profiles for which ACS estimates were zero or not possible to produce-yielded an overall estimate of roughly 218,000 US residents who are potentially stateless or potentially at risk of statelessness. Because CMS's WRAPS estimates cover populations not in the ACS data, its overall estimates do not "double" count those who are potentially stateless or potentially at risk of statelessness.

15 CMS also calculated upper and lower bounds for this estimate. CMS estimates that the number of individuals who are potentially stateless or potentially at risk of statelessness falls between 192,000 and 204,000 persons. 
The 218,000 figure should be used with caution. As discussed, many of those included in these provisional estimates may not in fact be stateless. Some may have obtained nationality in their own country or in a third country. Others may be stateless, but will ultimately be able to obtain nationality in the United States. On the other hand, this figure excludes some US residents who are potentially stateless or potentially at risk of statelessness. In short, it represents a population of non-US citizens who fall within profiles of persons who are potentially stateless or potentially at risk of statelessness.

For information purposes, CMS also analyzed federal immigration data-some publicly available and some provided by the Transactional Records Access Clearinghouse, Inc. (TRAC) at Syracuse University-on populations listed as "stateless" or of "unknown" nationality. This data included populations that: (1) sought asylum "affirmatively" (not in removal proceedings) before US Citizenship and Immigration Services (USCIS); (2) sought asylum "defensively," i.e., while in removal proceedings; (3) were placed in removal proceedings between 2001 and 2018; and, (4) were in immigrant detention in 2018 (TRAC 2019d).

These data sources do not capture the total number of foreign-born persons who come to the attention of federal agencies. Nor do they count stateless persons not encountered by federal immigration officials. In addition, some persons may be incorrectly characterized in these datasets as nationals of particular states. The report provides CMS's analysis of this immigration data, not to add to its estimates of those who are potentially stateless or potentially at risk of statelessness, but to present a fuller picture of certain populations and to highlight the limitations of US administrative data.

Section I of the report outlines the project's methodology. Section II describes the causes of statelessness, the legal context faced by stateless persons in the United States, CMS's profiles of populations that are potentially stateless or potentially at risk of statelessness in the United States, and descriptions of certain populations not included in CMS's estimates. Section III provides provisional estimates of select populations that are potentially stateless or potentially at risk of statelessness. It also sets forth the strengths and limitations of the data used to make these estimates, and the numbers of persons listed as stateless or of unknown nationality in US immigration and refugee datasets. Section IV describes the challenges facing stateless persons in the United States, drawing heavily from CMS's interviews with stateless persons and its online survey. Section $V$ recommends ways to improve data collection in order to better identify stateless persons. It also outlines some of measures set forth in the 1961 Convention, US legislation, and academic and policy literature to prevent and reduce statelessness, including a designated path to citizenship for stateless persons. It also sets forth a series of policy recommendations to protect and integrate stateless persons. 


\section{Section I: Methodology}

The stateless population is difficult to identify in US government data and, more broadly, in US society in part because no government entity makes statelessness determinations or systematically collects information on stateless populations. Few (if any) federal immigration officials that encounter stateless persons are trained or tasked to identify them. Failing to look for stateless persons, federal, state and local governments fail to find them. The lack of a designated path for stateless persons to register or to secure legal status, in turn, makes stateless persons less likely to disclose their status and increases their sense of isolation.

In order to attempt to map statelessness in the United States, CMS developed a methodology that accounted for these factors. It incorporates quantitative and qualitative research approaches to attempt to estimate the size of the population of potentially stateless persons or those potentially at risk of statelessness in the United States, to profile distinct populations, and to document their situations, challenges and lived experiences.

\section{Qualitative Methods}

After conducting preliminary research, CMS convened a group of 28 statelessness experts in October 2017 to discuss the sources, strengths, and limitations of data on statelessness, to identify particular concentrations of stateless persons, and to examine CMS's proposed methodology. The group included government officials, statisticians, analysts, scholars, human rights experts, legal professionals, and stateless persons. In preparation for the meeting, CMS produced a literature review that included UNHCR mapping statelessness studies for other countries, academic articles, and policy reports. Prior to this study, the stateless population in the United States was unofficially estimated to be around 4,000 persons (UNHCR 2015a, 9), a figure extrapolated from the number of stateless asylum seekers over a 10-year period. As a way to focus the discussion, CMS provided its draft profiles of populations in the United States that are potentially stateless or potentially at risk of statelessness to its project advisors, who fine-tuned profile descriptions and identified additional populations to include.

To ensure that the research met the highest ethical standards, CMS sought a full board review of its qualitative methods-which included an online survey and in-depth interviews with stateless individuals - from Syracuse University's Institutional Review Board (IRB). As part of the IRB application process, interviewers completed the relevant Collaborative Institutional Training Initiative (CITI) Web-based training program for human subjects, as required by Syracuse University. CMS submitted the interview protocol, survey, informed consent form, phone and email scripts, and outreach materials to the IRB as part of its application.

Following the expert advisory group meeting, CMS developed an online survey (Attachment $A$ ) for community-based organizations (CBOs), legal service providers, ethnic organizations, faithbased entities, and other non-governmental organizations (NGOs) that may represent, serve or otherwise encounter stateless persons. The survey had four overarching purposes: (1) to identify stateless persons to interview; (2) to supplement CMS's stateless profiles; (3) to develop a fuller understanding of the causes and challenges of statelessness; and (4) to expand the growing network of service providers and stateless persons who could educate the public on this issue.

The survey asked non-identifying details about stateless individuals, such as the causes of their 
statelessness, immigration benefits they sought, possession of national identity documents, and basic demographic information like age, place of birth, ethnicity, race, religion and languages spoken. CMS initially circulated a draft of the survey to large legal and refugee service networks that (it believed) would be likely to encounter stateless persons. These included Kids in Need of Defense, Catholic Charities Community Services of the Archdiocese of New York, Catholic Legal Immigration Network, Inc., the American Bar Association's Commission on Immigration, Refugee Council USA member agencies, and the Vera Institute for Justice. Ultimately, it shared the survey with more than 340 organizations that work with immigrants and refugees, focusing on communities that the project advisory group identified as potentially having high concentrations of stateless persons. CMS also followed up via phone calls with these entities to encourage responses. ${ }^{16}$ Forty-one of these organizations reported having worked with stateless people in recent years.

Thirty-seven agencies fully completed the survey. Twenty-eight of these organizations reported providing legal services to immigrants. Five provided resettlement and integration assistance to refugees. Eleven reported that they work with stateless individuals a few times a year, four at least once a month, two on a weekly basis, and one every day. The 37 organizations reported having contact with more than 45 stateless persons, from 32 countries and territories and representing more than 25 ethnic groups. Palestinians deemed to be stateless by these agencies represented the largest group (seven persons) described in the survey. Attachment B provides a short description of survey respondents focused on the causes of their statelessness and their legal status in the United States.

CMS also conducted in-depth, semi-structured interviews with 48 stateless persons in Chicago, Illinois, New York, New York, and Manchester and Concord, New Hampshire. In order to identify respondents, CMS used a snowball sampling method. In particular, it contacted CBOs and NGOs to inform them about the project and request their support to locate potential interviewees. Given the vulnerability and marginalization of stateless persons, CMS needed to rely on the trust and rapport of these organizations with the relevant communities to establish contact with potential respondents. United Stateless, a national organization led by stateless persons, helped CMS to locate interviewees for this project.

Pervasive anti-immigrant rhetoric in the public sphere and harsh enforcement policies made it difficult to obtain a high number of interviewees. Some organizations were unwilling to cooperate due to the perception of risk for participants, despite assurances of full anonymity. Even on occasions when organizational staff wished to cooperate, some organizations reported receiving no response from members or clients to participate in the study, which they attributed to the fear engendered by the current US administration's immigration and refugee policies and its antiimmigrant rhetoric. Attachment $\mathrm{C}$ contains the interview questionnaire.

The CMS research team also conducted several interviews by phone with individuals in other locations. The interviews provided insights into the lived experiences and challenges of stateless persons, and supplemented the CMS profiles of the potentially stateless or those potentially at risk of statelessness in the United States. Section IV of the report highlights insights from these 
interviews on the difficulties and challenges facing stateless persons in the United States. ${ }^{17}$

The semi-structured interview instrument included questions on demographic background, causes of statelessness, immigration status, migration history, conditions before and after coming to the United States, experience with US immigration authorities, and support needs. As necessary, interpreters facilitated the interviews, which took place between May and December 2018. The interviews began with a description of the project, and review and signing of the consent forms. These steps allowed CMS to underscore the benefits, risks and voluntary nature of the project, and the fact that participants could withdraw consent at any time and their identity would remain protected.

\section{Quantitative Methods}

After reviewing multiple immigration-related data sources, CMS selected the ACS as the most comprehensive source of data on US residents who are potentially stateless or potentially at risk of statelessness. The ACS is a nationally representative survey that gathers detailed social and economic data on approximately 3.5 million US households each year. CMS distilled its population profiles of those potentially stateless or potentially at risk of statelessness into discrete characteristics that aligned with variables contained in the ACS. These characteristics included country of birth, year of entry, ancestry, and language. It then used these (profile) characteristics to query ACS data on foreign-born US residents who had not naturalized.

To supplement ACS data, CMS sought immigration and refugee-related administrative data on non-citizens who shared some of the characteristics of CMS's stateless profiles and of those designated as "stateless" or of "unknown" nationality. In particular, it gathered publicly-available data on refugee admissions from WRAPS, an interactive computer system employed by DOS's Refugee Processing Center that "process[es] and track[s] the movement of refugees ... to the US for resettlement under the US Refugee Admissions Program" (RPC n.d.). This interactive data tool contains data on refugees' country of birth, admission date, religion, ethnicity, age, education, and native language. These variables match (in part) the characteristics identified in CMS's stateless profiles. The WRAPS system does not permit cross-tabulations of admitted refugees by ethnicity, nationality, language, and other characteristics. CMS researchers requested detailed crosstabulations of WRAPS data, but did not receive them.

In addition, CMS compiled data-collected by TRAC-from the Executive Office for Immigration Review (EOIR) on asylum seekers and others in removal proceedings. This data includes information on custody status, relief from removal, case outcome, country of birth and case year. However, it does not include year of entry and other important characteristics identified in the profiles. In addition, CMS reviewed USCIS data on "affirmative" asylum seekers (those not in removal proceedings). It also obtained data, compiled by TRAC, of every person in immigrant detention in 2018.

CMS also submitted a far more extensive data request on potentially stateless or potentially at risk of statelessness US residents that the US Department of Homeland Security (DHS) had

17 Some participating organizations self-selected due to their willingness to participate in the study and their familiarity with one or more stateless population. In addition, the project advisory groups pre-identified select geographic areas. In order to reduce this inherent bias, CMS reached out to entities with diverse missions, geographic locations, and target populations, including $\mathrm{CBOs}$, legal service providers, community organizers, and places of worship. 
encountered through its immigration admission, benefit, and enforcement programs. It sought data, for example, on persons ordered removed, but who remained in immigrant detention or who had been released from custody under an order of supervision. ${ }^{18}$ CMS also requested counts of admitted non-immigrants, lawful permanent residents (LPRs), and refugees who had been identified as stateless or who matched the profiles developed by CMS. CMS also approached the Office of Refugee Resettlement (ORR) to obtain data on stateless refugees and asylees who accessed ORR-funded benefits and services. CMS did not receive any of the data it requested from DHS or ORR.

CMS did not conduct individual status determinations of persons meeting its profiles of potentially stateless persons or those at risk of statelessness, or of the persons it interviewed. Statelessness must be determined on a case-by-case basis. These determinations require extensive knowledge of the individual's circumstances and the relevant nationality and citizenship laws in their states of origin and prior residence. As a result, the CMS report identifies persons who are potentially stateless or potentially at risk of statelessness.

\section{Section II: Causes of Statelessness, the US Legal Context, and Profiles of Potentially Stateless US Residents or Those Potentially at Risk of Statelessness}

Statelessness - not being considered "a national by any State under the operation of its law"19 - has many causes. It can occur when a state dissolves into two or more states, and residents cannot secure citizenship under the restrictive and sometimes discriminatory laws of the new states, or if the successor states lack the administrative capacity to register their residents or do not afford them sufficient time to register. The dissolution of the Soviet Union, for example, and the subsequent implementation of new citizenship laws in successor states created a significant stateless population (Fullerton 2014; ISI 2014; UNHCR and OSJI 2012; Helton 1996). Similarly, certain individuals from the former Yugoslavia and Ethiopian-born persons of Eritrean descent could be stateless due to revisions to citizenship laws following state succession (ISI 2014).

"I was born in Estonia in 1981. (...) If you were born before 1990 in Estonia, in order for you to have automatically citizenship of Estonia by birth, either one of your parents had to be Estonian citizen. My mother was born in Russia, but she moved to Estonia before I was born. My father was born in Ukraine.

I grew up there until 1999. I never lived anywhere else. I had this "Alien Passport" in Estonia. I'm thinking this is also my fault. I could have become Estonian citizen but it never really bothered me because I considered that country as my own and I was also too young to understand. [When I was in the United States,] I applied for passport, and I received a letter from the Consulate telling me that the fact that I was born in Estonia does no longer grant me any rights there."

Stateless man from Estonia

18 An order of supervision (OSUP) sets the terms of release for persons in removal proceedings or that have received orders of removal. These conditions can range from reporting requirements, to wearing GPS monitoring devices. Potentially stateless persons or those potentially at risk of statelessness may be among those ordered removed who cannot be removed.

19 Convention Relating to the Status of Stateless Persons, art. 1(1), Sept. 28, 1954, 360 U.N.T.S. 117. 
Many countries do not extend nationality to Palestinians or persons from Western Sahara, rendering many Palestinians and Sahrawis that reside in those countries stateless unless they have acquired nationality in another country (ibid., 121-122, 130-131). ${ }^{20}$

As of 2019, women in 25 countries cannot confer nationality on their children.

Statelessness also results from nationality and citizenship laws outside of the context of state succession. In some cases, nationality is withdrawn or denied based on ethnicity, religion, language, or other characteristics. This is the case for the Rohingya of Myanmar, the Kurds in Syria in the 1960s, and Black Mauritanians in the 1980s (ISI 2014).

As of 2019, women in 25 countries cannot confer nationality on their children (UNHCR 2019). This can lead to statelessness for children born to a native-born mother and a foreign father, particularly if the father is stateless. Some countries also require that a child's father and mother be married in order to confer the father's citizenship to a child, resulting in the statelessness of children born out of wedlock (UNHCR and OSJ 2012). In some countries, foreign-born women lose their citizenship upon the dissolution of their marriage, sometimes rendering them and their children stateless. In these and other circumstances, statelessness can be inherited.

"A mother can't pass her citizenship down to her children, only a father could. [My] father is stateless. He is considered Bidoon. His children as soon as they're born, they're Bidoon. They don't get rights, they don't get anything like Kuwaiti citizens. [When I approached the embassy to obtain a passport], they told me that since[(my] father is not a Kuwaiti citizen, then [I] cannot apply for the passport. I try to argue that my mother is a Kuwaiti citizen, and they're like no, you have to follow your father."

Stateless woman born in Kuwait

Statelessness can also result from gaps in nationality laws, conflicts in citizenship laws, and individual oversight or error. Individuals may lose their nationality if they reside abroad for a period without registering with their Embassy or Consulate (UNHCR and OSJI 2012; Price 2013).

"I was born in the Soviet Union, so I was recognized as a citizen of the Soviet Union, but ... I found out years later that Uzbekistan never officially recognized me as a citizen because I didn't register with Uzbekistan after it had become independent, which I was supposed to apparently. I didn't know that."

Stateless woman born in former Soviet Union

Article 7(1) of the Convention on the Rights of the Child stipulates that each child be "registered immediately after birth and shall have ... the right to acquire a nationality." ${ }^{21}$ For persons who "have difficulties furnishing relevant proof of nationality," the "most important proof ... relates

20 The situation of Palestinians is complicated by the issues of Palestinian nationality policy, the diversity of persons sharing "a common heritage and attachment to Palestine," the nationality policies of states where Palestinians reside, and the mandate of the UN Relief and Works Agency (UNRWA) which "covers some but not all Palestinians," both stateless Palestinians and those who have acquired nationality (ISI 2014, 127-132).

21 Convention on the Rights of the Child, Nov. 20, 1989, 1577 U.N.T.S. 3. 
to place of birth and to parentage" which "are recorded through birth registration" (UN 2011, 6). For this reason, birth registration can be "crucial" to "realising the right to a nationality" (ibid.). In some cases, states do not deny nationality by force of law, but certain populations cannot register the birth of their children, which denies these children proof of nationality and its rights and entitlements. In other cases, as with members of Hill Tribes in northern Thailand, local officials refuse to register childbirths (Rijken et al. 2015).

The United Nations Children's Fund (UNICEF), which maintains a global database on birth registration (UNICEF 2017), reports lower than average rates of registration in some developing countries, for certain ethnic and religious minorities, in remote and rural areas, and for children from poor households and with uneducated mothers (UNICEF 2013). Some unregistered migrants may find themselves "doubly undocumented"; that is, without identity documents indicating their nationality in their home state or in their current state of residence. Exacerbating this problem, some countries also make it difficult to register births abroad by requiring a return visit, exorbitant fees, or registration within a short window of time (UNHCR and OSJI 2012; Price 2013).

Similarly, some persons lack the documentation to prove their place of birth. This may occur due to weak civil registry systems, lack of access to government offices and services, extreme poverty, or rapid flight (Price 2013). Children born to refugees or asylum seekers may not be able to secure identity documents and to prove their nationality if they cannot return to their countries of origin or contact the government because they fear persecution (ibid.).

The 1961 Convention on the Reduction of Statelessness requires Contracting States to prevent and reduce statelessness by addressing several of these situations. However, these problems persist in the United States, which for the reasons explained below, is home to stateless persons in most, if not all of these categories.

\section{The US Legal Context}

Generous US citizenship policies-anchored by the Fourteenth Amendment of the US Constitution's guarantee of citizenship to "All persons born or naturalized in the United States, and subject to the jurisdiction thereof" - operate as a strong check against statelessness for those born in the United States. For this reason, this report primarily covers US residents who migrated to the United States and are potentially stateless or potentially at risk of statelessness. As discussed, these persons have not yet become naturalized US citizens, whether due to the lack of an available legal avenue, the inability to meet the requirements for permanent residence or citizenship, extended processing delays or backlogs, or for other reasons. Some US residents may have lost their nationality while living in the United States.

The US Refugee Act of $1980^{22}$ sought to harmonize US law with the international standards for refugee protection set forth in the 1951 United Nations Convention Relating to the Status of Refugees and the 1967 Protocol Relating to the Status of Refugees. ${ }^{23}$ However, the United States has not ratified the 1954 Convention or the 1961 Convention, and it lacks a designated legal framework on statelessness (Baluarte 2015; Corgan 2012), including a facilitated path to citizenship. Stateless persons in the United States must instead meet the requirements of US immigration and naturalization law to secure nationality. Although generous in some respects, US 
law offers very limited and often protracted paths to immigration status, permanent residence, ${ }^{24}$ and naturalization.

There is only one dedicated program, "registry," available for persons that lack immigration status (the "undocumented"). To qualify, an undocumented person must have lived continuously in the United States since January 1, 1972 (at least 48 years), have good moral character, not be ineligible for citizenship, and must be otherwise "admissible." ${ }^{25}$

Undocumented persons or temporary residents ${ }^{26}$ can secure LPR status based on a close family relationship to a US citizen or LPR, through sponsorship by an employer, or if they fit in other, narrower legal categories (Bier 2019, 16). However, family-based immigration is not available to persons without a qualifying family relationship and employment-based immigration is not possible for those without a sponsoring employer or who do not fit the narrow employment preferences, which afford (for example) only 5,000 visas for "unskilled workers" per year.

The process of securing a visa can take decades. Application processing times (for approval of a visa) averaged more than 18-months in 2018 and the average wait for a visa to become available for an intending immigrant was five years and eight months in 2018 (Bier 2019). The length of backlogs varies based on "the interplay between numerical limits for all family-based preference categories $(226,000)$ and each preference category [category of qualifying family relationship], per country limits, existing backlogs, and ongoing demand" (Wheeler 2019). For some of the 3.7 million persons mired in backlogs, the projected waiting period is 60 to 70 years (Kerwin and Warren 2019a; Wheeler 2019).

Moreover, a person seeking admission or adjustment to LPR status may be found inadmissible as a likely "public charge," for health-related reasons, for past immigration violations, on criminal or security grounds, and for other reasons. ${ }^{27}$ The current administration has issued a rule that would significantly expand the "public charge" grounds of inadmissibility (Kerwin, Warren and Nicholson 2018), and a "presidential proclamation" that would deny LPR status to those without qualifying health insurance or who lack the income to obtain it (Gelatt and Greenberg 2019). Immigrants lack health insurance at high rates, typically because their employers do not provide it (ibid.). These measures, if implemented, would block hundreds of thousands of (mostly) lowincome immigrants, particularly those who would otherwise qualify for family-based visas, from securing permanent residence each year (Kerwin and Warren 2019b).

To naturalize, applicants must be at least age 18, have been an LPR for at least five years (three years for the spouse of a US citizen), have been continuously present in the United States for at least 30-months of the five years preceding the date of filing, be a person of good moral character, and be attached to the principles of US Constitution. ${ }^{28}$ They must also be able to speak, read and write in English, and pass a US history and civics test, ${ }^{29}$ with certain exceptions based on age,

24 LPR status (a "green card") can be secured through acquiring an "immigrant" visa or "adjustment" in the United States.

25 INA § 249.

26 Temporary residents include "non-immigrants" (admitted for a temporary period and a particular purpose), Temporary Protected Status recipients, and others.

27 INA § 212.

28 INA § 317.

29 INA § 312(a). 
long-term permanent residency and disability or impairment. ${ }^{30}$ Many LPRs cannot meet these requirements, or afford the $\$ 725$ fee (which includes biometric screening). Like those seeking LPR status, naturalization-eligible persons face significant and growing application processing delays, an average of 10.2 months in FY 2018 (Boyd and Chen 2019).

Moreover, the current administration has issued a proposed rule that would increase the fees for immigration petitions and applications, particularly for naturalization and in cases involving adjustment to LPR status, and it has separately proceeded to make the fee waiver process more restrictive and onerous. These measures would price out large numbers of immigrants from the possibility of permanent residence and citizenship (Kerwin and Warren 2019b).

Refugees and asylees can adjust to LPR status a year after being resettled or after being granted asylum. ${ }^{31}$ Thus, they potentially enjoy a faster path to LPR status and citizenship than most immigrants. However, they may still be found inadmissible for committing a crime or for other reasons, $^{32}$ or they may not be able to satisfy the English language or other requirements to naturalize.

Persons in removal proceedings can avail themselves of only very limited forms of relief from removal available (Kerwin 2018). To qualify for one of the most common forms of relief, cancellation of removal, non-LPRs must establish that: (1) they have lived continuously in the United States for at least 10 years; (2) possess good moral character; (3) have not been convicted of any of a laundry list of crimes; and (4) their removal would cause "exceptional and extremely unusual hardship" to their US citizen or LPR spouse, parent or child. ${ }^{33}$ Even if a non-LPR can meet these requirements, Immigration Judges can still exercise discretion to deny them relief.

In short, some stateless persons may not qualify for legal status or protection, including asylum (Fullerton 2014). Stateless persons who enter the United States as refugees or non-immigrants (for a fixed purpose and temporary period) may not be able to adjust to LPR status, or they may qualify in categories so backlogged that they will not live long enough to receive a visa. Some stateless LPRs may not be able to meet the criteria for citizenship. Others may be placed in removal proceedings.

A small number of formerly stateless persons may have become US citizens, but then lost their citizenship through denaturalization due to fraud or past errors in their immigration applications (Robertson and Manta 2018). Denaturalization has become a far higher priority for the current, than for past US administrations (Robertson and Manta 2019, 404). ${ }^{34}$

Some nations offer extensive consular services to their nationals in the United States, which can include assistance in securing a passport, issuance of an identity card, birth registry (typically for children of foreign nationals born in the United States), and extensive protection and integration services. These services can help to establish a US resident's nationality, but not to provide nationality to those without it. To obtain a passport or identity card, foreign

30 INA § 312(b).

31 INA § 209(a)-(b).

32 Certain grounds of inadmissibility do not apply to refugees.

33 INA $\S 240 A(b)(1)$.

34 There may also be a handful of former US citizens who renounced their citizenship, failed to secure nationality in another state, and live in the United States. 
nationals must still prove their nationality (Halling 2014; US GAO 2004, 11). ${ }^{35}$

\section{Profiles of Populations That Are Potentially Stateless or Potentially at Risk of Statelessness in the United States}

It is impossible to determine statelessness without exhaustive, individual screening. Legal screenings of persons in US detention centers, for example, or of persons who self-identify as undocumented, regularly find persons with derivative citizenship (Wong et al. 2014, 292; MRS/ USCCB and CMS 2015, 163). ${ }^{36}$ Similar screening programs, particularly of populations in CMS's profiles, would identify significant numbers of stateless persons. Yet some community groups interviewed for this project, which serve stateless persons, incorrectly believe that this problem no longer exists in their communities. Like US undocumented residents, many stateless people may not realize that they are stateless until they reach a certain age, or they may not realize that they are eligible to pursue legal status and, ultimately, a path to citizenship.

The size and diversity of the US foreign-born population suggest that a wide range of people who are potentially stateless or potentially at risk of statelessness may be living in the United States. Such individuals can arrive in the United States as refugees, temporary visa holders or with other temporary statuses, permanent residents, or through irregular channels. CMS identified the following profiles of stateless populations in the United States based on a review of available literature, ${ }^{37}$ consultations with experts on statelessness, and interviews with stateless persons. As stated, per the 1954 Statelessness Convention, a "stateless person" is defined as someone "who is not considered as a national by any State under the operation of its law." The term "at risk of statelessness" denotes those who have "difficulties furnishing relevant proof to establish their nationality" and who are therefore "at risk of not being considered nationals by a State" (UN 2011, 5). CMS considers members of the groups profiled below to be potentially stateless or potentially at risk of statelessness. Members of these groups may possess the nationality of their country of origin or may have acquired nationality in a third country. They may also be on a path to US citizenship, but have not naturalized. CMS cannot determine the exact likelihood or risk of statelessness for each profile, although some groups are likely to have much higher incidences of statelessness than others.

Many stateless people may not realize that they are stateless until they reach a certain age, or they may not realize that they are eligible to pursue legal status and, ultimately, a path to citizenship.

35 Mexico's 51 consular offices in the United States provide matricula consular (identity) documents, Mexican passports on an expedited basis, and a range of "new generation functions ... to empower the Mexican community so they may fully integrate into American society." (Celorio 2017). Other states, like Guatemala, offer similar core services from a smaller network of consular offices (Consulado General de Guatemala 2019). Mexican consulates also permit Mexican residents in the United States to register childbirths that occurred in Mexico (Consulado General de México en Nueva York 2019). In 2015, Mexican consulates also began to issue birth certificates to Mexicans residing in the United States (Linthicum 2015). On the other extreme, Venezuela has announced the closure of its consular offices in the United States (BBC News World 2019), and this writing its consular websites are inaccessible. 36 Derivative citizenship is available to persons born abroad on or after February 28, 1983, who are under the age of 18, and who: (1) have at least one US citizen parent at the time of their application; (2) were admitted as LPRs and live in the United States in the custody of their US citizen parent; and, (3) (for adopted children) were adopted through a legally sound process. INA § 320 .

37 These profiles and their descriptions draw heavily from Institute on Statelessness and Inclusion (ISI) (2014), as well as UNHCR “Mapping Stateless" reports and other references cited in the text. 


\section{Europe and Eurasia}

\section{Former Soviet citizens and their descendants}

In 1991, the Soviet Union dissolved and several new states emerged. At that point, Soviet passports became invalid and citizens of the former Soviet Union had to obtain citizenship from successor states. These states' citizenship laws diverged significantly. Any former Soviet citizen living in Russian territory, for example, was entitled to Russian citizenship. Other successor states-like Estonia, Latvia and Lithuania-had more restrictive laws, which linked citizenship to ethnicity (UNHCR 1993).

\section{Emigrants from the Soviet Union prior to its Collapse}

Any resident who left the Soviet Union prior to its collapse may have experienced difficulty in securing citizenship in a successor state. Such persons may not have been able to prove they met residence requirements in their countries of origin (UNHCR and OSJI 2012, 13, 23). Members of this group are potentially stateless or potentially at risk of statelessness.

\section{Estonia}

Estonia's post-Soviet citizenship law defined Estonian citizens as descendants of citizens of the previously independent Estonian republic. This law excluded Estonia's large minority of Russians, Ukrainians, and Belorussians that constituted 35.1 percent of the population at independence (UNHCR 1993). This population received the status of "persons with undetermined citizenship," a status denoting statelessness (UNHCR 2016c, 15). In 1993, Estonia adopted legislation that gave most members of this group a temporary residence permit and the right to apply for a permanent residence permit through July 1995. The vast majority applied and became permanent residents, although an estimated 3,000 to 30,000 of those eligible did not apply (UNHCR 2016c, 16; Poleschuk 2004, 12). Former USSR military personnel, their spouses, and persons convicted of a crime were not permitted to apply. Permanent residents with "undetermined citizenship" are permitted to obtain Estonian citizenship if they meet an Estonian language requirement, which is a significant hurdle for most in this group (Poleschuk 2004, 33).

In 1998, the 1995 citizenship act was amended so that children born after February 1992 to persons with "undetermined citizenship" and who were younger than 15 years old could acquire Estonian citizenship through a streamlined naturalization procedure. In 2015, a new provision was adopted that automatically grants nationality at birth (parents no longer have to apply). As a result, the number of those with "undetermined citizenship" fell from roughly 500,000 in 1992 to 82,561 at the end of 2015 , with naturalization accounting for about half of this decrease, and death, emigration, or acquisition of other citizenships accounting for the rest (UNHCR 2016c, 16).

Ethnic Russians, Ukranians, and Belorussians from Estonia are thus potentially stateless or potentially at risk of statelessness.

\section{Latvia}

As in the case of Estonia, Latvia's initial post-Soviet citizenship law defined Latvian citizens as descendants of citizens of the previous independent Latvian republic. Many Soviet citizens who migrated to Latvia in the Soviet era were granted legal status, but excluded from Latvian nationality (ENS 2015, 3-4). These individuals made up 48 percent of Latvia's population at independence 
and include ethnic Russians as well as Belorussians and Poles (UNHCR 1993).

Although the size of this population has fallen, as of 2018 an estimated 11.6 percent of Latvia's population falls under the UNHCR's statelessness mandate (UNHCR 2019b, 66). ${ }^{38}$ In order to acquire Latvian citizenship, such persons must pass language and history exams. In 1999, Latvia's government amended its citizenship law to allow children born in Latvia after August 1991 to be registered as citizens. This process has been further simplified in recent years.

Any Latvian-born individual of Russian, Belorussian, or Polish ancestry who was born before 1991 is potentially stateless or potentially at risk of statelessness. People from these groups born after 1991 are also at risk of statelessness if their parents have not registered them in Latvia, as stipulated by the 1999 citizenship law.

\section{Lithuania}

Lithuania enacted citizenship laws in 1989 prior to its formal independence and in 1991 following the collapse of the Soviet Union. The 1989 law granted citizenship to descendants of legal residents of the first independent Lithuanian republic (1918-1940) living in Lithuania on December 11, 1991, and allowed others present in Lithuania to claim Lithuanian citizenship between 1989 and 1991. This latter group consisted of people of non-Lithuanian ethnicity, particularly ethnic Russians. The 1991 law affirmed the citizenship of all those who had obtained citizenship under the conditions of the 1989 law (UNHCR 2016a, 17). Additionally, individuals who moved to Lithuania following the collapse of the Soviet Union were eligible to claim citizenship until July 1993 (ibid.).

Populations that are potentially stateless or potentially at risk of statelessness include: Lithuanianborn individuals from minority ethnic groups who resided outside of Lithuania from 1989 to 1991 and could not claim citizenship; some prisoners who were ineligible to claim citizenship; and, some minors whose parents did not file for their citizenship and who are ineligible for subsequent descent-based naturalization (ibid., 20).

\section{South Caucasus: Ethnic Armenians and Azerbaijanis}

In the late 1980s and early 1990s, many ethnic Armenian refugees fled to the Republic of Armenia from the disputed region of Nagorno-Karabakh, an autonomous region within Azerbaijan. Many ethnic Armenians arrived with Soviet passports and were rendered stateless following the collapse of the Soviet Union. Many have acquired Armenian citizenship over time, but approximately 1,400 remained stateless as of 2017 (DOS 2017l, 25).

A significant number of ethnic Armenians also fled to Armenia from Abkhazia, a disputed territory within the Republic of Georgia. Individuals who fled to Armenia prior to 1993 were not recognized by Georgian citizenship law following the collapse of the Soviet Union (UNHCR Armenia 2013, 53). It is not clear to what degree they have obtained Armenian citizenship. Ethnic Azerbaijanis also fled Armenia and became refugees in Azerbaijan in the same time period, but most have naturalized and become citizens of Azerbaijan (UNHCR 2003, 22).

Furthermore, as of 2017, thousands of potentially stateless ethnic Azerbaijanis from Georgia resided in Azerbaijan (Tabachnik 2019, 2). Some ethnic Azerbaijanis born in Georgia fled to Azerbaijan in 1991 and 1992 and were not able to prove residency in Azerbaijan in order to claim

38 The authors calculated this percentage using official UN population statistics for Latvia. 
citizenship in accordance with that country's citizenship laws. Georgian-born Azeris continue to face strict naturalization restrictions. Some of these migrants were residing in Azerbaijan at the time of the collapse of the Soviet Union and thus cannot meet residency requirements for Georgian citizenship (Tabachnik 2019, 10). Many such individuals also migrate frequently between Georgia and Azerbaijan, further complicating their access to Georgian citizenship. Ethnic Azerbaijanis from Georgia thus are potentially stateless or potentially at risk of statelessness if they have not acquired Azerbaijani or Georgia nationality (Tabachnik 2019).

Ethnic Armenians from Azerbaijan and Georgia and ethnic Azerbaijanis from Georgia are potentially stateless or potentially at risk of statelessness.

\section{Meskhetian Turks}

The Meskhetian Turks are a Turkish-speaking minority from what is now the Republic of Georgia. In 1944, the Soviet Army deported them from Georgia to Uzbekistan. Following ethnic persecution in Uzbekistan's Ferghana Valley in 1989, many were forcibly relocated to regions across Russia (Helton 1996; Cobb 2013). After the collapse of the Soviet Union, Meskhetian Turks were routinely denied citizenship in the region of Krasnodar Kray, Russia, and faced severe obstacles to naturalization in Georgia, where they were required to adopt Georgian surnames in order to gain legal residence (Pentikainen and Trier 2004, 17). Most had left Uzbekistan before its independence and are ineligible for Uzbek citizenship (DOS 1994, 11). Some came to the United States as refugees.

Meskhetian Turks born in Georgia, Uzbekistan, or the Krasnodar Kray region of Russia are thus potentially stateless or potentially at risk of statelessness.

\section{Russia and Central Asia}

Citizens of the former Soviet Union residing in Russia in 1992 were considered by law to be Russian citizens (UNHCR 2015c, 22). Furthermore, in 1993, the government permitted all former Soviet citizens who arrived in Russia after February 6, 1992 to acquire Russian citizenship, provided they registered by December 2000. In 2002 and 2003, the government enacted a series of measures granting former Soviet citizens residing in Russia a "simplified" path to citizenship, waiving documentation requirements that had barred some from registering prior to 2000 (ibid., 22-25). The Russian Federation enacted additional policies in 2012 and 2018, which further "simplified" naturalization procedures (ibid., 25; Russian Federation Office of the President 2018). As a result, the number of stateless individuals in Russia has declined significantly over time. An estimated 75,680 remained under the UNHCR's statelessness mandate as of 2018, but this figure includes members of ethnic minority groups such as Roma and Meskhetian Turks (UNHCR 2019b, 67).

Statelessness is also widespread in successor Central Asian republics, including Kazakhstan, Tajikistan, Turkmenistan, and Uzbekistan. According to the UNHCR, in 2018 about 4,700 persons under the UNHCR's statelessness mandate resided in Turkmenistan, 4,600 resided in Tajikistan, and almost 80,000 resided in Uzbekistan (ibid., 68). Many in these countries became stateless due to post-Soviet demarcation of territories, or because they were labor migrants living in a Soviet republic other than where they were registered (Farquharson 2011).

Some individuals from former Soviet countries that left after the Soviet Union's collapse are thus potentially stateless or potentially at risk of statelessness. 


\section{Former Yugoslav citizens and their descendants}

Yugoslavia dissolved between 1991 and 1995. Following the formation of its successor states, many people experienced problems with civil registration and documentation. The conflicts of the 1990s and the 1999 Kosovo conflict displaced many individuals across borders within the Balkans and wreaked havoc on civil registry systems. Many records were destroyed during these conflicts. As a result, some persons were left without personal records and faced substantial challenges claiming citizenship in Yugoslavia's successor states (UNHCR 2011b, 5). Moreover, some missed the "window of opportunity" to apply for citizenship in their state of residence (ibid. 16).

\section{Roma, Ashkali, and Balkan Egyptians}

Members of minority groups throughout the Balkan region are at particular risk of statelessness. The Roma and Albanian-speaking Ashkali and Balkan Egyptians live in poverty throughout the region and often face systematic discrimination (ibid., 5, 27). Many fled their states of origin during conflicts in the 1990s. As a result, many lacked registration in their countries of residence at the time of their independence and faced obstacles to citizenship acquisition. Even when they are eligible for nationality, language barriers and steep fees create difficulties for many Roma, Ashkali, and Egyptians (ibid., 25). It is difficult for many in these groups to register their children at birth, which perpetuates inter-generational statelessness (ibid.). Roma, Ashkali, and Balkan Egyptians from any former Yugoslavian country are thus potentially stateless or potentially at risk of statelessness.

\section{Individuals with Yugoslavian Passports}

People who left Yugoslavia before or during the region's numerous conflicts from 1991 to 1995 may have been unable to acquire citizenship in any of its successor states (UNHCR and OSJI 2012, 23). Such individuals are potentially stateless or potentially at risk of statelessness.

\section{North Macedonia}

Following its independence, North Macedonia enacted strict citizenship laws requiring applicants to prove registered permanent residence in North Macedonia at the time of independence, 15 years of uninterrupted lawful residence, and sufficient means of subsistence. Applicants who met these requirements and applied by November 1993 were granted citizenship. Some individuals who could not meet these requirements or did not apply by November 1993 may remain stateless. Statelessness disproportionately affects North Macedonia's Roma minority, whose members often lack documentation to prove habitual residence (UNHCR 2011b, 29; Macedonian Young Lawyers Association et al. 2018, 6).

Since 1993, North Macedonia has required that applicants furnish a certificate from their countries of origin indicating that they have never been convicted of a crime. This certificate is difficult to obtain for persons who have never registered residence outside of North Macedonia (UNHCR 2011b, 19).

Individuals from North Macedonia of Roma descent or descent from other ex-Yugoslavian countries are potentially stateless or potentially at risk of statelessness.

\section{Croatia}

Following its independence, Croatia enacted citizenship laws that required continuous habitual 
residence on Croatian territory. Many Serbians and other ethnic minorities fled during the conflict between Serbia and Croatia and subsequently returned. Some who could not prove habitual residence in Croatia faced significant challenges to citizenship acquisition (ibid., 18). Furthermore, ethnic minorities not registered in Croatia at the time of its independence, particularly Roma, faced difficulties proving habitual residence (ibid.). Some of these individuals remain stateless despite legal reforms aimed at facilitating these groups' naturalization (UNHCR 2014f, 2).

Ethnic Serbians and Roma from Croatia are potentially stateless or potentially at risk of statelessness.

\section{Roma in Italy and Germany}

Roma from Italy and Germany are potentially stateless or potentially at risk of statelessness. Many German and Italian Roma have resided in those countries for centuries and possess their respective nationalities. However, thousands of Roma migrated from Yugoslavia to Italy and, to a lesser extent, Germany, in the 1970s through the 1990s to escape persecution and violence (IOS 2019a; IOS 2019d). Some of these Roma, as well as their children, live without any "defined" legal status (ISI 2014, 98). Those that cannot attain citizenship in any former Yugoslavian country may be stateless (ibid.).

\section{The Middle East and North Africa}

\section{Syrian refugee children}

Many major countries of destination for Syrian refugees-for example, Germany, Jordan, Lebanon, Sweden, Turkey, or the United Kingdom-do not grant birthright citizenship, putting children of Syrian refugees at risk of statelessness (Howard 2017, 1). While such children are, in many cases, entitled to Syrian citizenship, families cannot travel back to Syria to register them.

Syria's gender-discriminatory nationality laws also exacerbate the risk of statelessness for children born abroad. While children born to Syrian fathers are entitled to Syrian citizenship, mothers cannot generally confer Syrian citizenship to children born outside of Syria (ibid., 303). As a result, children born abroad to Syrian refugees who are single mothers or born abroad to a Syrian mother and a father who cannot transmit his nationality are potentially stateless or potentially at risk of statelessness.

Children born to Syrian refugees in Germany, Jordan, Lebanon, Sweden, Turkey, and the United Kingdom after 2011, the year the Syrian Civil War began, are potentially stateless or potentially at risk of statelessness. These children cannot travel to Syria to register as citizens and are generally unable to acquire citizenship in their countries of birth. Children born abroad to single Syrian women or Syrian women and non-Syrian men may face a particular risk of statelessness due to gender discrimination in Syrian nationality law.

\section{Kurds and Bedouin}

Some Kurds from Iraq, Iran, Syria, and Lebanon are potentially stateless or potentially at risk of statelessness.

\section{Feyli Kurds in Iraq and Iran}

The Feyli Kurds are a Shi'ite Muslim Kurdish minority group from the border region of Iran and 
Iraq. In April 1980, the Iraqi government passed a decree stripping some 220,000 to 300,000 Feyli Kurds of Iraqi citizenship (Campbell 2010). Their property was confiscated and many where forcibly expelled to Iran, where they were denied access to work, education, and travel documents (ibid.). Some Feyli Kurds in Iran have obtained Iranian citizenship by proving Iranian ancestry or family ties, but most are ineligible to naturalize in Iran (DIAC 2011, 16). While the Iraqi government passed a law in 2006 permitting Feyli Kurds to reinstate their Iraqi citizenship, those wishing to do so must prove that their families were registered in the 1957 Iraqi Census. Given that many civil records were destroyed or lost during recent conflicts in the region, some are unable to provide proof of registration and may remain stateless (Campbell 2010). Kurds who were born in Iraq's border region and have entered the United States since 1980 are potentially stateless or potentially at risk of statelessness.

\section{Syrian Kurds}

In 1962, the Syrian government carried out a one-day census in al-Hasakah, a predominantly Kurdish province, to identify unauthorized migrants from Turkey. To attain Syrian nationality, those deemed authorized had to demonstrate to census officials that they resided in Syria in 1945. About 120,000 Kurds lost their Syrian citizenship as a result of this census (Albarazi 2013, 16). These included persons who could not prove residence, who were registered as foreign citizens, and who either could not be reached by Syrian authorities or who refused to participate in the census (ibid.). Since Syria has not implemented laws granting citizenship to children of stateless parents, many descendants of these 120,000 individuals are stateless. At the onset of the Syrian Civil War in 2011, an estimated 300,000 Syrian Kurds were stateless (ISI 2014, 111).

In 2011, Syrian authorities passed a decree granting Syrian citizenship to those denied citizenship and registered as foreigners in 1962. This decree, however, did not offer citizenship to persons who either missed or refused to participate in the 1962 census (Albarazi 2013, 19).

Since the outbreak of Syria's civil war, some Kurds have fled Syria for other countries, particularly Iraq (ibid.). Some of these persons may be eligible for citizenship under the 2011 decree, but cannot obtain proof of citizenship without returning to Syria (ibid.)

Ethnic Kurds from Syria are thus potentially stateless or potentially at risk of statelessness.

Kurds and Bedouin in Lebanon

Small numbers of Kurds and Bedouin (Arab nomads) from Lebanon are potentially stateless or potentially at risk of statelessness.

Most Kurds in Lebanon were born in Syria and Turkey and arrived in Lebanon either before the collapse of the Ottoman Empire or as refugees from political violence in the 1950s and 1960s (Meho and Kawtharani 2005). Until the 1990s, Lebanese authorities barred most immigrants to Lebanon from citizenship. In 1994, Prime Minister Rafik Hariri issued a decree permitting nonnaturalized groups residing in Lebanon to apply for citizenship, but some did not apply and remained stateless (ibid., 7).

Many Lebanese Bedouin were overlooked during the French colonial authorities' initial efforts to register Lebanon's population in the 1920s and 1930s, rendering many of them stateless. Although some Bedouin have been granted legal residence, most had not acquired full citizenship 
as of 2013. Thus, many Lebanese Bedouin remain stateless (Chatty et al. 2013, 415).

\section{Potential Statelessness or Risk of Statelessness due to Lebanese Nationality Laws}

Some Lebanese-born individuals are potentially stateless or potentially at risk of statelessness regardless of their ethnic group. If Lebanese parents do not register a child's birth within a year, they must petition courts to recognize the child's nationality. In addition, Lebanese women cannot pass on nationality to their children, rendering children who cannot acquire nationality from their father stateless (ISI 2014. 108).

The exact number of the stateless in Lebanon today is unknown, although 200,000 has been estimated as an upper bound (ibid.).

\section{Tebu Libyans}

The Tebu are a tribe from the border area of Libya and Chad. They were subject to significant discrimination by Ghadafi's policies of Arabization and many were rendered stateless (Van Waas 2013, 5). Under Ghadafi, many Tebu were evicted and forced to relocate, and many were registered in the Aouzou strip close to the Libya-Chad border. In the 1970s, the Libyan military attempted to seize the Aouzou strip from Chad. When the International Court of Justice granted Aouzou to Chad, the Ghadafi regime issued an edict in 1996 declaring that all Tebu registered in Aouzou were foreign, regardless of whether they had acquired Chadian nationality. In 2007, Libyan authorities began to rescind the Tebus' citizenship. Even after the Libyan Civil War of 2011, the citizenship of the Tebu remains contested (Van Waas 2013, 12). A representative of the Tebu community in Libya recently stated that roughly 50,000 Tebu reside in Libya. An unknown share of this population is stateless (ibid.). Libyan-born Tebu are thus potentially stateless or potentially at risk of statelessness.

\section{Palestinians}

Palestinians constitute an ethnically- and religiously-diverse group with ancestral ties to Palestine. Since the Arab-Israeli War in 1948, Palestinians have experienced mass displacement. Palestinians live in many states and territories throughout the world. Their access to nationality is determined by the policies of the states in which they reside. Globally, the bulk of Palestinians live in states and territories that deny them citizenship (ISI 2014, 127-129; Shiblak 2006).

Palestinians from the Israeli-occupied territories of the West Bank and the Gaza Strip may be de jure stateless or potentially at risk of statelessness if they have not acquired citizenship in their country of residence. While once Jordanian nationals, these Palestinians lost Jordanian citizenship when Jordan disengaged from the West Bank in 1988. In addition, Israel bars Palestinian residents of these territories from acquiring Israeli citizenship (Shiblak 2006, 8). ${ }^{39}$ In addition, many

39 Most individuals residing in the West Bank and Gaza who were born in Palestine to Palestinian parents qualify for Palestinian Authority (PA)-issued passports and possess political rights within those territories. PA passports function as travel documents and do not convey citizenship (Khalil 2007, 28-29). In order to obtain a PA passport, individuals must be registered in Palestine's Population Registry as residents of these territories by Israeli authorities. Most Palestinians born outside of the West Bank and Gaza Strip are ineligible for PA passports. While the United Nations recognizes Palestine as a state, and despite the fact that the PA can confer travel and political rights to West Bank and Gaza residents, the Palestinian government lacks a formal nationality law and cannot grant de jure citizenship to its residents (Migration Policy Centre 2013). Moreover, many countries, including the United States, do not recognize the sovereignty of the Palestinian Authority and thus cannot directly deport holders of Palestinian travel documents to the West Bank or the Gaza Strip. 
Palestinians residing in East Jerusalem are ineligible for Israeli citizenship and may be stateless (ibid.).

Many Palestinians live in Lebanon and Syria and, to a lesser degree, Egypt and Saudi Arabia. These countries have not enacted policies to permit Palestinians to naturalize or granted nationality to children born of stateless Palestinians. As a result, thousands of persons of Palestinian origin in these countries may be stateless (ISI 2014, 127-129; Shiblak 2006, 8-9).

Jordan has historically extended its citizenship to some Palestinians, but the right of Palestinians to hold Jordanian citizenship depends on the time and place of their residency in Jordan (IRB 2015). Most critically, in order to acquire Jordanian citizenship, Palestinians must have held Jordanian passports at the time of the Six Day War in 1967, when Israel annexed the Gaza Strip and the West Bank (Shiblak 2006, 9). Following Jordan's disengagement with the West Bank in 1988, former West Bank residents that had entered Jordanian territory or third countries by July 1988 maintained their entitlement to Jordanian citizenship, while those remaining in the West Bank and Gaza, for the most part, lost their eligibility (IRB 2014). Those entering Jordan after July 1988 are also ineligible for Jordanian citizenship (ibid.).

In recent years, several thousand Palestinians residing in Jordan have also been stripped of Jordanian nationality, rendering some of them stateless (Human Rights Watch 2010; IRB 2014). Many of these had expired or revoked Israeli-issued West Bank residence permits (ibid.).

Finally, many Palestinians also reside outside of the Middle East. Some Palestinians in Europe hold only travel documents, most commonly from Lebanon, Egypt, or Israel, and lack proof of nationality (Shiblak 2006, 9). Many Palestinians are likely stateless not only in the Middle East, but across the world.

Palestinians born in the Middle East-including Israel, the West Bank, and Gaza-are thus potentially stateless or potentially at risk of statelessness.

\section{The Bidoon}

The Bidoon descended from persons who were not registered as citizens of Kuwait, Saudi Arabia, the United Arab Emirates, in their periods of state formation following the First World War. Bidoon is short for "bidoon jinsiya", or "without nationality." Some Bidoon were not aware of procedures for registration, while others were deliberately excluded from registration (Van Waas 2010, 6-7). To date, these states have not embraced policies that limit the intergenerational transmission of statelessness or provide the Bidoon with a straightforward path to citizenship (ibid.).

\section{Kuwaiti Bidoon}

Kuwait possesses the largest population of Bidoon (Shiblak 2009, 38). Kuwait's Bidoon have diverse origins. Some Bidoon are the descendants of persons not registered as Kuwaiti citizens following the passage of Kuwait's first nationality law in 1959. Others were recruited from neighboring states, namely Saudi Arabia and Iraq, to fight for Kuwait's military following the country's independence in 1961 (Longva 1997, 51). Many of these persons renounced their original nationalities upon moving to Kuwait (ibid.). Some fled to Iraq in the aftermath of the first Gulf War (ibid.; Van Waas 2010, 16).

Although Kuwait allows Bidoon to naturalize, its naturalization policies present significant 
obstacles. For one, many are unable to access and furnish records proving their ancestry (DOS 2017f, 14). Moreover, the government maintains a naturalization quota of only 2,000 applicants for citizenship each year (Van Waas 2010, 35). Finally, women cannot pass Kuwaiti nationality to children. Since up to a third of the Bidoon are linked to female Kuwaiti citizens through marriage or descent, this policy perpetuates statelessness (ibid., 40).

Bidoon from Kuwait are thus potentially stateless or potentially at risk of statelessness.

\section{Saudi Arabian Bidoon}

In Saudi Arabia, the Bidoon are mostly descendants of members of nomadic tribes that did not register for Saudi nationality during the country's period of state formation. Some also descend from foreign-born men who arrived in Saudi territory before the country regulated nationality. Although the Saudi government began to issue 5-year permanent residence permits to Bidoon in 2009, they are ineligible for Saudi citizenship (ISI 2018b, 5).

Bidoon from Saudi Arabia are thus potentially stateless or potentially at risk of statelessness.

\section{Bidoon in the United Arab Emirates}

Emirati Bidoon are mostly descendants of individuals who did not possess the tribal affiliations used to determine citizenship following the formation of the United Arab Emirates (UAE) (DOS 2017k, 20)

It is very difficult for Bidoon to naturalize in the UAE. The UAE pledged to naturalize the Bidoon in 2006, but few have naturalized (Van Waas 2010, 31). In order to naturalize, applicants must furnish proof that they have resided in the Emirates for 30 years or more. For many, such documentation is difficult to obtain (ibid., 34). The UAE has also purchased Comorian passports for some Bidoon, but most remain stateless (DOS 2017k, 20).

Bidoon from the UAE are potentially stateless or potentially at risk of statelessness.

\section{Asia and the South Pacific}

\section{Nepalese born after 1990}

Prior to 1990, Nepal granted citizenship to those born in the country, but a 1990 revision of its Constitution restricted automatic citizenship to those descended from a Nepalese father. This revision required children born to foreign fathers to naturalize, creating difficulties for families that could not procure the required documentation (DOS 2017h, 19-20). As a result, millions of people could not establish citizenship (ISI 2014, 88-89). Citizenship rules changed again in 2006, and citizenship on the basis of birth became possible if individuals applied within two years. In 2011, Nepal passed further reforms that allow children to acquire citizenship through mothers if their father is unknown or absent (DOS 2017h, 20).

In practice, single women still face many difficulties registering children whose fathers have left the country, abandoned the family, passed away, or refuse to acknowledge paternity (ibid.). Furthermore, married women can only qualify for citizenship by descent with the attestation of their husband or father. As a result, many Nepalese face obstacles to obtaining citizenship. Persons born in Nepal in 1991 or later are potentially stateless or potentially at risk of statelessness. 


\section{Ethnic Nepali Bhutanese born in Bhutan and Nepal}

Nepali-speaking groups, or Lhotshampas, have lived in southern Bhutan since the $19^{\text {th }}$ century, when they were contracted by the government to clear forests and build rice terraces (Hutt 2005, 45). Lhotshampas were granted citizenship by Bhutan's 1958 Citizenship Act. In 1985, however, the Bhutanese government instituted strict nationality criteria that applied retroactively. These reforms stripped Bhutanese citizenship from all Nepali speakers who could not prove residence in Bhutan in 1958. While some were permitted to apply following a census in 1985 through 1989, many remained stateless (DOS 2017b, 9-10). Since the late 1980s, Bhutan has expelled over 100,000 Lhotshampa to Nepal (ISI 2014, 80). Bhutanese refugees in Nepal are not permitted to apply for Nepalese citizenship (DOS 2017h). It is estimated that 1,000 stateless families remain in Bhutan (DOS 2017b, 10).

Nepali speakers born in Bhutan who arrived in the United States in 1986 or later are thus potentially stateless or potentially at risk of statelessness.

Statelessness is also exacerbated by Bhutan's nationality laws. In order for children to become Bhutanese citizens, both of their parents must be Bhutanese citizens. Unwed mothers are sometimes unable to prove the identity of their child's father (DOS 2017b, 10). As a result, some Bhutanese-born children, regardless of their ethnic group, are stateless. Bhutanese-born children born to single Bhutanese mothers or with at least one foreign parent are potentially stateless or potentially at risk of statelessness.

\section{Rohingya}

The Rohingya are a Muslim, linguistically-distinct ethnic minority from the Rakhine State in Myanmar. The country's 1982 Citizenship Act excluded Rohingya from Burmese citizenship, rendering over one million people stateless (ISI 2014, 87). The Burmese government does not recognize them as an official minority group. Instead, it considers them unauthorized immigrants from Bangladesh (Albert and Chatzky 2018). The Rohingya face widespread discrimination, including restrictions on employment, education, access to health, family planning, and freedom of movement (ibid.).

In 2017, following clashes in Rakhine State, the Burmese government mounted a campaign that destroyed hundreds of villages and forced hundreds of thousands of Rohingya to flee Myanmar (ibid.). At present, Rohingyas reside in many countries, including Bangladesh, Malaysia, Thailand, Indonesia, India, Pakistan, Saudi Arabia and the UAE (British Broadcasting Corporation 2018). Most Rohingya in these countries are barred from naturalization in their countries of residence. Small numbers of Rohingya refugees have been resettled in the United States. Rohingya residing in the United States are potentially stateless or potentially at risk of statelessness.

The Rohingya face widespread discrimination, including restrictions on employment, education, access to health, family planning, and freedom of movement. 


\section{Other groups from Myanmar}

Myanmar's 1982 citizenship law grants full citizenship to members of "national races" that the government claims have been present in the country since 1823, the year prior to its colonization by Britain (DOS 2017c, 31). As a result, some Burmese-born individuals of Indian, Chinese, and Nepali descent are stateless. Many of their families have lived in Myanmar for generations (Lynch $2005,33)$. Although the Burmese government has permitted some persons of Indian and Chinese descent to naturalize, many remained without full Myanmar citizenship as of 2017 (ISI 2014, 88; Arraiza and Vonk 2017, 9-10). Burmese law does not provide citizenship to children born to stateless parents. Consequently, statelessness in these communities passes from generation to generation (DOS 2017c, 31).

Ethnic Chinese and Indians from Myanmar who arrived in the United States in 1982 or later are thus potentially stateless or potentially at risk of statelessness.

\section{Hmong from Laos}

Small numbers of Hmong from Laos who arrived in the United States in 1975 or later are potentially stateless or potentially at risk of statelessness. The Hmong are a minority group in Laos and Thailand. Many fought with the US military against Communist militias in Laos during the Vietnam War. Following the 1975 Communist victory in Laos, the Hmong faced severe persecution and many fled to Thailand (Yau 2005). Approximately 90 percent of Hmong refugees in Thailand have been resettled in the United States since 1975, and all Hmong refugee camps in Thailand were shut down in the mid-1990s (ibid.). Soldiers who fought in US-sponsored missions were resettled first, followed by those fleeing poor economic conditions and repression (ibid.). The Hmong Veteran's Naturalization Act of 2000 facilitated the naturalization of Hmong soldiers who served in US-backed groups in Laos, ${ }^{40}$ leading many to naturalize. Others, however, failed to secure LPR status or citizenship for a variety of reasons. Those who have not naturalized are potentially stateless or potentially at risk of statelessness (Nyhan 2016). Although Hmong born in Laos are in theory entitled to Lao citizenship, the Lao government has for decades refused to recognize the citizenship of ethnic Hmong with deportation orders (ILCM 2018).

\section{Hmong from Thailand, Thai Hill Tribes, and children of Burmese refugees in Thailand}

Statelessness is a significant problem in Thailand. Many members of the Hmong, Lahu, Lisu, Yao, Shan, and other Hill Tribes in Thailand's northeast are potentially stateless or potentially at risk of statelessness, as are persons born to refugees from Laos and Myanmar (Rijken et al. 2015, 30-31).

In 1972, the Thai government issued a decree stating that, when a child is born in Thailand to foreign parents, both parents must have permanent residence in order for that child to obtain Thai nationality (ibid.). This decree was applied retroactively, rendering many persons from border regions stateless. The decree affected many members of northern Thai Hill Tribes with ties

40 Prior to 1998, naturalization rates among the Hmong-particularly among Hmong elders-were low, due largely to language barriers. When the Personal Responsibility and Work Opportunity Reconciliation Act of 1996 went into effect in 1998, many Hmong elders received notice that their food and financial benefits would soon be terminated. This development spurred Hmong activists to work with legislators and CBOs in states such as Minnesota to facilitate Hmong naturalization (Lee 2016). Hmong naturalization rates have since increased dramatically. The Pew Research Center reports that 77 percent of Hmong now possess US citizenship, the highest rate among Asian-Americans (Budiman et al. 2019). 
to neighboring countries. These tribes also historically faced systematic discrimination in birth registration, which made it difficult for Thai-born children to acquire citizenship documents (ibid., 32-33).

These provisions also affected children of refugees born in Thailand. Many refugees from Myanmar and Laos lacked Thai permanent residence at the time of their children's birth. Consequently, their Thai-born children were not eligible for Thai nationality (Rijken et al., 30-31; IOS 2019b). Most of the children born to refugees from Myanmar are ineligible for citizenship in that country due to a 1982 law barring many ethnic minorities from citizenship. Most Thai-born children of Hmong refugees, the bulk of which were resettled in the United States, are not eligible for Lao citizenship (ILCM 2008).

The Thai government has begun to take steps to eradicate statelessness within its borders. A 2008 amendment granted individuals whose nationality was revoked by the 1972 decree the right to apply for Thai citizenship, provided they could furnish documentation of their birth and subsequent residence in Thailand (Rijken et al, 2015, 13). In 2017, up to 80,000 children of migrants born in Thailand were allowed to apply for citizenship if they had either lived there for 15 or more years or obtained a university degree (ILO 2017). Despite these reforms, many in Thailand remain stateless (UNHCR 2019b).

The Thai-born of Hmong, Lahu, Lisu, Yao, and Shan ethnicities are potentially stateless or potentially at risk of statelessness. Thai-born children of Lao Hmong refugees and Karen, Chin, and Shan refugees from Myanmar who arrived in the United States after 1982 are also potentially stateless or potentially at risk of statelessness.

\section{Chinese without Hukou Registration}

Many children born in China lack birth registration and may be at risk of statelessness if they leave China. Chinese law requires that parents register their children at birth in a family booklet known as the "hukou" in order for children to be recognized as citizens. Due to China's "One Child" policy, which until 2013 barred many Chinese parents from having multiple children, parents with more than one child had difficulties registering their births in the hukou. Parents who could not afford to pay penalty fees often did not register their children. Mothers without a marriage certificate, parents who carried out informal adoptions, and women who refused to implement contraceptive measures were sometimes not permitted to register their children in the hukou (ISI 2014, 81).

Even though many unregistered children gain recognition later in life and others are, in theory, entitled to Chinese citizenship, the Chinese government has denied recognition and travel documents to some unregistered Chinese living abroad (Gordon 2017). Chinese-born individuals who are unregistered in the hukou are potentially stateless or potentially at risk of statelessness.

\section{Tibetans}

In the aftermath of China's occupation of Tibet in 1949 and conflict in Tibet's capital, Lhasa, in 1959, thousands of Tibetans fled to Nepal and India. Several thousand more fled annually to India through Nepal until 2008, when China tightened restrictions on Tibetan emigration (Tibet Justice Center 2016, 6). 
Nepal hosts an estimated 20,000 Tibetans. In Nepal, most Tibetans lack legal status, although persons born in Nepal before 1990 are entitled to Nepali nationality (IOS 2019c; Tibet Justice Center 2003, 1).

Over 100,000 Tibetans fled to India (Tibet Justice Center 2016, 5). In theory, India's 1987 Citizenship Law grants citizenship to any Tibetan born in India between 1950 and 1987, and by extension almost anyone born later to an Indian-citizen parent. In practice, however, Indian citizenship remains very difficult for Tibetans to obtain due to documentation requirements (ibid.,9). Additionally, some Tibetans in India have refused Indian citizenship since they hope to repatriate to Tibet (McGranahan 2018, 367).

Although China considers Tibetans to be Chinese nationals, many Tibetans lack Chinese documentation and refuse to acquire Chinese nationality on ideological grounds, as they perceive that it would legitimize China's claim to Tibet (Tibet Justice Center 2016, 62-63). As a consequence, many Tibetans born in Tibet, India, or Nepal are potentially stateless or potentially at risk of statelessness.

\section{The Afghan Jogi}

The Jogi are a semi-nomadic tribe from the Jat ethnic group living in northern Afghanistan (ISI 2014, 79). They have lived in Afghanistan for hundreds of years and are thought to number between 20,000 and 30,000 (Frotan 2019; Samuel Hall Consulting 2011, 4). Most Jogi do not possess and cannot secure a national identification card (ID) that provides proof of nationality, and the Afghan government does not recognize them as citizens (ISI 2014, 79). Afghan Jogi are potentially stateless or potentially at risk of statelessness.

\section{Various groups in India}

Several ethnic groups from India are potentially stateless or potentially at risk of statelessness, including Chakmas and Hajongs from Bangladesh, Tamil refugees from Sri Lanka, individuals born in Pakistan who arrived in Kashmir around the time of the partition of Pakistan's partition from India, and Nepali-speaking refugees from Bhutan.

In addition, Indian nationality law makes it difficult for the children of stateless parents to gain Indian nationality, and many children born in India to parents from these groups are potentially stateless or potentially at risk of statelessness.

In particular, Indian law grants automatic citizenship to those born in India between January 26, 1950, and July 1, 1987, when a new nationality law went into effect. After that date, in order to acquire Indian citizenship, children born in India must have had at least one parent with Indian citizenship. In 2003, India further tightened its citizenship laws. As of 2019, a child born in India is only entitled to Indian citizenship if at least one parent is an Indian citizen and the other is legally present in India (Ashesh and Thiruvengadam 2017). Children born in India after 1987 to stateless parents are potentially stateless or potentially at risk of statelessness. Some children born prior to 1987 to stateless parents may also become stateless if they cannot furnish proof that they were born in India.

\section{Chakmas and Hajongs}

The Chakmas and Hajongs are originally from the Chittagong Hill Tracts of the former East Pakistan 
(now Bangladesh). They were resettled in Arunachal Pradesh, India, following the construction of the Kaptai Dam in 1964 (CRG 2009). India's Home Ministry declared in 2017 that Chakmas and Hajongs were eligible for Indian citizenship following a 2015 Supreme Court ruling, but the local government in Arunachal Pradesh opposes this decision and the status of the Chakmas and Hajongs remains contested (Chandran 2017; Dodum 2018). Chakmas and Hajongs from Bangladesh, as well as their Indian-born children, are potentially stateless or potentially at risk of statelessness.

Hindus from Pakistan who came to Jammu and Kashmir after the 1947 partition riots and are not considered Indian citizens

Following the partition of India and Pakistan in 1947, many Hindus fled riots in Pakistan and settled in the disputed region of Jammu and Kashmir. As Jammu and Kashmir only granted permanent residency to individuals who were present in that territory for 10 years prior to 1954, many of these refugees were ineligible for permanent residency and, as a consequence, cannot naturalize in India. In 2005, small numbers of refugees were permitted to naturalize, but many remain stateless (CRG 2009; ISI 2014). Most of these refugees are, therefore, potentially stateless or potentially at risk of statelessness.

\section{Tamil Refugees from Sri Lanka}

Some Tamils from Sri Lanka in the Indian state of Tamil Nadu are potentially stateless or potentially at risk of statelessness. These are the descendants of Tamils taken by the British from India to Sri Lanka 200 years ago to work as bonded laborers on tea plantations (CRG 2009 ; 2011). During Sri Lanka's civil war, some of their descendants fled to India, where they remained in refugee camps as of 2010. While Sri Lanka has granted citizenship to Tamils of Indian origin, many Indian-origin Sri Lankans in refugee camps in India can apply neither for Indian nor Sri Lankan citizenship (ibid.). Likewise, many children born to Tamil refugees in Indian refugee camps are potentially stateless or potentially at risk of statelessness (Times of India 2015).

\section{Bhutanese of Nepali origin living in eastern/ north-eastern India}

Some ethnic Nepalese from Bhutan, known as Lhotshampas, fled to India following persecution in their homeland (see "Bhutan" above). India has not granted Lhotshampas a path to citizenship, and most remain stateless (CRG 2009; ISI 2014, 80). Bhutanese-born Lhotshampas from India and their Indian-born children are potentially stateless or potentially at risk of statelessness.

\section{Bengalis in Pakistan}

Many ethnic Bengalis from Bangladesh settled in Pakistan at the time of Bangladesh's independence in 1971. While many were permitted to obtain Pakistani citizenship upon arrival, some had difficulty providing the documentation necessary to obtain Pakistani identification cards and, ultimately, to naturalize (Mughal and Baloch 2017). Many were neither eligible for citizenship in Bangladesh nor Pakistan. In 2018, however, Pakistan's Prime Minister, Imran Khan, pledged to grant citizenship to stateless Bengali Pakistanis, although it is unclear how many have naturalized (Stubley and Baynes 2018). Ethnic Bengalis from Pakistan who have not obtained Pakistani citizenship are potentially stateless or potentially at risk of statelessness. 


\section{Malaysian Ethnic Minorities}

Some ethnic minorities from Malaysia, including some ethnic Indians, Indonesians, and Filipinos, are potentially stateless or potentially at risk of statelessness. Furthermore, children born abroad to single Malaysian mothers, or out of wedlock, are not automatically entitled to Malaysian citizenship and are potentially stateless or potentially at risk of statelessness (Razali 2017, 8).

\section{Ethnic Tamils from India}

During British rule, many Tamils from India were brought to western Malaysia to work on plantations. Historically, neither Malaysia nor India has recognized them as citizens (Razali 2017, 6). Since 2011, however, the Malaysian government, together with NGOs and the UNHCR, has launched several campaigns (e.g., MyDaftar, Mega MyDaftar) to register stateless Indians (DHRRA Malaysia et al. 2018, 5; Razali 2017, 6). In 2018, the Malaysian government granted citizenship to Indians over 60 years old with permanent residency (UNHCR 2018). Ethnic Indian Tamils from Malaysia that left that country prior to 2018 are potentially stateless or potentially at risk of statelessness, as some have not been granted Malaysian citizenship.

\section{Ethnic Indonesians and Filipinos}

Many children of Indonesian and Filipino parents in the Malaysian region of Sabah are potentially stateless or potentially at risk of statelessness. In the 1970s and 1980s, Muslim refugees fled violence in the southern Philippines and settled in Sabah. At the same time, many Indonesian migrant workers settled in Sabah to work in the timber and oil palm industries (Allerton 2014, 28). Many remained in Malaysia without obtaining legal status. Malaysia has strict citizenship requirements and children of refugees and undocumented immigrants are not recognized as citizens (Razali 2017, 5). While some children may be eligible for Filipino or Indonesian citizenship, they face significant obstacles.

Most Sabah-born children with Indonesian parents are eligible for Indonesian citizenship but must register at the consulate and pay fees. If their parents do not register them, they are at risk of statelessness (ibid., 30).

Children born in Sabah to Filipino refugees must return to the Philippines to claim citizenship. Many cannot do so due to security concerns and mobility restrictions imposed by the Malaysian government (ibid., 31). Ethnic Indonesians and Filipinos from Malaysia are thus potentially stateless or potentially at risk of statelessness.

\section{Ethnic Vietnamese from Cambodia}

Some ethnic Vietnamese and Vietnamese Khmer (Khmer Krom) in Cambodia are stateless. Most of the stateless ethnic Vietnamese come from families that have lived in Cambodia for generations. In the 1970s, persons with ties to Vietnam were deported en masse by the government and the Khmer Republic and, subsequently, the Khmer Rouge. Many have since re-entered Cambodia (Minority Rights Organization [Cambodia] et al. 2019, 5). While some possess Cambodian citizenship, most are not recognized as citizens by Cambodia or Vietnam. Many have been issued cards identifying them as Vietnamese, and ethnic Vietnamese children are systematically denied birth certificates (Minority Rights Organization [Cambodia] et al. 2019, 9). Moreover, many individuals' identity documents were lost or confiscated during their displacement, and the Khmer Rouge destroyed 
countless records. Consequently, many ethnic Vietnamese face significant difficulties proving ties to Cambodia. Ethnic Vietnamese from Cambodia are potentially stateless or potentially at risk of statelessness.

\section{Ethnic Chinese Cambodians in Vietnam}

Some individuals deported by the Cambodian government to Vietnam in the 1970s were of Chinese ancestry. For many years, they lived in refugee camps along the Vietnamese and Cambodian border, unrecognized as citizens of either Cambodia or Vietnam. Many persons of Chinese ancestry have since been granted Vietnamese citizenship, but it is possible that some remain stateless (Wallace 2010; United Nations News 2010). Ethnic Chinese Cambodians are potentially stateless or potentially at risk of statelessness.

\section{Stateless peoples in Brunei}

A significant number of people from Brunei, particularly those of Chinese and indigenous Iban descent, is potentially stateless or potentially at risk of statelessness. The Brunei Nationality Act of 1961 contains provisions that limit access to nationality on the basis of race and gender. To be automatically recognized as citizens under the Act, children born in Brunei must be from a Malay ethnic group or have a father that possesses Brunei nationality or is an ethnic Malay born in that country. Persons born outside of Brunei are recognized as Brunei citizens if their mother and father were born in Brunei and belong to one of 22 specified ethnic groups. In all cases, children must be registered at birth to obtain nationality (Statelessness Network Asia Pacific et al. 2018, 5-10).

Due to these provisions, many people from Brunei are potentially stateless or potentially at risk of statelessness. These provisions bar most ethnic Chinese and indigenous Iban peoples form obtaining Brunei citizenship. In addition, children born out of wedlock or to single mothers, or children whose fathers are absent, may not be able to register their births and obtain citizenship regardless of their ethnicity (ibid.). In either case, they face severe obstacles to the acquisition of Brunei citizenship.

\section{Sub-Saharan Africa}

\section{Ivoirians with roots in neighboring countries}

Statelessness is a widespread problem in Côte d'Ivoire. Several social groups in Côte d'Ivoire have high incidences of statelessness, including:

- Populations living along its borders;

- Refugees and returnees following the country's civil war;

- Children of unknown parents; and,

- Descendants of laborers from neighboring countries - particularly Burkina Faso, Mali, and Guinea - who were brought to Côte d'Ivoire under the French colonial regime to work on rail lines and on cocoa and coffee plantations (Adjami 2016, 6-7).

Some members of the latter group may be eligible for citizenship in neighboring countries, but many no longer have connections to their ancestral countries and may be stateless (ibid., 44). 
The foreign-born made up 13 percent of Côte d'Ivoire's population at its independence in 1960 (ibid., 3). The country's first nationality law allowed foreigners who were present at that time to acquire Ivorian nationality within a year, and children (with foreign parents) born after 1960 were allowed to naturalize by declaration before reaching adulthood (ISI 2014, 62 ; ISI 2019, 5; Adjami $2016,17)$. Children of unknown origin were also presumed to have been born in the country and, therefore, to be eligible for citizenship (ISI 2019, 4). However, very few foreigners naturalized under this law (Adjami 2016, 3).

In 1972, the nation's nationality laws were amended to eliminate the ability of children of foreign parents to naturalize by declaration. In addition, the provision granting citizenship to children of unknown origin was repealed (ISI 2019, 4-5). Furthermore, the transmission of nationality to foreign spouses was restricted (ISI 2014, 62). Despite these changes, President Felix HoupouetBoigny granted foreigners rights similar to those of citizens, although the state did not formally acknowledge their nationality (Adjami 2016, 19).

The mid-1990s saw a period of increased political and economic instability, culminating in a 2002 civil war. Starting in the mid-1990s, the government began to deny identification cards and citizenship to many individuals of foreign origin (Adjami 2016, 11, 47-48, 74; ISI 2014, 62). Côte d'Ivoire's civil registry system is weak, and many populations living along the border, children of unknown parentage, refugees, and returnees following the civil war were also denied citizenship or identification (Adjami 2016, 48-52).

Since 2013, the Ivorian government restored the right of foreign residents living on Ivorian territory at the time of independence, and those born in Côte d'Ivoire between 1961 and 1973, to acquire nationality through declaration. As of 2018, however, many remain stateless or at risk of statelessness (ISI 2019, 1-2). This policy also does not address the situations of returning refugees, refugee children born abroad, and the children of unknown parents (Adjami 2016, 4852).

Persons from Côte d'Ivoire whose ethnicity is Burkinabé, Malian, or Guinean are potentially stateless or potentially at risk of statelessness.

\section{Various groups from Kenya}

Several groups from Kenya are potentially stateless or potentially at risk of statelessness. Most of these groups are descendants of migrants from other countries that settled in Kenya in the 1930s during the British colonial period. The largest groups include the Pemba of Mombasa, whose ancestors came from Zanzibar in present-day Tanzania; ethnic Somalians such as the Galjeel tribe that settled in northeast Kenya in the 1930s; the Nubians, descended from Sudanese ex-servicemen in the British army; and Shona with ancestry in Zimbabwe (Adam 2009; Lochery 2012; ISI 2014; Ndubi 2017).

Kenyan nationality law has historically required that groups with foreign origin submit detailed documentation of their ancestry in order to register as citizens (DOS 2017e, 26). Many could not furnish documentation and were rendered stateless. Ethnic Somalis faced particularly tight scrutiny, including a screening campaign in 1989 that made some Somali groups that had resided in Kenya for generations stateless (Manby 2009, 258; Lochery 2012).

In 2011, Kenya enacted a new citizenship law that establishes a procedure through which stateless 
persons tracing ancestry in Kenya back to its independence can apply for Kenyan citizenship. To date, however, the government has not yet identified and registered many stateless persons (DOS 2017e, 26).

Individuals born in Kenya of Nubian, Somali, Shona, or Pemba ethnicity are potentially stateless or potentially at risk of statelessness.

\section{The Karana of Madagascar}

When Madagascar became independent in 1960, its post-independence government permitted only those who had been naturalized as French citizens to register as Malagasy citizens (citizens of Madagascar) (Mclnerney 2014, 1). Many foreigners residing in Madagascar at the time were rendered stateless (Aikomus 2017; ISI 2017, 35-36).

This policy most significantly affected the Karana, a Muslim ethnic group of Indian and Pakistan origin who have resided in Madagascar since before its independence (ISI 2014, 65; Mclnerney 2014, 183). Some individuals whose ancestors settled in Madagascar from Comoros were also rendered stateless (ISI 2017, 35).

In order to obtain Malagasy citizenship, an applicant's mother or father must be considered Malagasy (Mclnerney 2014, 183). Until 2017, women could not pass nationality to children, exacerbating the inter-generational transmission of statelessness (Aikomus 2017). While some Karana and ethnic Comorians have been able to naturalize, many remain stateless.

Madagascar-born Karana of Indian or Pakistani descent and Madagascar-born individuals of Comorian descent are potentially stateless or potentially at risk of statelessness.

\section{The Bakassi of Nigeria and Cameroon}

In 2002, the International Court of Justice granted sovereignty to Cameroon over the Bakassi peninsula. In 2006, Nigeria and Cameroon concluded a bilateral agreement under which Cameroon agreed not to force Nigerian citizens living in the Bakassi peninsula to leave it or change their citizenship. The region was formally handed over to Cameroon in 2008 (ISI 2018a, 4; Odinkalu 2012). Although former Nigerian citizens living in Bakassi are theoretically entitled to Cameroonian citizenship, the 2006 agreement does not set forth a procedure for proving entitlement. Many former Nigerian citizens from Bakassi have also migrated to neighboring Nigerian states following Bakassi's transfer to Cameroon (Odinkalu 2012). It has been difficult to establish recognition of Cameroonian nationality for Bakassi residents who stayed in their homes, and Nigerian nationality for those who moved to the Nigerian side of the border (ISI 2018a, 4). Many lack appropriate documentation to claim either Nigerian or Cameroonian nationality (ibid.).

Those born in the Bakassi region of Nigeria or Cameroon are potentially stateless or potentially at risk of statelessness.

\section{Zimbabwean migrants and their descendants}

Some Zimbabweans descended from farm workers from neighboring countries, particularly Mozambique, Malawi, and Zambia, are potentially stateless or potentially at risk of statelessness (Ridderbos 2009, 73). 
In 2001, Zimbabwe enacted a policy that required holders of Zimbabwean citizenship to furnish proof of renunciation of all citizenships to which they were eligible (ISI 2014, 67; Manby 2015, 233-234). Many Zimbabweans with parents and grandparents from neighboring countries lacked identification and registration documents and were unable to secure documentation proving that they had renounced citizenship in their families' countries of origin (ISI 2014, 67; Manby 2015, 234-235). Correspondingly, they were not able to confirm their Zimbabwean citizenship.

In 2003, Zimbabwe loosened its requirements, permitting those with foreign backgrounds to confirm Zimbabwean nationality without proof that they have renounced foreign citizenships. This policy, however, was not applied retroactively, and many remained without nationality (Manby 2015, 240).

In 2013, Zimbabwe recognized the citizenship of individuals born in Zimbabwe before that year, who had at least one parent from a neighboring country, provided they were habitually resident in Zimbabwe (ibid., 244). It also recognized the citizenship of children of unknown parentage born in Zimbabwe (ibid.). As of 2014, these laws had not been fully implemented and some individuals may remain stateless despite policy changes (Ridderbos 2009).

Zimbabweans abroad may be at particular risk of statelessness. The 2013 law does not guarantee the right to Zimbabwean citizenship of Zimbabweans with foreign ancestry who habitually reside outside of Zimbabwe (UNHCR 2014e, 4).

Zimbabweans of Mozambican, Malawian, or Zambian descent are potentially stateless or potentially at risk of statelessness. Additionally, children of Zimbabwean parents born in third countries are potentially stateless or potentially at risk of statelessness.

\section{Returned Mozambicans}

Mozambicans who fled for Zimbabwe during its civil war and subsequently returned to Mozambique in the 1990s may be stateless. Many persons in this situation lack documentation to prove their Mozambican nationality and they face harassment and persecution from authorities. They are also generally ineligible for Zimbabwean nationality due to that country's strict nationality laws (Manby 2015, 240). Such individuals are potentially stateless or potentially at risk of statelessness.

\section{Black Mauritanians}

Mauritania's population is comprised of three principal groups: (1) persons of Arab and ArabBerber descent; (2) Black former slaves of Arab Mauritanians known as Haratines; and (3) Black African speakers of Fulani, Wolof, Soninke, and Bambara (Manby 2015, 390). In 1989 and 1990, Mauritania's Arab-led government, seeking to consolidate control over fertile lands in the Senegal River Valley, expelled 60,000 to 65,000 Black Mauritanians to Senegal (ibid., 391). The government alleged that these deportees were unauthorized immigrants from Senegal. Those perceived to be opposed to the government's Arabization campaign were explicitly targeted, and the identity documents of many were destroyed during expulsion (ibid.).

Following a détente with Senegal in 1994, some of those who had been expelled returned to Mauritania. In 2007, then President Abdallahi expressed intent to repatriate Black Mauritanians expelled to Senegal and restore their citizenship. Some were returned and repatriated (ibid., 393). 
After a coup in 2008 , the new government suspended repatriation while it replaced its national population register with a biometric one. It resumed repatriation, but many Black Mauritanians experienced difficulties reclaiming citizenship due to new policies (ibid., 394). In 2010, the government enacted a new citizenship law restricting citizenship to those who could prove ancestry in Mauritania. It also removed Bambara from the list of Mauritania's official languages, making it harder for some Black Mauritanians to reclaim citizenship (ibid.). In 2011, the government began a Census designed to identify unauthorized residents, and some allege that Black Mauritanians have faced obstacles to recognition in the context of the census (Kohn 2011). Many Black Mauritanian returnees to date have not been able to reinstate their citizenship. Black Mauritanians who have arrived in the United States since 1989 are potentially stateless or potentially at risk of statelessness.

\section{Sahrawi}

The status of the Western Sahara territory currently remains unresolved after a 30-year dispute between Morocco and the Polisario Front independence movement. Following the withdrawal of Spain from the territory in February 1976, the Polisario Front declared the independence of the Sahrawi Arab Democratic Republic (SADR). The Moroccan military took control of the territory shortly thereafter, and about half of the territory's population fled, mostly to Algeria. Those who remained in the territory are entitled to Moroccan citizenship, but some activists and individuals who fled to Algeria face difficulties attaining Moroccan nationality (Manby 2015, 389).

Most Sahrawi remain in refugee camps in Algeria where the SADR government operates in exile. The United Nations considers the Western Sahara a "non-self-governing territory." Most of these persons cannot claim Moroccan nationality. Sahrawi refugees are eligible for SADR identification cards and passports, but the SADR is only recognized as a state by several dozen governments worldwide (ibid., 388). The United States, for example, does not recognize the SADR. Consequently, many Sahrawis who possess only a SADR passport experience difficulties traveling abroad (ibid., 390). Most residents of these camps are not entitled to Moroccan nationality.

Algeria issues short-term passports to Sahrawi refugees so they can travel to countries that do not recognize the SADR, but these passports do not convey citizenship and few have obtained Algerian nationality (ibid.). Some refugees have also obtained Mauritanian citizenship through family members (ibid.). Sahrawis outside the Western Sahara are potentially stateless or potentially at risk of statelessness (ISI 2014, 122).

\section{Ethiopians/Eritreans}

Persons of mixed Ethiopian and Eritrean heritage who arrived in the United States on or before 1998 are potentially stateless or potentially at risk of statelessness.

In 1993, Eritrea gained its independence from Ethiopia through a referendum. Following its independence, it adopted a nationality law granting citizenship to all those born to an Eritrean parent who could trace their ancestry to Eritrean territory in 1933. Those who entered Eritrea between 1934 and 1951 were also entitled to a certificate of nationality upon application.

In 1994, Ethiopia adopted a new constitution granting citizenship to anyone who has a parent with Ethiopian citizenship. Prevailing laws, however, stipulated that those acquiring Eritrean citizenship would lose Ethiopian citizenship (Manby 2015, 327). 
In 1998, a war broke out between the two countries. Many Eritreans residing in Ethiopian were arrested and expelled. In 1999, the Ethiopian government declared that all Eritreans who had voted in the 1991 Eritrean independence referendum had assumed Eritrean citizenship and were no longer Ethiopian nationals. These Eritreans were thus required to register for foreigner residence permits (ibid., 328). In 2000, the Eritrean government declared that individuals of Ethiopian descent living in Eritrea who had not sought nationality by 1998 would be considered foreigners.

In 2004, an independent commission formed following the 1998 war declared that all who had voted in the independence referendum were entitled to dual Eritrean and Ethiopian nationality (ibid., 331). Most people who were rendered stateless by past Ethiopian policies had their nationality restored. However, many individuals of mixed Ethiopian and Eritrean parentage found it impossible to gain either nationality, often due to administrative challenges (Southwick 2009). Some Ethiopian- and Eritrean-born individuals of mixed parentage remain stateless (ibid.).

\section{Sudan and South Sudan}

In 2011, the Sudanese government passed a law stripping Sudanese citizenship from those acquiring South Sudanese citizenship. This placed many individuals from South Sudanese ethnic groups residing in the Republic of Sudan at risk of statelessness. The Republic of Sudan does not require confirmation of citizenship from South Sudan and lacks a clear documentation requirement of South Sudanese citizenship, which makes the process of denationalization arbitrary (Sanderson 2014, 87-88).

Many persons born in South Sudan are also potentially stateless or potentially at risk of statelessness. Since South Sudan's independence from the Republic of Sudan, individuals have been required to secure certificates that confirm their South Sudanese nationality. If they do not, the South Sudanese government does not consider them citizens. Many people have to travel to Juba, South Sudan's capital, to confirm their citizenship (UNHCR 2017b, 3). Poor people and persons living in remote areas - for whom this trip is difficult-face significant obstacles to citizenship. Moreover, members of nomadic groups and populations near borders may have difficulty proving their right to nationality (ibid., 32-33). In addition, in order to apply for a nationality certificate, individuals must provide birth certificates. The South Sudanese government has little capacity to register births, placing many children at risk of statelessness (ibid., 3).

Sudanese-born individuals of South Sudanese descent who arrived in the United States in or after 2011 are potentially stateless or potentially at risk of statelessness. All South Sudanese who arrived in or after 2011 are potentially stateless or potentially at risk of statelessness.

\section{Banyarwanda in Democratic Republic of Congo}

Banyarwanda and Banyamulenge, ethnic Hutu and Tutsi speakers of Kinyarwanda from the Democratic Republic of Congo (DRC), are potentially stateless or potentially at risk of stateless. These groups arrived in the DRC in several waves. The earliest arrivals were Tutsi herders who migrated from Rwanda and Burundi in the $18^{\text {th }}$ and $19^{\text {th }}$ centuries. Their descendants are now known as the Banyamulenge. Other Kinyarwanda speakers were brought to the DRC by Belgian colonial authorities to work in mines and coffee plantations before the country's independence (Manby 2015, 275). Subsequent waves mostly consisted of economic migrants and refugees fleeing ethnic violence in Rwanda and Burundi in the 1960s, 1970s, and early 1990s. The Rwandan 
genocide of 1994, in particular, led to mass migration into the DRC (ibid.).

The citizenship of the Banyarwanda and Banyamulenge remains unresolved. The DRC has amended its citizenship laws pertaining to these groups multiple times since independence. The DRC's constitution at independence deemed that only those whose ancestors had been present in its territory before 1908 were entitled to citizenship. As a result, most Kinyarwanda speakers were effectively barred from DRC citizenship. In 1972, the DRC amended its citizenship law and permitted those whose ancestors had been present since 1950 to naturalize. In 1982, however, a new law required that citizens prove ancestry in the DRC back to 1885, the date when the borders of the Congo Free State were recognized, and those Banyamulenge and Banyarwanda that had attained citizenship were denationalized. In 1995, following the Rwandan genocide and increased ethnic violence in the states bordering Rwanda, the DRC government declared that all Banyarwanda and Banyamulenge had "fraudulent" DRC nationality and began a campaign of eviction and deportation (ibid., 286). Many were deported to Rwanda and their DRC identification cards were confiscated or destroyed (ibid., 287).

\section{Many Banyarwanda and Banyamulenge face difficulties documenting their ancestry in the DRC, and many face discrimination when applying for nationality.}

In 2006, the DRC enacted a new constitution, providing that all individuals whose ancestors were present in the DRC at the time of its independence in 1960 were entitled to citizenship. While the constitution permits Banyarwanda and Banyamulenge to obtain DRC citizenship, many remain stateless due to a provision excluding those perceived as having ties to foreign governments - an accusation often levied against these groups (ibid., 291). Moreover, many Banyarwanda and Banyamulenge face difficulties documenting their ancestry in the DRC, and many face discrimination when applying for nationality (ibid.). As a result, Banyarwanda and Banyamulenge in the United States are potentially stateless or potentially at risk of statelessness.

\section{The Americas}

\section{Dominicans of Haitian ancestry}

Dominican Republic (DR)-born individuals of Haitian descent are potentially stateless or potentially at risk of statelessness.

Until 2010, the DR's Constitution afforded citizenship to all children born in its territory, with the exception of children whose parents were diplomats or in transit to another country. In 2010, the DR revised its Constitution to add the children born to parents who are considered "foreign nationals in transit" and those born to undocumented parents to the list of those excluded (prospectively) from birthright citizenship (Aber and Small 2013, 87).

In 2013, the Dominican Constitutional Court issued Judgment 168-13, which introduced a new interpretation of the nationality criteria set out in the Constitutions in force between 1929 and 2010. The Constitutional Court determined that only individuals born in the country to Dominican nationals or legal residents were to be considered to have acquired Dominican nationality on 
the basis of birth in the territory (birthright citizenship).The ruling had a retroactive effect and deprived nationality to DR residents born after 1929 who were born to Haitian undocumented parents. As a result, many Dominican-born persons with Haitian ancestry were rendered stateless. Most of those stripped of Dominican nationality also lacked Haitian citizenship because Haiti did not recognize dual citizenship until 2012 (ISI 2014, 73; DOS 2017d, 13).

In 2014, the DR's president enacted a law aimed at restoring their DR citizenship and re-issuing identity documents to those born in the DR between June 16, 1929, and April 18, 2007, whose undocumented parents had registered them in the country's civil registry (known as "Group A") (DOS 2017d, 13). Following an administrative process, Group A individuals would again be recognized as Dominican citizens from birth. The government also permitted those born during the same period whose parents never registered in the civil registry (known as "Group B") to apply for legal residency within a 180-day period, after which they could apply to naturalize. However, many in Group A experienced difficulties and delays in the recognition of their citizenship, and many in Group B did not apply within the 180-day window (ibid., 14). As such, despite these reforms, many DR-born persons of Haitian descent remain stateless.

\section{Bahamians of Haitian ancestry}

Children born in the Bahamas with foreign parents are not automatically entitled to Bahamian citizenship (ISI 2014, 74). Such children can apply for Bahamian citizenship when they are 18 years old and they must present proof of birth and residence, among other documents.

Bahamian-born children of Haitian descent, with foreign parents, often experience discrimination and an attenuated citizenship process (ibid.). They also often have difficulties providing documentation of their eligibility for citizenship (DOS 2017a, 9-10). Some may face difficulties securing Haitian citizenship due to Haitian documentation requirements (IRB 2013).

The children of married non-Bahamian parents can apply for citizenship after they turn 19 years old, "but it is granted at the discretion of state authorities, and not by right" (ISI 2014, 74). Those who miss their eligibility window may have significant difficulties claiming Bahamian citizenship (DOS 2017a, 9-10).

Bahamian-born children with foreign parents, particularly those whose parents are from Haiti, are potentially stateless or potentially at risk of statelessness.

In addition, Bahamian women cannot confer Bahamian nationality to children born abroad or to non-Bahamian spouses. Children that are unable to acquire their father's citizenship or the citizenship of their birth country are potentially stateless or potentially at risk of statelessness (Global Campaign for Equal Nationality Rights and Institute for Statelessness and Inclusion 2017).

\section{Additional Considerations for Stateless Populations or those at Risk of Statelessness}

This section discusses several populations in the United States that are potentially stateless or potentially at risk of statelessness, but are not included as separate categories in CMS's estimates. These groups include:

- "Doubly undocumented" individuals who lack documentation of birth or nationality in both the US and their countries of origin; 
- Children born in refugee camps in countries without birthright citizenship;

- Children born to mothers that cannot confer their nationality;

- Individuals from nomadic tribes, individuals that have been de-nationalized; and,

- Persons who have renounced their citizenship without acquiring another nationality.

Some individuals in these categories may also fit in the profiles above.

\section{a. The "doubly undocumented" or "doubly invisible"}

Individuals lacking birth or nationality registration in their home countries and US citizenship are potentially stateless or potentially at risk of statelessness. Such individuals may not be able to claim citizenship in their origin countries despite being entitled to it. The term "doubly undocumented" refers to those without identity documentation in either their country of origin or destination.

UNICEF reports lower than average rates of birth registration in some developing countries, for certain ethnic and religious minorities, in remote and rural areas, and for children from poor households (UNICEF 2013, 22-23). Many children born in top immigrant-sending countries to the United States, including Mexico and Guatemala, have substantial unregistered populations. Seven million individuals in Mexico in 2012 and an estimated 10 percent of Guatemala's population in 2018 lacked proof of nationality (Mercado Asencio 2012; González 2018).

Although Mexico has taken steps to address this challenge in recent years, birth registration remains a particular problem for street children, single-parent families in rural areas, indigenous children, and the children of migrants, especially those without documentation. Such persons may not be able to travel to municipal offices or afford registration fees, and may face language barriers. They may also face difficulties working in the formal sector and be particularly likely to migrate to the United States in search of economic opportunity (Mercado Asencio 2012).

Five-year data from the American Community Survey suggests that 13,329 non-citizen residents from Mexico, Guatemala, and El Salvador speak indigenous languages at home. It is likely that a nontrivial number of these individuals are "doubly undocumented."

\section{b. Children born in refugee camps or urban settings in countries without birthright citizenship}

Children born to stateless or refugee parents are potentially stateless or potentially at risk of statelessness. Many refugee-hosting countries across the world either lack birthright citizenship or limit it to those meeting residency or ethnic criteria. Of the top eight refugee-hosting nations in 2018 - Turkey, Pakistan, Uganda, Sudan, Germany, Iran, Lebanon, and Bangladesh- none currently grant citizenship automatically to children born to refugees, although Pakistan's prime minister has pledged to extend citizenship to Afghan refugees (UNHCR 2019b, 17; Stubley and Baynes 2018). In cases where their parents are stateless, children born in such countries often become stateless themselves.

In other cases, children may be entitled to their parents' nationality. However, obtaining official recognition of children's nationality is impractical in some cases and impossible in others. This is the case for Syrian children, for example, who must be registered in Syria in order to obtain Syrian 
nationality (Howard 2017, 1). In these circumstances, children may be at risk of statelessness when their refugee parents cannot secure documentation for them from their countries or origin or transit (Price 2013).

\section{c. Children born to mothers who cannot confer nationality}

As of 2018, mothers cannot confer nationality upon their children on an equal basis with fathers in 25 countries (UNHCR 2019, 6). In some countries, such as Iran, Qatar, and Lebanon, mothers cannot confer nationality at all. In others like Barbados, Bahamas, Kiribati, Jordan, Saudi Arabia, the United Arab Emirates, and Liberia, mothers can confer nationality only if their child is born in the mother's country of nationality or if their father is unknown or stateless (ibid.).

In most cases where mothers cannot pass on citizenship, children can acquire the nationality of their father. However, children can become stateless if they cannot acquire citizenship from their father and do not reside in a country with birthright citizenship or safeguards against childhood statelessness. This is most likely to occur if the father is stateless or if the child's birth must be registered in their fathers' home countries in order to gain nationality (Price 2013, 494).

Children whose mothers cannot pass on citizenship may also be stateless if born to a single mother or out of wedlock (ibid., 493-494). In cases of absent fathers, it is often difficult for mothers to secure the documentation necessary to prove that their children are entitled to citizenship through their father. This may also occur in some countries if fathers have abandoned the family or passed away (DOS 2017h, 20).

\section{d. Members of nomadic groups}

Some small nomadic groups are at risk of statelessness. They often migrate across borders and may not be able to prove habitual residence in their territories of origin (Conklin 2014). They may also be less likely to register their children at birth (ibid.). Many nomadic groups also face discrimination by public officials that can make it difficult to register or obtain travel documents. In addition to the Roma, Afghan Jogi, and Bedouin mentioned above, other nomadic groups including possibly stateless persons and persons at risk of statelessness include nomadic pastoralists in Pakistan and Bangladesh, the Tuareg of the Sahara and Sahel, Malaysian and Indonesian ethnic minorities in places such as Borneo and West Papua (including the Bajau Laut maritime nomadic tribes), the Dom people (Romany from the Middle East), and India's de-notified tribes (nomadic tribes that have been deemed "criminal" under Indian law since 1871).

\section{e. De-nationalized individuals who have not yet obtained another nationality}

Some individuals are stateless because their home countries stripped them of nationality before they could obtain a new nationality. As of 2018, 130 countries' constitutions allow the revocation of citizenship, although revocation remains rare globally (Trimbach and Reiz 2018). Most commonly, citizenship is revoked if individuals are thought to be security threats, particularly if they are suspected of terrorism or engaging in military activities on behalf of an enemy state (UNGA 2013, 7-8; Trimbach and Reiz 2018). It may also be revoked if citizenship is found to have been obtained fraudulently (UNGA 2013, 5-6; Trimbach and Reiz 2018). Some countries can also de-nationalize individuals who have lived abroad for an extended period of time (UNGA 2013, 9). Although uncommon, some countries also de-nationalize their citizens due to their political opinions or ethnic or religious backgrounds (ibid., 10). US residents who lose their original nationality before obtaining US citizenship may be stateless. 


\section{f. Persons who have renounced or rejected their nationality without acquiring another nationality}

Individuals who voluntarily renounced their nationality without possessing other nationalities, or who have rejected the possibility of acquiring nationality for political reasons, are stateless if they have not obtained another nationality.

This category includes persons who are eligible for citizenship but have not naturalized for political reasons, such as Druze who refuse Israeli citizenship (Plachta 2017). In such cases, persons may remain stateless if they refuse to acquire the nationality of the state in which they reside.

\section{g. Illegal overseas adoptions and children from international commercial surrogacy}

Under the Child Citizenship Act of 2000, children adopted overseas automatically become US citizens if one of their parents is a US citizen, the child is under age 18, he or she lives (or lived) in the custody of the US citizen parent, has been admitted to the United States as an immigrant, and the adoption is final. ${ }^{41}$

However, children illegally adopted from abroad by US citizen parents may be stateless and, if they lack documentation to secure nationality in their country of origin, they may remain stateless after arrival in the United States.

Children born overseas to surrogate mothers with donors' egg and sperm may also be stateless (Batha 2014). DOS only recognizes biological parentage in overseas births, meaning that children born to surrogates may not be entitled to US nationality if donor sperm and eggs are used (DOS 2019). Also, international surrogacy agreements require the gestational mother to waive all parental rights, and sperm and egg donors are anonymous. Consequently, such children may be ineligible for the citizenship of their surrogate mother.

\section{h. Non-migrant Stateless Populations}

Globally, most stateless persons do not cross international borders or leave their country of long-term residence (UNHCR 2014g, 3). It is likely that some former US citizens are in this position, either having relinquished US citizenship through certain acts (including a formal renunciation), ${ }^{42}$ or having been stripped of their citizenship through denaturalization, ${ }^{43}$ without acquiring nationality in another country. The estimation of this population-persons who became stateless under the operation of US law-is beyond the scope of this project. 


\section{Section III: Estimates of Those Who are Potentially Stateless or Potentially At Risk of Statelessness}

\section{Sources of Data and Tentative Estimates of US Stateless Populations}

This section provides provisional estimates and profiles of populations who are potentially stateless or potentially at risk of statelessness in the United States. Data limitations preclude definitive estimates of the populations set forth in CMS's profiles, much less an aggregate estimate of the US stateless population. CMS's provisional estimates come from two main sources, the American Community Survey and refugee- and immigration-related administrative data, particularly WRAPS data. This section describes these sources of data and offers a brief summary of UNHCR mapping statelessness studies in other nations.

\section{American Community Survey}

The ACS is an annual individual-level survey conducted by the US Census Bureau. Its large sample size, thorough geographic coverage, and high response rate allow CMS researchers to provide provisional estimates and profiles of several populations that are potentially stateless or potentially at risk of statelessness in the United States. Unlike administrative data, the ACS can be used to estimate the potentially stateless or those potentially at risk of statelessness, even if they have never applied for asylum, been granted refugee status, or come to the attention of US immigration enforcement agencies. It is thus likely to include individuals who became stateless following their entry in the United States, as well as persons who entered the United States without sufficient documents.

The ACS is based on a representative sample of the US population; i.e., 3.5 million households in all US Census tracts across all 50 states and the District of Columbia. ${ }^{44}$ From 2013 to 2017, each round of the survey had a response rate of 90 percent or above (US Census Bureau 2019e), ensuring broad coverage of the US population. That said, exact response rates vary from year to year. Given the likely small size of many potentially stateless or potentially at risk of statelessness populations, CMS based its provisional estimates on 5-year combined ACS data spanning 20132017 (US Census Bureau 2019, Table S1501). The 5-year microdata contain more than 15 million individual records, permitting the identification of groups with a low incidence in the overall population, including stateless groups. ${ }^{45}$

To arrive at its estimates, CMS tabulated counts of individuals whose countries of birth, ethnic backgrounds, birth years, years of arrival, and language proficiencies match the CMS profiles of persons in the United States who are potentially stateless or potentially at risk of statelessness. For example, in the case of ethnic Nepali Bhutanese, CMS counted populations born in Bhutan that arrived in the United States between 1986 and 2017 (the most recent year for which data

44 The ACS sample includes populations residing in group quarters such as nursing homes, correctional facilities, mental hospitals, college dormitories, group homes, military barracks, and shelters (US Census Bureau 2017). Anyone residing for at least two months at a given address is included in the sample. Populations that are potentially stateless or potentially at risk of statelessness that are detained in correctional facilities or that reside in shelters may be included in the ACS.

45 The 5-year PUMS data combines data from 5 years of statistically independent ACS rounds. Each one-year survey is based on a sample of 3.5 million households and actual response rates vary from year to year. The 5-year PUMS microdata include about 15.6 million observations. For more information about how the 5-year PUMS sample is assembled, see US Census Bureau,"PUMS Technical Documentation," https://www.census.gov/programs-surveys/ acs/technical-documentation/pums/documentation.html. 
is available) and listed their ancestry as Nepali or their language spoken at home as Nepali, Dotyali, or Dangaura Tharu. ${ }^{46}$ To ensure that its estimates are as accurate as possible, CMS considered only non-naturalized, foreign-born persons; that is, persons without US citizenship. The final estimates represent aggregated estimates of individuals matching the CMS profiles, weighted to population level, using standard Census Bureau-established person weights that take into account the ACS's sampling design and the aggregation of 1-year samples into the 5-year microdata sample. ${ }^{47}$ Using these weights, CMS is able to produce estimates of the number of individuals matching each profile above that resided in the United States in 2017.

The ACS does not permit researchers to determine definitively whether individuals are stateless or at risk of statelessness. Its questionnaires do not include explicit questions about nationality or statelessness. It also does not ask questions about non-US citizenship and, therefore, it is not possible to gauge whether ACS respondents possess nationalities other than US citizenship. As stated, individuals included in CMS's estimates may possess the nationality of their country of origin or a third country. Thus, CMS's estimates should be considered provisional estimates of persons who are potentially stateless persons or potentially at risk of statelessness.

As noted above, also, the incidence and risk of statelessness is likely to vary significantly across profiles. Some small groups included in CMS's profiles, notably former Yugoslavians from North Macedonia, ethnic Somalis from Kenya, ethnic Eritreans from Ethiopia, ethnic Ethiopians from Eritrea, ethnic Tamils from Malaysia, Palestinians from Jordan, and Serbians from Croatia may experience statelessness at lower rates than other profiled groups. Without additional data and individual screening, it is impossible to estimate the incidence of statelessness for each profile.

\section{Limitations}

The 5-Year ACS aggregates some countries of birth into larger geographic regions. ${ }^{48}$ As a result, the ACS precludes the identification of individuals born in some key countries and territories set forth in the CMS profiles, including Estonia, the Western Sahara, Mauritania, Côte d'Ivoire, Brunei, Madagascar, Turkmenistan, Tajikistan, and South Sudan. Likewise, ACS data does not capture speakers of several languages, including Rohingya, Tedaga (Tebu Libyan), Dinka, Nuer, and several minority languages of Kenya, Ethiopia, Côte d'Ivoire, and Thailand. The ACS aggregates these into larger language families, making it difficult to identify speakers who are potentially stateless or potentially at risk of statelessness with precision.

ACS data also does not capture certain ethnicities from CMS's profiles, including Sahrawi, Lebanese Bedouin, Dinka, Nuer, Burkinabé, Guinean, Tanzanian, Mozambican, and Zimbabwean individuals and members of some Thai minority groups. As in the case of languages not captured by the ACS, these ancestries are aggregated into larger categories. In addition, some ethnicities, such as Afghan Jogi and Bakassi are missing entirely from the ACS. Furthermore, ACS data does not permit the identification of Iraqi Feyli Kurds born in Iran and Chinese Cambodians born in Vietnam, as

\footnotetext{
46 The ACS permits respondents to list up to two ethnicities. Both ethnicities were taken into account in CMS calculations.

47 ACS weights incorporate Census-derived population data produced by the Census Bureau's Population Estimates Program (PEP), including data on respondents' sex, age, race, and Hispanic origin, to increase the precision of the estimates. Person weights also correct for differential coverage by geography and demographic detail (US Census Bureau 2014, 135-167).

48 Individuals born in the Côte d'Ivoire or Mauritania, for example, are recorded only as having been born in Western Africa.
} 
it is impossible to disaggregate them from Iranian Kurds and Vietnamese of Chinese origin. The ACS estimates also cannot be used to distinguish ethnic Somali Kenyans whose ancestors arrived in Kenya in the 1930s from those whose ancestors were in Kenya prior to that decade, who may have a lower incidence of statelessness. Likewise, these estimates cannot be used to differentiate between Thai-born ethnic Hmong, Lahu, Yao, Lisu, and Shan individuals with immediate ancestry in Laos or Myanmar, and members of these groups with immediate ancestry in Thailand, who may have a lower rate of statelessness, or between ethnic Nepalese of immediate Bhutanese ancestry and ethnic Nepalese with immediate ancestry in Nepal.

In addition, this data does not allow the identification of individuals born in Pakistan and Sri Lanka who were stateless in India before arriving in the United States, as the ACS lacks data on country of last habitual residence for individuals who arrived in the United States more than one year prior to the survey. Nor does the data permit the accurate identification of Indian-born individuals of Pakistani origin from Jammu and Kashmir, since the ACS does not record region of birth within India. As a result, CMS excludes this profile from its final estimate. Finally, ACS data does not permit CMS to distinguish between Feyli Kurds and other Kurds born in Iraq. CMS's estimates of Feyli Kurds may include some non-Feyli Iraqi Kurds that possess Iraqi citizenship.

Moreover, many non-US citizens born in the countries set forth in the CMS profiles did not list their ancestries or they listed ancestries coded as "Other" in the ACS. About 403,000 of a total 5.5 million (about 7.4 percent) born in these countries did not list any ancestry and 20,100 listed "other" ancestries. Some of these individuals may match the criteria in CMS's profiles. Consequently, this analysis may fail to capture small numbers of persons who are potentially stateless or potentially at risk of statelessness. ${ }^{49}$

Finally, the ACS does not permit the identification of persons who are potentially stateless or potentially at risk of statelessness who were not registered in their home countries at birth but do not belong to a minority ethnic or linguistic group. In particular, CMS cannot identify Bidoon that are not ethnic minorities in their countries of residence or Chinese-born individuals without hukou registration.

\section{Provisional Estimates of Persons who are Potentially Stateless or Potentially at Risk of Statelessness in the United States}

CMS's analysis of ACS data reveals 198,000 individuals who match its profiles of persons who are potentially stateless or potentially at risk of statelessness. To account for potential inaccuracies due to survey error, CMS also calculated upper and lower bounds for this estimate. CMS estimates that the number of persons who are potentially stateless or potentially at risk of statelessness, as defined by the above profiles and accounting for the data limitations described above, falls between 192,000 and 204,000 persons. ${ }^{50}$

49 About 100 persons meeting the criteria in CMS's profiles also listed "other" ethnicities as secondary ethnicities. The majority of these persons were born in Soviet successor countries. In this analysis, CMS considers these individuals to be potentially stateless or potentially at risk of statelessness.

50 Specifically, CMS used Census Bureau-defined "replicate weights" that account for ACS sampling methodology in order to construct a 95-percent confidence interval around the 200,000 estimate. 
CMS's analysis of ACS data based on its statelessness profiles reveals 198,000 individuals that match the above profiles of persons who are potentially stateless or potentially at risk of stateless.

Table 1 gives ACS-based estimates for each profile identified in section II above. As discussed, data limitations made it impossible to develop estimates for some profiles. Profiles with counts of zero in Table 1 reflect groups with no respondents in the 5-Year ACS. CMS left the count column blank when it was not possible to calculate counts based on ACS data limitations.

Table 1: ACS Estimates of Profiles of Those Potentially Stateless or Potentially at Risk of Statelessness ${ }^{51}$

\begin{tabular}{|c|c|c|}
\hline $\begin{array}{l}\text { Profile Description (rounded to the } \\
\text { nearest 100) }\end{array}$ & $\begin{array}{c}\text { Estimate }^{52} \text { (rounded to the } \\
\text { nearest 100) }\end{array}$ & Note \\
\hline \multicolumn{3}{|l|}{$\begin{array}{l}\text { Emigrants from the Former Soviet } \\
\text { Union before its collapse who } \\
\text { arrived in the US before } 1992\end{array}$} \\
\hline Latvia & 700 & \\
\hline USSR & 1,300 & \\
\hline Byelorussia & 400 & \\
\hline Moldova & 400 & \\
\hline Ukraine & 5,800 & \\
\hline Armenia & 2,500 & \\
\hline Azerbaijan & 300 & \\
\hline Georgia & 400 & \\
\hline Kazakhstan & 400 & \\
\hline Uzbekistan & 400 & \\
\hline Lithuania & 700 & \\
\hline Tajikistan & & $\begin{array}{l}\text { Data on Tajikistan not } \\
\text { available in ACS; data } \\
\text { only presented in a } \\
\text { regional aggregate. }\end{array}$ \\
\hline Turkmenistan & & $\begin{array}{r}\text { Data } \\
\text { on Turkmenistan not } \\
\text { available in ACS; data } \\
\text { only presented in a } \\
\text { regional } \\
\text { aggregate. }\end{array}$ \\
\hline
\end{tabular}

51 Due to space limitations, this chart does not include technical details of how each profile was calculated or confidence intervals around each group estimate.

52 These counts are weighted using ACS person weights. 


\begin{tabular}{|c|c|c|}
\hline Estonia & & $\begin{array}{r}\text { Data on Estonia not } \\
\text { available in ACS; data } \\
\text { only presented in a } \\
\text { regional aggregate. }\end{array}$ \\
\hline $\begin{array}{l}\text { Ethnic } \\
\text { Russians, } \\
\text { Belarussians, } \\
\text { Ukrainians } \\
\text { from Estonia }\end{array}$ & & $\begin{array}{r}\text { Data on Estonia not } \\
\text { available in ACS; data } \\
\text { only presented in a } \\
\text { regional aggregate. }\end{array}$ \\
\hline $\begin{array}{l}\text { Ethnic } \\
\text { Russians, } \\
\text { Belarussians, Poles from Latvia }\end{array}$ & 2,300 & \\
\hline $\begin{array}{l}\text { Members of Ethnic Minority } \\
\text { groups from Lithuania }\end{array}$ & $<100$ & \\
\hline \multicolumn{3}{|l|}{ South Caucasus } \\
\hline Armenians from Azerbaijan & 1,100 & \\
\hline Azerbaijanis from Georgia & 0 & \\
\hline \multicolumn{3}{|l|}{ Meskhetian Turks } \\
\hline Georgia & 0 & \\
\hline Russia & 1,200 & \\
\hline Uzbekistan & 800 & \\
\hline USSR & 0 & \\
\hline \multicolumn{3}{|l|}{ Roma, Ashkali, and Balkan Egyptians } \\
\hline Roma, Yugoslavia & 0 & \\
\hline Roma, Croatia & 0 & \\
\hline Roma, Serbia & 0 & \\
\hline Roma, Montenegro & 0 & \\
\hline Roma, Bosnia & 0 & \\
\hline Roma, North Macedonia & 0 & \\
\hline Roma, Slovenia & 0 & \\
\hline Balkan Egyptians, Albania & 0 & \\
\hline Balkan Egyptians, Serbia & 0 & \\
\hline Balkan Egyptians, Montenegro & 0 & \\
\hline Balkan Egyptians, North Macedonia & $<100$ & \\
\hline Balkan Egyptians, Yugoslavia & 0 & \\
\hline $\begin{array}{l}\text { Individuals with } \\
\text { Yugoslavian } \\
\text { passports } \\
\text { that entered the US before } 1992\end{array}$ & 4,300 & \\
\hline
\end{tabular}




\begin{tabular}{|c|c|c|}
\hline $\begin{array}{l}\text { Born in North Macedonia, } \\
\text { Other Ex-Yugoslav } \\
\text { Descent }\end{array}$ & 2,000 & $\begin{array}{r}\text { This profile may have a } \\
\text { relatively low incidence } \\
\text { of statelessness and may } \\
\text { include } \\
\text { numerous } \\
\text { individuals that are } \\
\text { neither potentially } \\
\text { stateless } \\
\text { nor potentially at risk of } \\
\text { statelessness. }\end{array}$ \\
\hline Born in Croatia, Serbian descent & 1,500 & \\
\hline \multicolumn{3}{|l|}{ Roma born in Italy and Germany } \\
\hline Germany & $<100$ & \\
\hline Italy & $<100$ & \\
\hline
\end{tabular}

Syrian Refugee Children

Born Abroad

\begin{tabular}{|c|c|c|}
\hline Germany & 0 & \\
\hline Jordan & 200 & \\
\hline Lebanon & 0 & \\
\hline Sweden & 0 & \\
\hline Turkey & $<100$ & \\
\hline United Kingdom & 0 & \\
\hline Feyli Kurds from Iraq & 5,400 & $\begin{array}{r}\text { Feyli Kurds born in } \\
\text { Iran cannot be identified. } \\
\text { They cannot be } \\
\text { distinguished from } \\
\text { Iranian Kurds. This sum } \\
\text { may include some non- } \\
\text { Feyli } \\
\text { Kurds from Iraq. }\end{array}$ \\
\hline Syrian Kurds & 300 & \\
\hline Lebanese Kurds and Bedouin & 0 & $\begin{array}{l}\text { Lebanese Bedouin } \\
\text { cannot be identified. } \\
\text { No Lebanese Kurdish } \\
\text { respondents were } \\
\text { registered in the ACS. }\end{array}$ \\
\hline $\begin{array}{l}\text { Individuals rendered stateless } \\
\text { by } \\
\text { Lebanese nationality laws }\end{array}$ & & $\begin{array}{l}\text { ACS data is not specific } \\
\text { enough for estimates } \\
\text { based on this profile. }\end{array}$ \\
\hline
\end{tabular}




\section{Tebu Libyans}

Tebu Libyans cannot

be identified; Tedaga

language is aggregated with other North African

languages

\begin{tabular}{lc}
\hline Palestinians & \\
\hline Jordan & 1,600 \\
\hline Lebanon & 500 \\
\hline Syria & 100 \\
\hline Israel and Palestine & 700 \\
\hline Kuwait & 600
\end{tabular}

This figure reflects the number of Kuwait-born persons that indicated Saudi ancestry in the ACS.

\begin{tabular}{ll}
\hline Saudi Arabia & 300 \\
\hline United & 400 \\
Arab Emirates & \\
\hline
\end{tabular}

\begin{tabular}{ll} 
Egypt & $<100$ \\
\hline Yemen & $<100$ \\
\hline "Other Asia", inc. Bahrain, Oman, & 6,200 \\
Qatar & \\
\hline
\end{tabular}

\section{Bidoon}

Kuwait

Only Bidoon of Iraqi and Saudi descent are identifiable; other Bidoon are ethnic Kuwaitis and speak Arabic. Some individuals of Iraqi and Saudi descent from Kuwait may also not be Bidoon. Saudis and speak Arabic and thus cannot be identified.

United

Arab Emirates
Bidoon are ethnic

Emiratis and speak Arabic and thus cannot be identified. 


\begin{tabular}{|c|c|c|}
\hline $\begin{array}{l}\text { Nepalese born after 1990, } \\
\text { including Lhotshampas born in } \\
\text { Nepal }\end{array}$ & 42,100 & $\begin{array}{r}\text { The ACS cannot be used } \\
\text { to distinguish between } \\
\text { Lhotshampa } \\
\text { Nepalese with } \\
\text { immediate ancestry in } \\
\text { Bhutan, and Nepalese } \\
\text { with direct ancestry in } \\
\text { Nepal. These groups may } \\
\text { have different incidences } \\
\text { of statelessness. }\end{array}$ \\
\hline $\begin{array}{l}\text { Ethnic Nepalis (Lhotshampa) born } \\
\text { in Bhutan }\end{array}$ & 41,700 & - \\
\hline Rohingya & & $\begin{array}{l}\text { Rohingya language and } \\
\text { ethnicity not identified } \\
\text { in ACS. }\end{array}$ \\
\hline \multicolumn{3}{|l|}{ Myanmar } \\
\hline \multicolumn{3}{|l|}{ Malaysia } \\
\hline \multicolumn{3}{|l|}{ Thailand } \\
\hline \multicolumn{3}{|l|}{ Australia } \\
\hline \multicolumn{3}{|l|}{ Bangladesh } \\
\hline \multicolumn{3}{|l|}{ Pakistan } \\
\hline \multicolumn{3}{|l|}{ India } \\
\hline \multicolumn{3}{|l|}{ Indonesia } \\
\hline \multicolumn{3}{|l|}{ Saudi Arabia } \\
\hline $\begin{array}{l}\text { United } \\
\text { Arab Emirates }\end{array}$ & & \\
\hline
\end{tabular}

\section{Other Minorities from Myanmar}

\begin{tabular}{lc}
\hline Ethnic Indians & 1,700 \\
\hline Ethnic Chinese & 11,400 \\
\hline Ethnic Nepali & $<100$ \\
\hline Hmong from Laos & 12,400 \\
\hline Hmong from Thailand & 10,000 \\
\hline Members of Thai Hill Tribes & 0 \\
\hline Thai-born Children of & 9,900 \\
Burmese Refugees & \\
\hline
\end{tabular}

Chinese without Hukou Registration

\section{Tibetans}

Tibetans
Cannot be measured using ancestry or language data. 


\begin{tabular}{|c|c|c|}
\hline Born in Tibet/China & 3,600 & \\
\hline Born in India & 1,900 & \\
\hline Born in Nepal & 900 & \\
\hline Afghan Jogi & & $\begin{array}{r}\text { Jogi ethnicity cannot be } \\
\text { identified in ACS }\end{array}$ \\
\hline \multicolumn{3}{|l|}{ Stateless Groups from India } \\
\hline Chakmas and Hajongs & & $\begin{array}{l}\text { ACS data is not specific } \\
\text { enough for estimates } \\
\text { based on this profile. }\end{array}$ \\
\hline $\begin{array}{l}\text { Indian-born persons with Sri Lankan } \\
\text { Tamil Origin }\end{array}$ & 0 & \\
\hline $\begin{array}{l}\text { Indian-born persons of Bhutanese } \\
\text { origin, } \\
\text { including } \\
\text { Lhotshampa }\end{array}$ & $<100$ & \\
\hline
\end{tabular}

Bengalis from Pakistan

Ethnic Minorities from Malaysia

Ethnic Tamil Indians 600

0

600
Note: This profile

may have a relatively

low incidence of statelessness and may include numerous individuals that are neither potentially stateless nor potentially at risk of statelessness.

\begin{tabular}{lc}
\hline Ethnic Indonesians & $<100$ \\
\hline Ethnic Filipinos & $<100$ \\
\hline $\begin{array}{l}\text { Ethnic Vietnamese and Khmer } \\
\text { Krom from Cambodia }\end{array}$ & 400 \\
\hline
\end{tabular}

Cannot be disaggregated from Chinese Vietnamese

Stateless Persons from Brunei Data on Brunei not available in ACS; data only presented in a regional aggregate.

Ivoirians with ancestry in Mali, Guinea, Burkina Faso
Malian, Guinean, Burkinabé ancestries are aggregated into "West African" in ACS 


\begin{tabular}{|c|c|c|}
\hline $\begin{array}{l}\text { Somalian ancestry, } \\
\text { including Galjeel. }\end{array}$ & 6,800 & $\begin{array}{r}\text { Note: This profile } \\
\text { may have a relatively } \\
\text { low incidence of } \\
\text { statelessness and may } \\
\text { include numerous } \\
\text { individuals that are } \\
\text { neither potentially } \\
\text { stateless nor potentially } \\
\text { at risk of statelessness }\end{array}$ \\
\hline Shona speakers & 300 & \\
\hline $\begin{array}{l}\text { Tanzanian } \\
\text { /Zanzibari ancestry (Pemba) }\end{array}$ & & $\begin{array}{r}\text { Cannot be identified; } \\
\text { Tanzanian, Zanzibari } \\
\text { ancestry only available } \\
\text { in "Other Subsaharan } \\
\text { African" aggregate }\end{array}$ \\
\hline Sudanese ancestry (Nubians) & & $\begin{array}{l}\text { Cannot be identified; } \\
\text { Nubian language only } \\
\text { available in aggregate }\end{array}$ \\
\hline $\begin{array}{l}\text { Karana } \\
\text { of Madagascar }\end{array}$ & & $\begin{array}{l}\text { Data on Madagascar not } \\
\text { available in ACS. Only } \\
\text { presented in aggregate. }\end{array}$ \\
\hline
\end{tabular}

South

Asian Ancestry

Comorian Ancestry

Bakassi of Nigeria and Cameroon

Bakassi ethnic group not identified in ACS

\section{Zimbabweans with}

Origins

in

Neighboring Countries

\begin{tabular}{lr}
\hline Malawian Ancestry & $\begin{array}{r}\text { Cannot be identified; } \\
\text { Malawian ancestry } \\
\text { available only in } \\
\text { aggregate }\end{array}$ \\
\hline $\begin{array}{l}\text { Mozambican } \\
\text { Ancestry }\end{array}$ & $\begin{array}{r}\text { Cannot be identified; } \\
\text { Mozambican } \\
\text { ancestry }\end{array}$ \\
& $\begin{array}{r}\text { available only in } \\
\text { aggregate }\end{array}$ \\
\hline Zambian Ancestry & $\begin{array}{r}\text { Cannot be identified; } \\
\text { Zambian ancestry only } \\
\text { available in aggregate }\end{array}$ \\
\hline
\end{tabular}




Returned Mozambican
Refugees
in Mozambique

Cannot be identified using ancestry or language data.

Black Mauritanians
Data on Mauritania not available in ACS; data

present only in a regional

aggregate.

Sahrawi (born in the Western
Sahara or Algeria)

Cannot be identified;

Data on Western Sahara

is only available in

"Other North Africa" and

"Other Arab" aggregates.

Ethiopians with
Eritrean
Ancestry

Note: This profile may

have a relatively low incidence of statelessness and may include numerous

individuals that are neither potentially stateless

nor potentially at risk of statelessness.

\begin{tabular}{lr}
\hline Eritreans with Ethiopian Ancestry & $\begin{array}{r}\text { Note: This profile may } \\
\text { have a relatively low } \\
\text { incidence }\end{array}$ \\
of statelessness \\
and may include \\
numerous individuals \\
that are neither \\
potentially stateless \\
$\begin{array}{l}\text { Sudanese-born individuals of Dinka } \\
\text { and Nuer (South Sudanese) } \\
\text { descent, arrived in 2011 or later }\end{array}$ & $\begin{array}{r}\text { nor potentially at risk of } \\
\text { statelessness. }\end{array}$ \\
\hline $\begin{array}{l}\text { Born in South Sudan, main South } \\
\text { Sudanese ethnic groups, arrived } \\
\text { in } 2011 \text { or later }\end{array}$ & $\begin{array}{r}\text { Dinka and Nuer } \\
\text { ancestries available only } \\
\text { in aggregate. }\end{array}$ \\
\hline
\end{tabular}




\section{Banyarwanda and \\ Banyamulenge from the \\ Democratic Republic of Congo}

0 Hutu, Tutsi, Banyarwanda, and Banyamulenge ethnic groups are not identified in the ACS. The Kinyarwanda language is identified in the ACS,

but no respondents identified as Kinyarwanda speakers.Most DRC-born identified as French or Swahili speakers.

\section{Dominicans}

(Dominican

Republic) of Haitian Ancestry

\section{Bahamians of Haitian Ancestry 2,800}

TOTAL 198,000 53

Source: CMS calculations based on 2013-2017 5 Year PUMS data

Many members of these populations-particularly those from Bhutan, the DRC, Laos, Thailand, and Myanmar-are legally present as refugees in the United States, but they are not assured of securing US citizenship.

The largest groups in these provisional estimates are:

- Nepali-born individuals born on or before 1990, including the Nepali-born children of refugees from Bhutan (42,100);

- Ethnic Nepalis from Bhutan (41,700);

- Ethnic Hmong from Laos (12,400);

- Ethnic Chinese from Myanmar (11,400);

- Palestinians from Arabic-speaking countries (10,600);

- Ethnic Hmong from Thailand (9,900);

- Thailand-born children of Karen, Chin, and Shan refugees from Myanmar and members of Thai tribes sharing these ethnicities $(9,900)$

- Ethnic Somalis from Kenya $(6,800)$;

- Eritreans with Ethiopian ancestry (6,000); and,

53 This number represents the sum of unrounded estimates by profile, rounded to the nearest hundred 
- Ukrainians who arrived in the United States before $1992(5,800)$.

Many members of these populations- particularly those from Bhutan, the DRC, Laos, Thailand, and Myanmar-are legally present as refugees in the United States (Chart 1), but they are not assured of securing US citizenship.

\section{Chart 1}

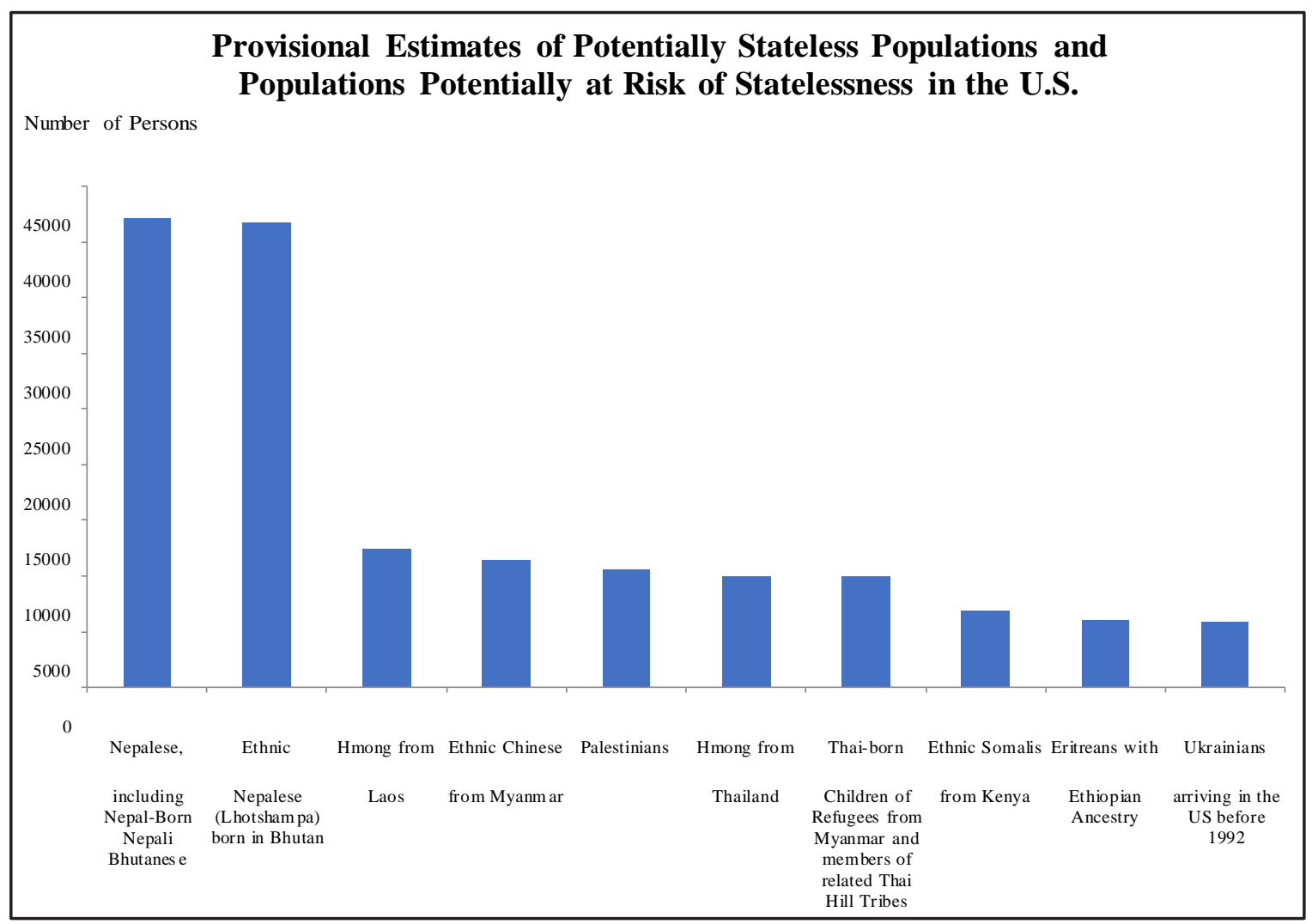

Source: CMS calculations based on 2013-2017 5 Year PUMS data

\section{Demographic and Labor Force Characteristics of Populations That are Potentially Stateless or Potentially at Risk of Statelessness}

Individuals who are potentially stateless or potentially at risk of statelessness are present in all 50 states and the District of Columbia. ${ }^{54}$ According to CMS's analysis and provisional estimates, the 10 states with the largest populations are California $(20,600)$, New York $(18,500)$, Texas $(15,200)$, Ohio (13,200), Minnesota (11,200), Illinois $(8,600)$, Pennsylvania $(8,200)$, Wisconsin $(7,300)$, Georgia $(6,600)$, and Virginia $(6,500)$ (Chart 2). 


\section{Chart 2}

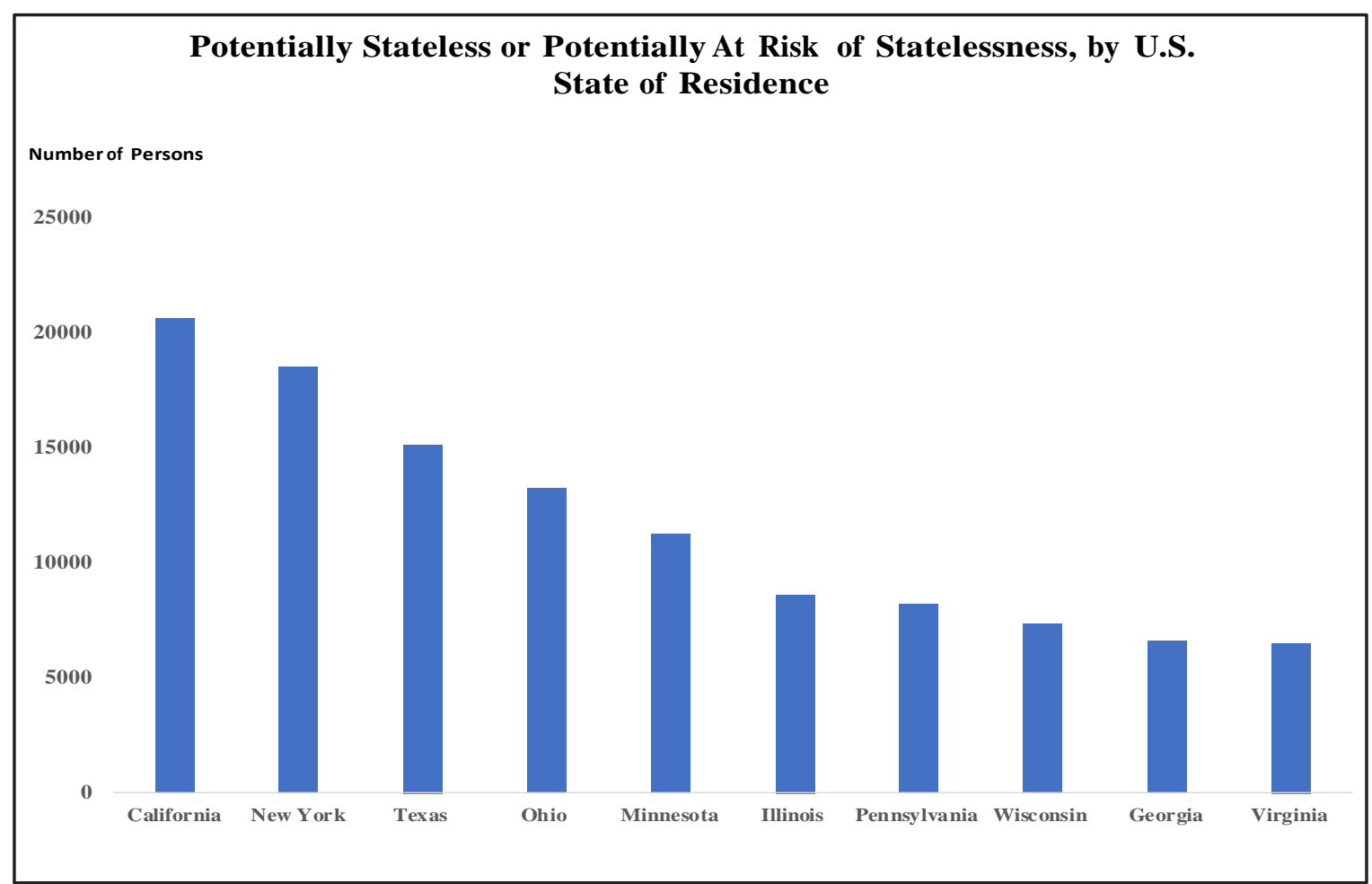

Source: CMS calculations based on 2013-2017 5 Year PUMS data

Individuals who are potentially stateless or potentially at risk of statelessness are present in all 50 states and the District of Columbia.

CMS's provisional estimates indicate that the US population of individuals that are potentially stateless or potentially at risk of statelessness is 52.6 percent male and 47.4 percent female. About 55 percent of those over age-15 are married.

While many are relatively new arrivals -45.1 percent have resided in the United States less than 5 years - 18.2 percent have lived in the United States for 20 or more years (see Chart 3 below). Many of the newer arrivals were born in Nepal, Bhutan, Thailand, and Myanmar. Many likely arrived as refugees and possess permanent residency. Those who have lived in the United States for 20 years or more are mostly Hmong from Laos and Thailand and persons from the former Soviet Union and Yugoslavia. 


\section{Chart 3}

\section{Time Spent in U.S.}

\section{Percent}

50

45

45.1

40

35

30

27.1

25

20

15

10

5

0

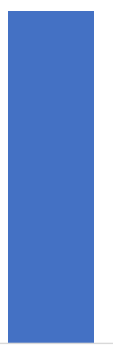

18.2

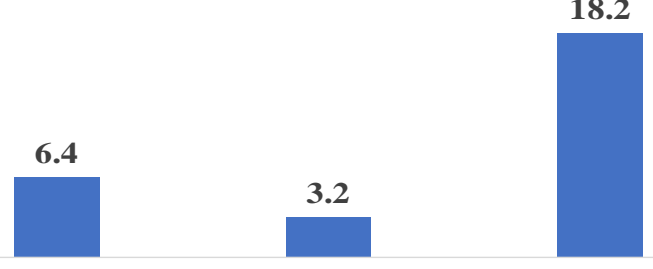

Less than 5 5 to 9 Years

10 to 14 Years 15 to 19 Years

20 Years or

more

Source: CMS calculations based on 2013-2017 5 Year PUMS data

At the time they were surveyed, 23.4 percent of this population was 18 years old and younger, 69.1 percent was between 18 and 64 years old, and 7.5 percent was 65 years of age or older (Chart 4).

\section{Chart 4}

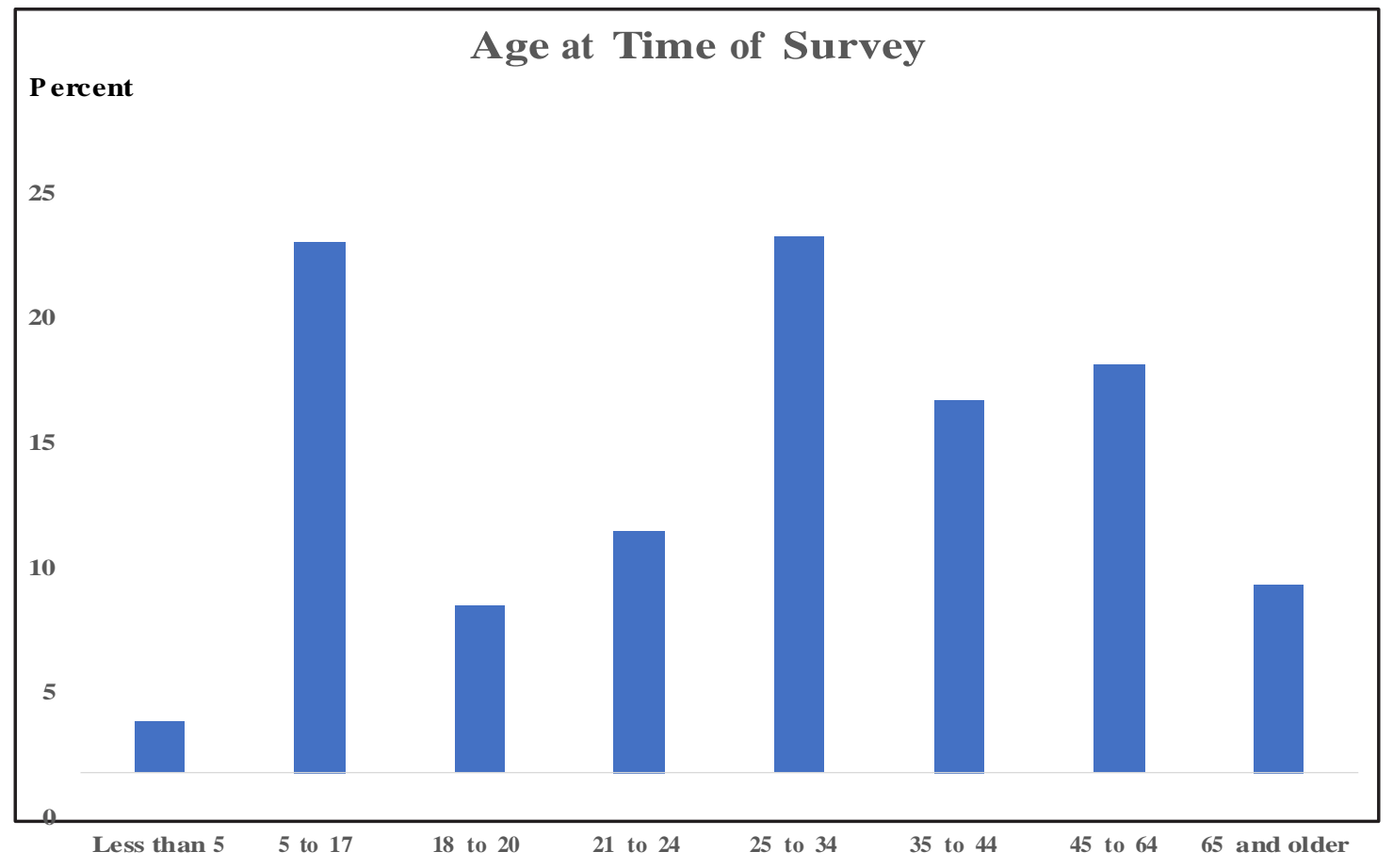

Source: CMS calculations based on 2013-2017 5 Year PUMS data 


\section{Chart 5}

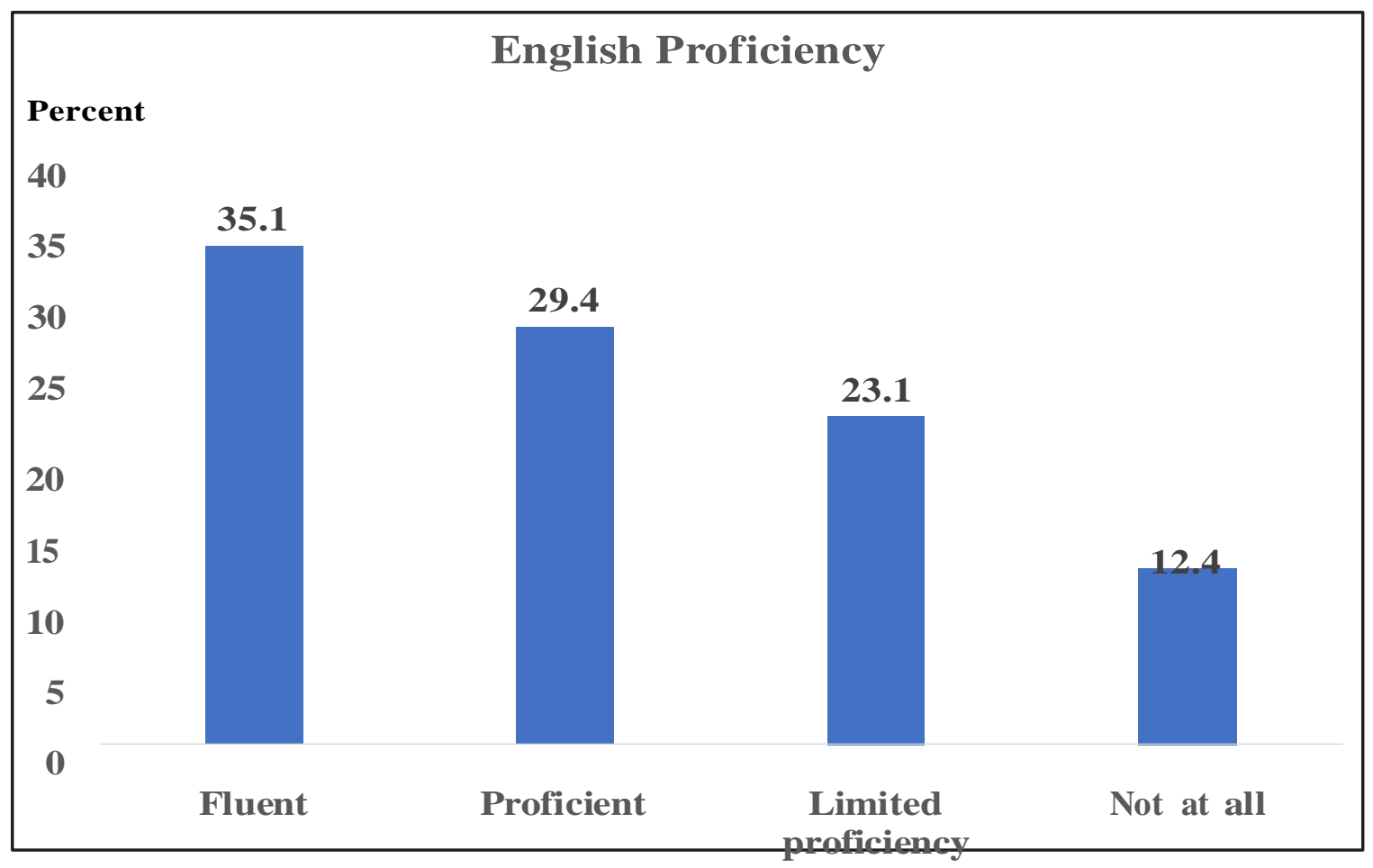

Source: CMS calculations based on 2013-2017 5 Year PUMS data

CMS's analysis suggests that most people who are potentially stateless or potentially at risk of statelessness are proficient in English. About 35.1 percent rated themselves as fluent and about 29.4 percent rated themselves as proficient. Many fluent and proficient English speakers in this population come from Nepal. Only 12.4 percent reported that they speak no English, including many from Bhutan and Myanmar.

Persons who are potentially stateless or potentially at-risk of statelessness possess a relatively low level of educational attainment. About 40.9 percent of those 18 years old or older possess less than a high school education and 25.7 percent possess a high school degree or its equivalent. For comparison, 12.7 percent of the remainder of the population 18 years old or older-all individuals who are neither potentially stateless nor potentially at risk of statelessnesspossesses less than a high school education and 27.8 percent possesses a high school degree or its equivalent. ${ }^{55}$ Only 14.7 percent possesses a bachelor's degree or higher, as compared to 28.3 percent of the remainder of the US population aged 18 or over. ${ }^{56}$

Yet many members of this population are enrolled in school. About 33.2 percent aged-3 and over are pursuing education, as compared to 26.4 percent of the population that is not potentially stateless or potentially at risk of statelessness. ${ }^{57}$

55 These differences are significant at the 99 percent level, as indicated by adjusted Wald tests carried out on weighted ACS data.

56 These differences are significant at the 99 percent level, as indicated by adjusted Wald tests carried out on weighted ACS data.

57 These differences are significant at the 99 percent level, as indicated by adjusted Wald tests carried out on weighted ACS data. 


\section{Chart 6}

\section{Educational Attainment}

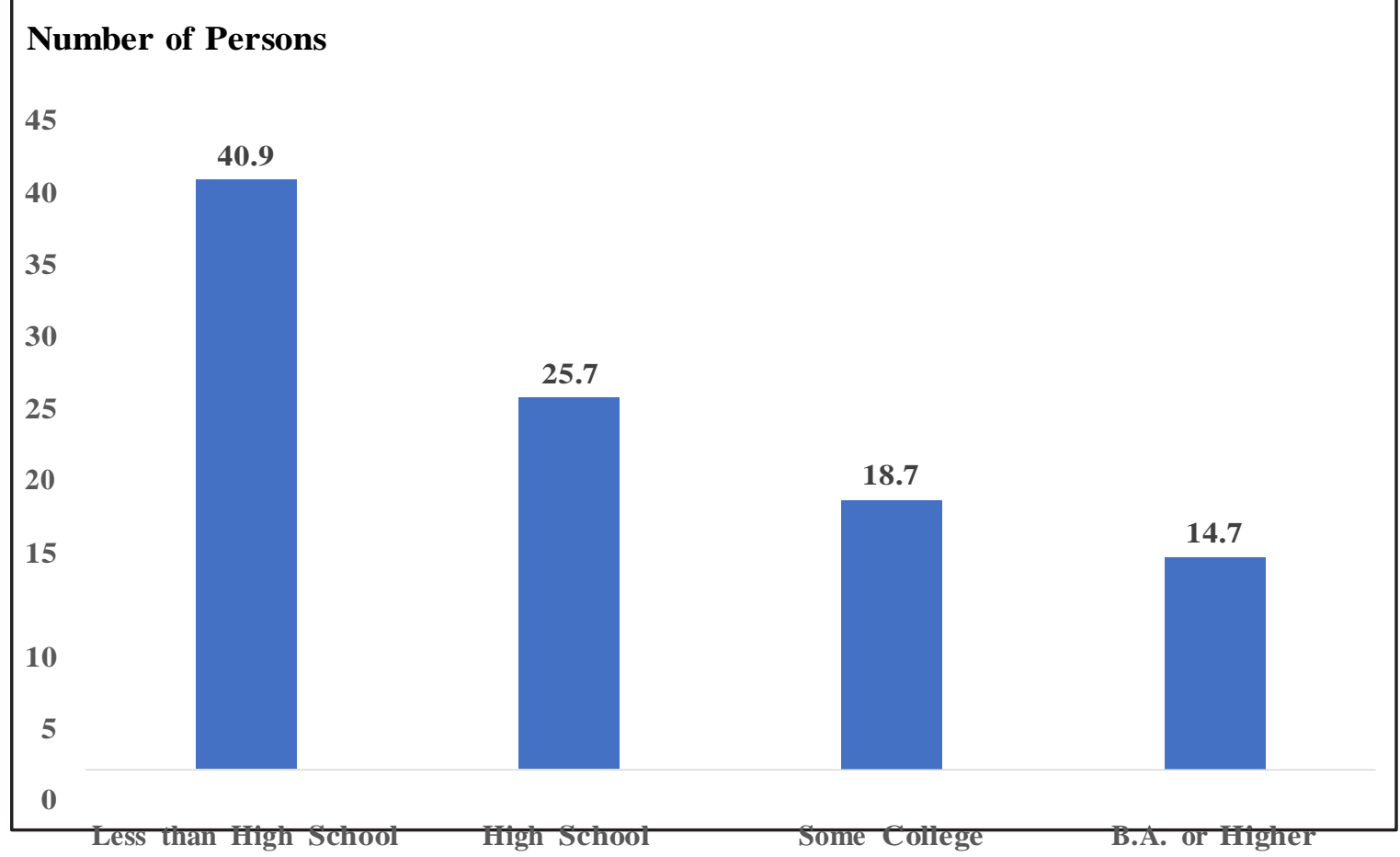

Source: CMS calculations based on 2013-2017 5 Year PUMS data

Given the immense barriers to socio-economic attainment of persons who are potentially stateless or potentially at risk of statelessness, it comes as little surprise that they participate in the labor force at relatively low rates and are more likely to be unemployed than the overall population. About 58.7 percent of the population that is potentially stateless or potentially at risk of statelessness, aged 16 or over, participates in the labor force, compared to 63.3 of those neither potentially stateless nor potentially at risk of statelessness, age 16 older. $^{58}$ Of those in the labor force, 90.6 percent are employed and 9.4 percent unemployed, compared to 6.5 percent among the remainder of the population over 16 years of age. ${ }^{59}$ Of those employed, 6.3 percent are self-employed, as compared to 10.4 percent of the remainder of the employed population over 16 years old. ${ }^{60}$

58 These differences are significant at the 99 percent level, as indicated by adjusted Wald tests carried out on weighted ACS data.

59 These differences are significant at the 99 percent level, as indicated by adjusted Wald tests carried out on weighted ACS data. These unemployment rates were calculated on the basis of 2013-2017 5-Year ACS data (US Census Bureau 2019b). This figure is not equivalent to the unemployment rate published by the Bureau of Labor Statistics. 60 These differences are significant at the 99 percent level, as indicated by adjusted Wald tests carried out on weighted ACS data. 
Given the immense barriers to socio-economic attainment of persons who are potentially stateless or potentially at risk of statelessness, it comes as little surprise that they participate in the labor force at relatively low rates and are more likely to be unemployed than the overall population.

Of those employed, many work in less-skilled occupations. The top 10 occupations of potentially stateless persons aged 16 or over are in Table 2 below.

Table 2: Top Occupations of Those Who Are Potentially Stateless or Potentially at Risk of Statelessness

\begin{tabular}{llr}
\hline Rank & Occupation & Number \\
\hline 1 & Cashiers & 5,066 \\
\hline 2 & Maids and housekeeping cleaners & 4,853 \\
\hline 4 & Janitors and building cleaners & 3,669 \\
\hline 5 & $\begin{array}{l}\text { Laborers and freight, stock, and material } \\
\text { movers, hand }\end{array}$ & 3,640 \\
\hline 6 & $\begin{array}{l}\text { Miscellaneous assemblers and } \\
\text { fabricators }\end{array}$ & 3,639 \\
\hline 7 & Packers and packagers, hand & 3,595 \\
\hline 8 & Cooks & 3,355 \\
\hline 9 & Personal care aides & 3,063 \\
\hline 10 & $\begin{array}{l}\text { Miscellaneous production workers, } \\
\text { including semiconductor processors }\end{array}$ & 2,666 \\
\hline Sourcers and other meat, poultry, and & 2,560 \\
\hline
\end{tabular}

Source: CMS calculations based on 2013-2017 5 Year PUMS data

Persons who are potentially stateless or potentially at risk of statelessness earn less than the US average. Over the 2013 to 2017 period, their average annual personal income was \$17,629, significantly lower than average annual personal income for the remainder of the population, $\$ 38,415$, during the same period. ${ }^{61}$ Such persons may face particular difficulties in adjusting to LPR status in the United States, given the recent release of a rule that significantly expands the standard for inadmissibility, including low income, based on likelihood of becoming a "public charge." About 80 percent of those who are potentially stateless and potentially at-risk reported having health insurance coverage.

Finally, 40,800 people or 20.6 percent of all US residents identified by CMS as potentially stateless

61 These differences are significant at the 99 percent level, as indicated by adjusted Wald tests carried out on weighted ACS data. 
and potentially at-risk of statelessness live in mortgaged homes. A further 7.9 percent lived in homes owned free and clear. While potentially stateless persons and those at risk of statelessness have established strong roots in the United States, their rates of homeownership remain below national averages.

\section{Potentially Omitted Groups}

CMS's provisional estimates do not represent a definitive count of US stateless persons or persons at risk of statelessness. An unknown number of persons in each profile possess the nationality of their country of origin or a third country. For this reason, these estimates may overestimate the numbers of stateless persons in the United States.

However, these estimates also omit groups of persons who are potentially stateless or at-risk or statelessness who do not appear in the ACS data and may not fit the profiles set forth above, which could contribute to undercount. In addition to stateless populations that cannot be found in the ACS, CMS's estimates may omit:

- Persons who were not registered in their country of birth and who lack citizenship in their country of origin, in a third country, and in the United States.

- Children who were born in refugee camps located in countries without birthright citizenship. Many of these persons are stateless since their countries of origins either will not recognize their citizenship or lack the capacity to do so.

- Persons who are stateless due to laws that prevent the transmission of citizenship from mothers to children, or due to divorce or birth out of wedlock. Such persons come from many countries and cannot be identified using the ACS.

- Individuals who have been de-nationalized by their countries of origin who have not yet obtained another nationality. This potentially includes those de-nationalized for political, religious, or ethnic reasons, as well as those deemed threats to national security.

- Persons who renounced or rejected their birth citizenship without acquiring citizenship in the United States or elsewhere. Members of some groups, such as Druze from the Golan Heights, voluntarily remain stateless as they perceive that acquiring nationality to which they are entitled constitutes the recognition and legitimation of their homeland's occupation.

- Children adopted illegally overseas and children born overseas to surrogate mothers with donor egg and sperm.

These estimates may also be biased if ACS respondents misrepresent their country of birth, ethnicity, language, or US citizenship. Some stateless persons may not answer questions on ethnicity or language truthfully out of fear of persecution, removal, or hope to become a US citizen. These same factors, however, may contribute to scrupulous accuracy in responding to these questions for fear of running afoul of the government.

Finally, the ACS may miss small stateless groups or those that speak languages for which translation is not available. Despite the ACS's large sample size, many US stateless groups likely number less than a few hundred individuals. The ACS may miss some of these small groups. Moreover, the ACS questionnaire is only available in English and Spanish, and interpretation and assistance are 
limited to roughly 30 other languages. It is possible that some stateless persons speak languages for which no assistance is available. Individuals with insufficient language skills may have difficulty completing the survey.

Without more reliable and detailed data, the scale and direction of biases in CMS's estimates cannot be determined.

\section{Refugee- and Immigration-Related Administrative Data on the Stateless}

The data from US refugee and immigration programs feeds into an extensive, interlocking set of federal databases and information systems (Meissner et al. 2013, 66-72). DHS has initiated an ambitious data integration project that seeks, in part, to ensure that immigration records can be linked across the various DHS data systems, and made accessible to DHS stakeholders. Stateless persons may come to the attention of federal officials that administer US refugee and immigration programs through applying for an immigration benefit, admission to the United States, refugee resettlement, requesting asylum, immigration enforcement, placement in removal proceedings, detention, and other ways. At each of these points of contact, non-citizens must provide their "nationality," which may be listed as "stateless," "unknown," or possibly "no nationality."

Ultimately, CMS researchers opted to build their provisional estimates around ACS data given its reach and detail, and because of the limitations of federal immigration and refugee data, starting with the fact that not all stateless persons come to the attention of immigration officials. After significant engagement with DHS on this study and their data needs, CMS formally requested from DHS detailed information on admissions of refugees, non-immigrants, and immigrants (LPRs), as well as anyone listed as stateless or of unknown nationality in the same datasets. CMS also requested detailed information on non-citizens-particularly those listed as stateless or of unknown nationality-who received removal orders, and either spent more than 90 days in detention following their order or who were released from custody.

As per the latter request, DHS is statutorily required to remove a non-citizen within 90 days following an administratively final order of removal. ${ }^{62}$ In Zadvydas v. Davis, ${ }^{63}$ the US Supreme Court found six months to be a presumptively reasonable time-period to effect removal. After six months, however, it held that the government bears the burden to demonstrate that the detainee is likely to be removed in the "reasonably foreseeable future." If it cannot meet this burden, it must release him or her. In Clark v Martinez, ${ }^{64}$ the Supreme Court extended this decision to inadmissible non-citizens; i.e., those encountered by immigration officials before they "enter" the nation as a matter of law. Following Zadvydas and Clark, the number of non-citizens, including stateless persons, detained for very long periods following receipt of a removal order, declined significantly (Kerwin, Alulema, and Tu 2015, 342).

That said, data on non-citizens who cannot be removed still remains a likely source of stateless persons. A study by the DHS Office of Inspector General (OIG) of all immigrant detainees on December 13, 2017, for example, found that 3,053 had not been removed within 90-days of their removal order (DHS-OIG 2019). This figure exceeded the numbers reported in earlier studies that examined all US immigrant detainees on particular nights in 2009 and 2012 (Kerwin and Lin 2009, 18; Kerwin, Alulema and Tu 2015, 3 43). Moreover, the OIG report attributed delays in 
removal to the failure to secure travel documents in 948 of the 3,053 cases, including in cases of statelessness in which citizenship could not be established (DHS-OIG 2019, 7).

To date, DHS/OIS has not responded to CMS's broad data request. However, CMS has secured refugee and immigration data from other sources.

\section{Worldwide Refugee Admissions Processing System (WRAPS)}

To complement its ACS estimates, CMS secured data from DOS's WRAPS database, which tracks refugees admitted for resettlement (RPC 2019), and contains records on country of birth, admission date, religion, ethnicity, age, education, and native language.

As above, CMS estimates individuals whose countries of birth, ethnic backgrounds, and years of arrival to the United States, or language proficiencies match its profiles of US residents who are potentially stateless or potentially at risk of statelessness. ${ }^{65}$ These estimates are in Table 3 below. To facilitate comparison with ACS data, CMS analyzed WRAPS data from calendar year 2002, the first year of its availability, through 2017.

Since WRAPS data does not indicate whether admitted refugees eventually naturalized, CMS used ACS data from 2017 to calculate estimated naturalization rates by country of birth (US Census Bureau 2018b). To ensure that these counts do not include persons who have naturalized, CMS multiplied WRAPS counts of refugees fitting each missing profile by the 2017 average naturalization rate of all US residents born in those refugees' birth countries. ${ }^{66}$

Table 3: WRAPS Estimates of Profiles of Those who are Potentially Stateless or Potentially at Risk of Statelessness

Profile Description Count

Ethnic Russians, 34

Belarussians, Ukrainians from

Estonia

Ethnic Russians, Belarussians, Poles from Latvia

South Caucasus

Armenians from Azerbaijan

Meskhetian Turks

\begin{tabular}{lr}
\hline Russia & 2,442 \\
\hline Uzbekistan & 37 \\
\hline
\end{tabular}

Roma, Ashkali, and Balkan Egyptians

65 WRAPS data is only available in aggregated form. It is not possible to filter the data by multiple categories (e.g., language and ancestry). Thus, CMS researchers used aggregated counts by ethnicity, when available, to produce estimates. When ancestry records were not available, CMS used aggregated counts by language. It is also not possible to filter WRAPS data based on year of birth (RPC 2019)

66 Data limitations did not permit the calculation of a naturalization rate for Mauritania or Estonia. For Mauritania, CMS researchers applied a global average naturalization rate for individuals born in Western Africa. For Estonia, CMS researchers applied a global average naturalization rate for individuals born in "Other Europe," a category including many small European countries. 


\begin{tabular}{lr}
\hline Roma, Yugoslavia & 4 \\
\hline Roma, Croatia & 157 \\
\hline Roma, Serbia & 1 \\
\hline Roma, Bosnia & 3 \\
\hline Roma, North Macedonia & 110 \\
\hline Born in Croatia, Serbian descent & 5,887 \\
\hline Feyli Kurds from Iraq. Note: Feyli Kurds born in & \\
\hline $\begin{array}{l}\text { Iran cannot be identified. They cannot be } \\
\text { distinguished from Iranian Kurds. This sum may }\end{array}$ & \\
include some non-Feyli Kurds from Iraq. &
\end{tabular}

Syrian Kurds

1,719

Palestinians

Israel and Palestine

Bidoon

Kuwait

Nepalese born after 1990, including Lhotshampas

born in Nepal

Ethnic

Nepalis (Lhotshampa) born in Bhutan

Rohingya

\begin{tabular}{lr}
\hline Other Minorities from Myanmar & 86 \\
\hline Ethnic Indians ${ }^{67}$ & 48 \\
\hline Ethnic Chinese & 35 \\
\hline Ethnic Nepali & 4,075 \\
\hline Hmong from Laos & 1 \\
\hline Hmong from Thailand & 4 \\
\hline Members of Thai Hill Tribes & 5 \\
\hline Thai-born Children of Burmese Refugees & 10 \\
\hline Tibetans & 11 \\
\hline Born in Tibet/China & 165 \\
\hline Ethnic Vietnamese and Khmer Krom from Cambodia & 6 \\
\hline Somalis from Kenya & 8 \\
\hline Black Mauritanians & 295 \\
\hline Ethiopians with Eritrean Ancestry & \\
\hline Eritreans with Ethiopian Ancestry & \\
\hline Sudanese-born individuals of Dinka and Nuer & (South Sudanese) descent, arrived in 2011 or later \\
\hline
\end{tabular}


62 distinguish between Mizos with recent origins in India and Mizos from Myanmar. 
Born in South Sudan, major South Sudanese

ethnic groups, arrived in 2011 or later

Banyarwanda

19,612

and Banyamulenge from the Democratic Republic

of Congo

TOTAL

117,370

Source: RPC (Refugee Processing Center). 2019. “Interactive Reporting.” http://ireports.wrapsnet.org/

WRAPS data does not permit the calculation of estimates for all groups for which CMS compiled ACS-based estimates. It only contains records of individuals admitted as refugees. Nor does it pick up many who are potentially stateless or potentially at risk of statelessness for reasons other than ethnic or religious persecution, like persons from the former Soviet Union and Yugoslavia who are stateless due to state succession. Furthermore, groups who are potentially stateless due to gender-discriminatory nationality laws, such as Nepalis born to non-Nepali fathers, or due to registration requirements, such as Bahamian Haitians, cannot be identified.

Moreover, WRAPS data is only available from 2002 through the present. Thus, tabulations based on WRAPS data may undercount the population of those who are potentially stateless or at risk of statelessness if some or all refugees from a given profile arrived before 2002.

Finally, many WRAPS ethnic categories are too broad to permit the calculation of estimates. In particular, WRAPS does not generally distinguish across "Arab" ethnic groups. Palestinians and Syrians are grouped together with all other Arab nationalities, making it impossible for CMS to tabulate estimates of stateless Palestinians and children born to Syrian refugees. Moreover, data from some countries and territories-including India, Malaysia, Côte d'Ivoire, Zimbabwe, and Madagascar, Brunei, the Western Sahara, and the Dominican Republic-is either missing entirely or insufficiently detailed to produce estimates.

CMS's analysis of WRAPS data reveals 117,370 refugees that fit the profiles set forth in Section II.

20,320 belong to profiles for which ACS estimates were zero or incalculable, including Roma from the Balkans (165), Black Mauritanians (165), Dinka and Nuer from the Republic of Sudan (295), South Sudanese (83), and Banyarwanda and Banyamulenge from the Democratic Republic of Congo $(19,612)$. Adding these 20,320 individuals from WRAPS to the total ACS estimate of those who are potentially stateless or potentially at risk of statelessness yields a combined total of about 218,000 persons.

\section{EOIR, USCIS and ICE}

CMS also secured federal refugee and immigration data-some of it publicly available and some provided by TRAC at Syracuse University-on populations listed as "stateless," "unknown" or "no" nationality who:

- Sought asylum "affirmatively" before USCIS;

- Sought asylum in removal proceedings;

- Were placed in removal proceedings between 2001 and 2018; and, 
- Were in immigrant detention in 2018 (TRAC 2019d).

This data covers only a fraction of the persons encountered by US immigration and refugee programs each year. The combined number of US asylum seekers, persons in removal proceedings, and immigrant detainees who are potentially stateless or potentially at risk of statelessness over a multi-year period represent only a small fraction of the 181 million non-immigrants admitted in FY 2017 (Navarro 2018). Researchers cannot make assumptions about the size of the overall US stateless population from these smaller samples. The report presents this data - which suggests a diverse and not insubstantial stateless population - for information purposes, not to contribute to the stateless estimates.

Thus, between 2001 and 2018, 1,985 persons in removal proceedings listed their nationality as "stateless" (meaning "unable to name a country" of nationality), 961 were listed of "unknown" nationality, and 84 of "no nationality" (TRAC 2019a). Stateless persons were also likely included among those listed as from the Soviet Union $(6,113)$, Yugoslavia $(3,595)$, and Palestine (682) during these years. Table 4 presents annual counts of deportation proceedings initiated in immigration courts by DHS between 2001 and 2018. Attachment $D$ shows the annual numbers of persons in deportation proceedings of the selected nationalities by outcome and custody status.

Table 4. Persons in deportation proceedings in immigration court

\begin{tabular}{|c|c|c|c|c|c|c|}
\hline $\begin{array}{c}\text { Fiscal } \\
\text { Year Case } \\
\text { Began }\end{array}$ & $\begin{array}{l}\text { Stateless- } \\
\text { Alien } \\
\text { Unable to } \\
\text { Name } \\
\text { Country }\end{array}$ & Unknown & $\begin{array}{c}\text { No } \\
\text { Nationality }\end{array}$ & $\begin{array}{l}\text { Soviet } \\
\text { Union }\end{array}$ & Yugoslavia & Palestine \\
\hline
\end{tabular}

\begin{tabular}{rrrrrrr}
\hline 2001 & 70 & 22 & 8 & 7 & 672 & 29 \\
\hline 2002 & 132 & 22 & 14 & 13 & 517 & 38 \\
\hline 2003 & 164 & 18 & 15 & 250 & 401 & 39 \\
\hline 2004 & 160 & 13 & 12 & 545 & 360 & 22 \\
\hline 2005 & 162 & 17 & 17 & 511 & 224 & 34 \\
\hline 2006 & 109 & 27 & 6 & 352 & 162 & 40 \\
\hline 2007 & 154 & 58 & 7 & 389 & 253 & 55 \\
\hline 2008 & 217 & 92 & 1 & 242 & 208 & 61 \\
\hline 2009 & 205 & 93 & 0 & 344 & 177 & 59 \\
\hline 2010 & 127 & 51 & 0 & 421 & 127 & 26 \\
\hline 2011 & 101 & 51 & 0 & 416 & 108 & 38 \\
\hline 2012 & 65 & 76 & 1 & 356 & 72 & 24 \\
\hline 2013 & 43 & 85 & 0 & 331 & 68 & 28 \\
\hline 2014 & 38 & 76 & 0 & 219 & 63 & 30 \\
\hline 2015 & 45 & 51 & 0 & 202 & 40 & 23 \\
\hline
\end{tabular}




\begin{tabular}{rrrrrrr}
\hline 2016 & 39 & 42 & 0 & 231 & 30 & 34 \\
\hline 2017 & 47 & 56 & 0 & 426 & 48 & 36 \\
\hline 2018 & 107 & 111 & 3 & 858 & 65 & 66 \\
\hline Total & 1985 & 961 & 84 & 6113 & 3595 & 682 \\
$2001-2018$ & & & & & & \\
\hline
\end{tabular}

Source: Data accessed through the data tool based upon analyses by TRAC at Syracuse University of court records obtained from EOIR using the Freedom of Information Act. Retrieved on March 25, 2019.

In addition, between 2001 and 2018, 1,285 persons who were listed as "stateless," 102 of "unknown" nationality, and 11 persons of "no" nationality received a decision on their asylum claims in immigration court (TRAC 2019b). ${ }^{68}$ Stateless persons were also likely included among individuals listed as from the former Soviet Union $(3,100)$, Palestine (114), and Yugoslavia $(3,115)$. These figures include asylum seekers whose claims were originally denied before USCIS and who made their claims in removal proceedings. They do not include asylum seekers whose affirmative claims were approved by USCIS during these years. Nor do they include asylum seekers with cases pending before the USCIS Asylum Division (320,000 as of March 2018) (USCIS Ombudsman 2018, 36), or among the 1.1 pending immigration court cases (TRAC 2019c). Table 5 sets forth annual totals of asylum decisions by EOIR immigration judges between 2001 and 2018. Attachment E shows annual numbers of asylum decisions in immigration court by select listings of nationality; i.e., "unable to name a country," "unknown" nationality, no nationality, Soviet Union, Yugoslavia, and Palestine.

Table 5. Asylum Decision for Stateless Persons and Likely Stateless Persons

\begin{tabular}{|c|c|c|c|c|c|c|}
\hline $\begin{array}{c}\text { Fiscal Year } \\
\text { of } \\
\text { Decision }\end{array}$ & $\begin{array}{l}\text { Stateless- } \\
\text { Alien } \\
\text { Unable to } \\
\text { Name } \\
\text { Country }\end{array}$ & Unknown & $\begin{array}{c}\text { No } \\
\text { Nationality }\end{array}$ & $\begin{array}{l}\text { Soviet } \\
\text { Union }\end{array}$ & Yugoslavia & Palestine \\
\hline
\end{tabular}

\begin{tabular}{rrrrrrr}
\hline 2001 & 29 & 3 & 0 & 6 & 355 & 5 \\
\hline 2002 & 50 & 12 & 1 & 5 & 436 & 7 \\
\hline 2003 & 55 & 20 & 3 & 27 & 464 & 5 \\
\hline 2004 & 97 & 10 & 0 & 137 & 381 & 10 \\
\hline 2005 & 99 & 15 & 1 & 260 & 341 & 5 \\
\hline 2006 & 110 & 2 & 0 & 251 & 236 & 7 \\
\hline 2007 & 113 & 2 & 0 & 244 & 181 & 11 \\
\hline 2008 & 93 & 5 & 2 & 213 & 154 & 6 \\
\hline 2009 & 94 & 7 & 0 & 169 & 124 & 10 \\
\hline 2010 & 101 & 3 & 0 & 187 & 97 & 5 \\
\hline 2011 & 139 & 7 & 0 & 252 & 84 & 4 \\
\hline 2012 & 108 & 2 & 1 & 296 & 69 & 14 \\
\hline
\end{tabular}

68 The US immigration courts granted asylum to "stateless" persons in 922 of 1,285 cases during this period, and granted "other relief" in an additional 17 cases. 


\begin{tabular}{rrrrrrr}
\hline 2013 & 59 & 5 & 2 & 269 & 58 & 5 \\
\hline 2014 & 49 & 4 & 0 & 183 & 40 & 2 \\
\hline 2015 & 39 & 0 & 0 & 185 & 16 & 2 \\
\hline 2016 & 22 & 1 & 0 & 147 & 18 & 3 \\
\hline 2017 & 15 & 3 & 1 & 136 & 35 & 5 \\
\hline 2018 & 13 & 1 & 0 & 133 & 26 & 8 \\
\hline Total & $\mathbf{1 2 8 5}$ & $\mathbf{1 0 2}$ & $\mathbf{1 1}$ & $\mathbf{3 1 0 0}$ & $\mathbf{3 1 1 5}$ & $\mathbf{1 1 4}$ \\
\hline
\end{tabular}

Source: Data accessed through the data tool based upon analyses by TRAC at Syracuse University of court records obtained from EOIR using the Freedom of Information Act. Retrieved on March 25, 2019.

Between 2011 and 2016, USCIS received 818 affirmative asylum cases involving stateless persons (USCIS, 2011, 2012, 2013, 2014, 2015, 2016). In addition, 127 cases with Yugoslavian nationality, applied affirmatively for asylum. Attachment $F$ provides annual figures of affirmative asylum applications filed and cases completed from 2011 to 2016 for these two groups.

Table 6. Affirmative Asylum Cases received by USCIS, 2011-2016

\begin{tabular}{lll}
\hline Calendar Year & Stateless & Yugoslavia \\
\hline 2011 & 95 & 22 \\
\hline 2012 & 68 & 27 \\
\hline 2013 & 86 & 28 \\
\hline 2014 & 107 & 21 \\
\hline 2015 & 202 & 21 \\
\hline 2016 & 260 & 8 \\
\hline Total 2011-2016 & $\mathbf{8 1 8}$ & 127 \\
\hline
\end{tabular}

Source: USCIS (2011, 2012, 2013, 2014, 2015, 2016).

On June 30, 2018, ICE had in its custody 21 detainees with unknown nationality, six from the former Soviet Union, and two from Yugoslavia (TRAC, 2019d). On September 30, 2012, ICE had in custody 15 detainees of unknown nationality, 15 from the former Soviet Union, and 13 from Yugoslavia (ICE 2012).

\section{Lessons from UNHCR Mapping Statelessness Studies for Other Countries}

With the support of UNHCR, a number of countries have attempted to map statelessness within their borders. UNHCR-sponsored mapping projects have been carried out in Austria (UNHCR 2017a), Belgium (UNHCR 2012), Estonia (UNHCR 2016), Finland (UNHCR 2014a), Iceland (UNHCR 2014b), Lithuania (UNHCR 2016a), Malta (UNHCR 2014c), Norway (UNHCR 2015b), Sweden (UNHCR 2016b), the Netherlands (UNHCR 2011a), and the United Kingdom (UNHCR and Asylum Aid 2011). With the possible exception of the UK, these nations lack the diversity of the US foreign-born population. All of them also have far smaller foreign-born populations than the 
United States. These studies relied on both the analysis of administrative data collected from national immigration agencies and on interviews with stateless individuals.

Administrative data sources include central population registries, population censuses, vital records, migration-related databases, information on refugees and asylum seekers, and data related to enforcement of immigration laws. Table 7 details the sources used by country. As is apparent from the table, the vast majority of projects draw at least in part on central population registries (UNHCR, 2011a, 2012, 2014a, 2014b, 2015, 2016a, 2016b, 2017a), a source not available or likely to be available in the United States. Moreover, most of these studies did not make estimates of national stateless populations or (if they did) their estimates did not include unauthorized stateless populations.

Table 7. Data sources examined to obtain estimates of stateless populations

\begin{tabular}{|c|c|c|c|c|c|c|c|c|}
\hline Country & $\begin{array}{l}\text { Central } \\
\text { population } \\
\text { registry** }\end{array}$ & $\begin{array}{l}\text { Population } \\
\text { census }\end{array}$ & Vital records & $\begin{array}{l}\text { Central } \\
\text { migration-related } \\
\text { database }\end{array}$ & $\begin{array}{l}\text { Refugee \& Asylum } \\
\text { seeker }\end{array}$ & $\begin{array}{l}\text { Immigration } \\
\text { enforcement (inc. } \\
\text { detention) }\end{array}$ & $\begin{array}{l}\text { Foreigners with or } \\
\text { applying for legal } \\
\text { residence }\end{array}$ & Naturalizations \\
\hline Australia* & & & & & $\mathrm{x}$ & $x$ & $x$ & \\
\hline Austria & $\mathrm{x}$ & & $\mathrm{x}$ & & $\mathrm{x}$ & & $\mathrm{x}$ & $\mathrm{x}$ \\
\hline Belgium & $\mathrm{x}$ & & & & $\mathrm{x}$ & & & \\
\hline Estonia & $\mathrm{x}$ & $\mathrm{x}$ & & & & $\mathrm{x}$ & & \\
\hline Finland & $\mathrm{x}$ & & & & & & $\mathrm{x}$ & \\
\hline Iceland & $\mathrm{x}$ & & & & $x$ & & $\mathrm{x}$ & \\
\hline Japan* & & & & $x$ & & & & \\
\hline Lithuania & $\mathrm{x}$ & $\mathrm{x}$ & & $\mathrm{x}$ & $\mathrm{x}$ & & & \\
\hline Malta & & $x$ & & & $x$ & & & $x$ \\
\hline Norway & $x$ & & & $x$ & & & & \\
\hline Sweden & $\mathrm{x}$ & & & $\mathrm{x}$ & $\mathrm{x}$ & & & \\
\hline $\begin{array}{l}\text { The } \\
\text { Netherlands }\end{array}$ & $\mathrm{x}$ & & & & $\mathrm{x}$ & & $\mathrm{x}$ & \\
\hline $\begin{array}{l}\text { The United } \\
\text { Kingdom }\end{array}$ & & $\mathrm{x}$ & & $\mathrm{x}$ & $x$ & $\mathrm{x}$ & & \\
\hline
\end{tabular}

* Not a UNHCR "Mapping Statelessness" report

** May include information from other columns

Sources: Abe (2010), UNHCR (2011a, 2012, 2014a, b, c, 2015b, 2016b,c, 2017a), UNHCR and Asylum Aid (2011), and Foster, McAdam, and Wadley (2017).

Reports from these projects suggest three key difficulties with administrative data. First, administrative data often records the nationality of individuals as "unknown." In some cases, individuals with "unknown" nationalities may be stateless, but it is not known how often this is the case. As a consequence, estimates of stateless persons based on registry data may not be accurate. Moreover, in many countries such as Belgium and The Netherlands, registration is carried out at the municipal level, and the determination of statelessness often varies across municipalities (UNHCR 2011a, 2012). Second, official records such as registries do not generally include migrants without lawful status. Often, registries are restricted to legal residents. Third, stateless persons may seek to avoid official detection because of their precarious situation, which may lead to undercount.

Six countries also interviewed stateless individuals in order to gain qualitative understanding of their experiences (Austria: UNHCR 2017a; Belgium: UNHCR 2012; Estonia: UNHCR 2016, Lithuania: UNHCR 2016a; Malta: UNHCR 2014c; Netherlands: UNHCR 2011a; United Kingdom: 
UNHCR and Asylum Aid 2011). Researchers identified and recruited participants with the help of stakeholders, including NGOs and UNHCR. The UK project team compiled a database of over 400 gatekeepers who could potentially refer participants to the study (UNHCR and Asylum Aid 2011). Three research teams also incorporated information from interview participants' immigration files in order to verify details of their immigration stories and gain insight into stateless persons' contacts with immigration authorities (Austria: UNHCR 2017a; Belgium: UNHCR 2012; United Kingdom: UNHCR and Asylum Aid 2011). In three countries where stateless individuals were not interviewed, researchers sent a survey to stakeholders who they thought were likely to encounter stateless persons in order to understand their situation (Iceland: UNHCR 2014b; Norway: UNHCR 2015b; Sweden: UNHCR 2016b).

\section{Section IV: Challenges Confronting US Stateless Persons}

This section will highlight key problems faced by stateless persons in the United States and their families. Many of these challenges do not apply exclusively to stateless persons. Undocumented persons, for example, experience the same obstacles to work and the same threat of arrest, detention, and deportation that all unauthorized persons do. The deleterious impact of these threats on affected individuals, families and communities has been well documented (Coon 2017; Boehm 2017; Kerwin 2018).

Unlike nationals, stateless persons cannot receive support or protection from an embassy or consulate. Nor can they return to their country of previous habitual residence. Stateless persons also have difficulties obtaining identification documents. Lack of an ID card can make even the most basic interactions difficult to negotiate.

However, undocumented stateless persons face additional hurdles due to their statelessness. The lack of a legal framework for them forces most "to remain in ... perpetual legal limbo, unable to leave the United States, but also unable to escape the stigma of living under a removal order and needing to justify their presence to ICE detention and removal authorities in regular intervals" (Baluarte 2015, 365). In addition, unlike nationals, stateless persons cannot receive support or protection from an embassy or consulate. Nor can they return to their country of previous habitual residence. Stateless persons also have difficulties obtaining identification documents. Lack of an ID card can make even the most basic interactions difficult to negotiate.

CMS's interviews with 48 stateless persons offered a first-hand view of the challenges facing stateless persons. Given the small sample size, the findings from these interviews should not be taken as representative of the entire stateless population. However, they provide powerful insights into the lived experiences of 48 stateless persons in the United States. CMS interviewed individuals born in 14 countries, including from many groups described in the profiles, such as Rohingya from Myanmar, stateless ethnic Nepalese from Bhutan, citizens of the former Soviet Union, and stateless Romani from France and The Netherlands. ${ }^{69}$ The interviewees included 14

69 The 14 countries were Estonia, Eritrea, Georgia, Myanmar, the USSR, France, The Netherlands, Nepal, The Democratic Republic of Congo, Bhutan, Uzbekistan, Turkey, Kuwait, and Ethiopia. 
women and 34 men. These individuals had become stateless for a variety of reasons, including:

- Discriminatory nationality policies in countries such as the DRC, Myanmar, and Bhutan;

- State succession in the case of individuals from former Soviet countries, Ethiopia, and Eritrea.

Some had lost their nationality, while others, including many Romani and Rohingya, had been born stateless. They included a mix of undocumented persons, LPRs, asylees, and refugees, most of whom had become LPRs.

Most of the undocumented stateless persons arrived legally in the United States. Some came as children, particularly people from the former Soviet Union and the Romani from Europe. Many sought, but did not receive asylum. Some lacked identification documents from their home countries. Some received orders of removal, but could not be deported. Instead, they experienced long periods of detention. Several had been released under orders of supervision, and others were in the process of re-applying for asylum.

Table 8. Interviewees' countries of birth

\begin{tabular}{ll}
\hline Country of Birth & Number of Interviewees \\
\hline Bhutan & 8 \\
\hline Myanmar & 24 \\
\hline Democratic Republic of Congo & 2 \\
\hline Eritrea & 1 \\
\hline Ethiopia & 1 \\
\hline France & 1 \\
\hline Kuwait & 1 \\
\hline Nepal & 1 \\
\hline Netherlands & 1 \\
\hline Turkey & 1 \\
\hline USSR / Russia & \\
\hline Estonia & 2 \\
\hline Georgia & 1 \\
\hline Russia & 2 \\
\hline Uzbekistan & 2 \\
\hline Total & $\mathbf{4 8}$ \\
\hline
\end{tabular}

\section{Ties to the United States}

The interviews revealed an embedded population that had established deep roots, but faced extraordinary disadvantages in US society. Most considered the United States home. They reported having US citizen children and (even) grandchildren. Several owned their own businesses and homes. Many had attended school in the United States, and were active members of their communities. 
One interviewee stated:

I found this place and let [my friends] know. They overnighted the money. I started the business with $\$ 16,000$. Two years later, I bought the building and then I bought a liquor license. It was a little café and now it has become twice, maybe even three times, bigger restaurant than it ever was, with the nicest garden and nice outside seating. We were expanding it, and ICE picked me up right in the middle of the construction and put me in jail for ten months. Thanks to the community, they took it over and they continued, and they kept it alive.

Many hope to give back to their communities and to the United States. One interviewee mentioned he participated in a recovery mission with medical doctors and nurses who went to the US Virgin Islands after Hurricane Maria and Irma. Another said that he hopes to serve in the military. He works as a teacher and volunteers at police stations, immigration courts, and elsewhere to translate for members of his community.

Even among those new to the United States, many expressed a deep gratitude to the US government for allowing them to stay. As a Rohingya man who arrived in the United States in 2015 put it: "The US government respects us as Rohingya... Even though we don't have US citizenship, we're not afraid to live here." Interviewees expressed enthusiasm about eventually naturalizing and contributing to US society.

\section{Challenges Facing Stateless Persons without Lawful Status}

The interviews revealed that stateless persons-particularly those without status-face a variety of challenges in the United States, including limited employment prospects, barriers to international and even domestic travel, difficulties obtaining drivers' licenses and opening bank accounts, psychological stress and a sense of stigma.

\section{Insecurity}

Many stateless persons, particularly those who have applied for asylum, endure often-crippling insecurity. They live in limbo without knowing whether they will be permitted to stay or will face deportation to their countries of origin. ${ }^{70}$ For many, the prospect of permanent separation from their family is terrifying. Others fear that, if they are deported, they will face persecution or imprisonment.

This insecurity is intensified by legal proceedings that can drag on for years. One woman from the former Soviet Union noted that her case lasted about five years. If not granted asylum, stateless people are often detained for months while the government attempts to deport them. If deportation cannot be accomplished, they are released under "orders of supervision." In such cases, they must keep trying to secure travel documents while the government tries to find a country to accept them. Many interviewees said they were "living in limbo" and did not know if they would ultimately be able to settle in the United States.

One participant grew tired of living as a stateless person and voluntarily turned himself in to the authorities. A man from the former Soviet Union noted, "Living all this time without a paper,

70 This fear is not groundless. ICE data indicate that "stateless" persons and likely stateless persons are, in fact, removed each year. 
without anything, it's very hard. You can't do practically anything."

\section{Travel Restrictions}

Undocumented stateless persons are restricted from international travel, and those under orders of supervision cannot travel outside of their US state of residence or region. These travel restrictions curtail their ability to visit family members abroad and domestically. One woman born in the Soviet Union had been separated from her son, who resides in Russia, for more than 26 years. She cannot travel to Russia, and her son cannot secure a visa to the United States. Without legal permanent residency, she cannot sponsor her son for a visa. Moreover, she cannot leave her US state for more than three days at a time, which limits her ability to visit family and friends. When she could not travel abroad to visit her dying father, a woman born in Uzbekistan tried to travel back to the country where she had previously lived.

Travel restrictions can also negatively impact stateless persons' careers. One stateless Eritrean reported that his wife, who is stateless and on a student visa, cannot travel to conferences due to her status. He emphasized that the inability to travel internationally had hurt their career prospects.

\section{Employment Consequences}

Undocumented stateless interviewees worked as caterers, construction workers, gas station attendants, house cleaners and freelance artists. Respondents with work authorization reported working as customer representatives, restaurant owners, nurse assistants, teachers, registered nurses, mental health workers, dental technicians, laundromat workers, and factory workers.

"Most of the companies won't take you," said one stateless man from Russia who lacked US immigration status. "They want somebody [with documents]." Several reported earning low wages, sometimes barely enough to survive. The same man noted "The quality of living: it was very low. I was making practically just enough to survive. Sometimes not even that." A man of mixed Eritrean/Ethiopian descent noted that his low salary makes it difficult for him to pay his legal fees.

Some stateless persons, namely those under orders of supervision, receive employment authorization, which they must renew annually. Many have reported difficulties caused by delays in issuing work re-authorization. Lapses in work authorization make it difficult for stateless persons to advance in the workplace or even retain their positions.

\section{Economic Hardships}

Due to their lack of identity documents, many stateless persons cannot obtain loans, credit cards, investment accounts or basic bank accounts. In addition, some stated they could not plan financially for their future. "Investment groups deny you retirement accounts," one person noted. "Last year I had to go to three different investment groups that I had a retirement account and my daughter's school account with. They take it in. Then three months later they are like, 'either we are going to sell all your things or you remove your account.'" Statelessness also stifles entrepreneurship as some stateless struggle to complete the necessary forms and paperwork to start and maintain a business, further limiting their ability to support themselves. 


\section{ICE Order of Supervision Requirements}

Stateless persons released from immigration detention on ICE orders of supervision must endure check-in requirements into perpetuity, electronic ankle monitors, and restrictions on domestic travel. The frequency of check-ins - which range from once every few months to once a yearcan pose a substantial burden. ICE offices are often located in other cities, requiring stateless persons to take time off from work and to find transportation. Repeat absences due to checkins can threaten employment and upward mobility. Furthermore, paying for transportation can create financial strain. One respondent said:

It was so upset me because why do they have to go after an old man like myself who has no criminal history or anything, right? Plus, Orlando is round-trip, 150 miles from where I live. I have just had a heart attack and lots of health issues. Just because the problem is that you are stateless. What I realized during those years is that you have no rights at all. With the stateless, the clerks have the discretion to decide your destiny right on the spot.

Persons under orders of supervision reported facing more difficult conditions over the past year, including more frequent visits, ankle bracelets, and a harsher disposition among immigration officials. One reported:

I'm taking my dad with me to go [to the] downtown office, because I'm scared to go there by myself because I don't know what happens. I can't even reason with the officers. I can't get on the same level of understanding with him, because then he starts to get angry. Every time you try to make them understand something, they get angry, so sometimes I just agree to things that I shouldn't agree because I'm afraid. When somebody got power over you, you can't talk to them like that, because no matter what, they're going to be right.

Another said:

I used to go every three months and then they pushed it to six months because I kept telling them I was in high school. In 2012, one of the officers was really nasty to me. He said that if I don't come back with papers, he's going to take me in and he's going to make me do the 90 days again. That's when my older brother said we should try to reach the UN and see if they could help us.

Another added:

I checked in the last eight years once a year. But in the previous check-in - that was in August - the USCIS guy put me for three months, and I asked him "why three months? I mean, I've been here for 25 years already in the USA." He was sarcastic: "if you don't like three months, I can put once a month for you.

\section{Effects on Personal and Work Relationships}

Statelessness also strains relationships. One respondent, an ethnic Eritrean from Ethiopia, noted that his statelessness "cost me a lot even in my relationship." He reported that his partner suspected him of wanting to marry for citizenship and benefits. He also noted that it is hard to develop social relationships. He feels like he has to keep up appearances and "live a lie" because he is afraid people will not understand his statelessness and its implications. 
Stateless persons noted that their status provokes suspicion and fear among their acquaintances and co-workers. This exacerbates feelings of marginalization, leading some to report feeling "hopeless and empty." One woman reported that she is "afraid to talk to people" and "feels like an outcast." "I was scared to speak openly," one stated. "It took me [a] long time even my friends. Our family friends didn't know that I'm stateless."

As a result, some interviewees felt compelled to live double lives, causing them significant psychological stress. One said:

It's not just about not being able to travel. It's not being able to live normal life. I can't tell anybody, I have to live a double life. I have to think about every word I say, who I say it to and what I say, and remember what I said before so they will not think that I'm some kind of liar.

Many also reported feelings of isolation. One noted the difficulty of "not being able to tell my story, not being able to share with people. Even my closest friends, what it is that I'm going through for fear of somehow the word getting out and the vulnerability that goes hand in hand with being undocumented."

\section{Interaction with Authorities}

Some of the persons interviewed mentioned being nervous about being stopped by a police officer. This fear is not unfounded. Between 2006 and 2018, ICE issued detainers - asking local police or sheriffs to hold persons - in the cases of 94 persons listed as stateless (TRAC, 2019e). One man reported that seeing police cars causes him stress. Interviewees emphasized that they did not commit any crimes and that their statelessness was not something that they could control.

In several cases, stateless persons reported encountering highly confrontational immigration officers. A few spoke of officers forcing them to call embassies and consulates to request a travel document. "The officers made one of my older brothers call the embassy right in front of them and tell them that he needs a passport," said one woman. "My brother said to them, 'I can't lie to them, I'm going to tell them I am a Bidoon and I'm requesting a passport. My mom is a Kuwaiti citizen but my dad is considered Bidoon. It was on speaker and the embassy clerk's voice changed. She was so nasty to my brother, and she said 'we're not going to give you passport."'

In addition, some respondents mentioned being concerned during basic interactions with government authorities due to their lack of identification. Some spoke about their inability to enter federal buildings or to pick up their children from school without identification.

\section{Disenfranchisement}

Some lamented their inability to participate fully in their communities. One said, "I cannot vote. I've been here for a long time, but I don't have the right to vote." Another stated, "I am one of the highest tax payers (in the town), but I cannot vote. When it comes to the part of the decision making I'm totally being pushed out. Every time when the township supervisor or an election comes up, I just have to stay behind and do what I can and not be able to directly have a say in it."

\section{Psychological Stress}

As a result of these factors, interviewees reported that their statelessness imposes a heavy 
psychological toll. Many reported feelings of depression, anxiety, and hopelessness. In particular, interviewees felt burdened by uncertainty about their future in the United States. A Romani woman stated that her son, who was born stateless, asks: "W hy should we go on living?"

Some felt powerless with respect to their situation. One noted, "Lawyers tell me that they can't do anything for me because my case is pretty much closed. The verdict is there and there is no way for you to turn around the verdict. Now I'm stuck like this for the rest of my life. If I can't go anywhere, the taxes I'm paying will not ... provide me benefits, or social security, or pension, or anything. I mean what am I here for? I was brought as a child."

Some stateless persons must face these challenges while coping with trauma and scars resulting from persecution or violence in their home countries. In these circumstances, the prospect of eventual deportation exacerbates feelings of anxiety and despair.

\section{Challenges Facing Refugees and Lawful Permanent Residents}

Stateless refugees who have obtained permanent residency face fewer challenges than undocumented stateless persons. Unlike the undocumented, stateless refugees can lawfully work, travel, access government benefits, and sponsor family members for green cards. Nonetheless, these stateless refugees face their own unique challenges during their journey from refugees to citizens.

\section{Barriers to Adjustment of Status or Naturalization}

That said, there is no guarantee that stateless refugees will be able to secure US citizenship. Many have very limited education. Some are illiterate in their native languages. As a result, many interviewees - particularly Rohingya from Myanmar - expressed fear that they would never be able to pass the citizenship test and thus would remain stateless forever. One Rohingya man stated, "I don't have the belief that I can get US citizenship because I don't have enough education." "I don't know how to read or write," said another. "For me to be able to learn English and to pass tests, it's a challenge. Even if I go to ESL class, it's still hard for me. I cannot understand what the teacher says. My husband can't even go to English class. He was just a farmer person taking care of sheep and cow so he doesn't know about school or English. My husband and I don't have any hope to pass the test."

\section{Travel Restrictions}

Although resettled refugees have access to US government-issued refugee travel documents, they nonetheless face challenges in travelling abroad despite having legal status in the United States. One man of Eritrean descent noted that he and his wife had been detained and questioned at airports by officials unfamiliar with refugee travel documents. He also noted that it can be difficult to secure visas to travel internationally without a nationality, as some countries do not recognize the refugee travel document as a valid form of travel document. In addition, refugees who have not acquired citizenship lack consular protection if they travel abroad. 


\section{Section V: Recommendations}

Based on its research, CMS has identified a series of recommendations aimed at gaining a fuller understanding of the scope of this problem, addressing the challenges facing stateless persons, and dramatically reducing statelessness in the United States. These recommendations are made to a range of government, international, and non-governmental actors.

\section{United Nations Agencies}

- UNHCR should redouble its efforts to increase the number of signatories to the 1954 and 1961 Conventions, to support states in implementing these Conventions, to prevent and reduce statelessness, and to safeguard the rights of stateless persons.

- UNHCR should establish regional advisory groups of states and civil society actors devoted to eliminating discrimination in nationality laws, closing gaps in nationality laws due to state succession, and responding to the conditions that create a risk of statelessness.

- UNICEF and other relevant UN agencies should expand their efforts to ensure universal birth registration and birthright citizenship.

- The United Nations Population Division, UNHCR, and other relevant UN agencies should work to harmonize procedures for collecting data on statelessness and produce annual reports on the global stateless population.

\section{The US Congress, the Administration, and State and Local Governments}

- The United States should become a party to the 1954 and 1961 Conventions, and should harmonize its laws and policies with them (Baluarte 2015, 355, 389).

- Congress should pass and the president should sign into law legislation that officially defines a stateless person and provides a designated path to lawful status and US citizenship for qualifying stateless persons. ${ }^{71}$

- Congress should also pass and the president should sign into law legislation that protects stateless persons from arbitrary deprivations of liberty, including repeat and prolonged detention and onerous conditions of supervision, unless they represent a national security or public safety threat.

- All federal agencies that may encounter stateless persons should adopt standardized training, guidelines and procedures on how to detect and screen for statelessness, based on UNHCR's Handbook on Protection of Stateless People and other guidance. Screening should preferably occur at the government's first point of contact with persons who are potentially stateless or potentially at risk of statelessness.

- DHS should eliminate domestic travel restrictions for stateless persons, and allow them to move and settle where they want in United States.

71 In recent years, two prominent pieces of legislation - the Senate-passed "Border Security, Economic Opportunity, and Immigration Modernization Act of 2013" and the "Refugee Protection Act of 2016" - would have offered "conditional" status, work authorization, travel documents, and a path to permanent residence to de jure stateless persons meeting certain conditions (Magner 2016). 
- DHS and DOS should offer documentation that allows stateless persons who have not naturalized to return to the United States after international travel.

- DHS should detain stateless persons only as a last resort (UNHCR 2014g, 113).

- DHS and EOIR should ensure the timely release of stateless persons from immigrant detention.

- DHS should not make stateless persons an enforcement priority and should reduce the number of check-ins by stateless persons to one per year.

- The US Department of Justice (DOJ) should provide training to immigration judges and clerks on the determination of statelessness and its legal implications.

- DOS should continue to promote awareness and the reduction of statelessness worldwide, and should continue to advocate for the rights of stateless persons.

- PRM, ORR, and states and localities should expand language assistance to stateless persons, such as English as a Second Language instruction, to facilitate their integration.

- State and local governments should provide stateless residents with identification cards that provide access to local services, programs, benefits, and facilities, and that otherwise extend to them the rights, entitlements, and responsibilities of membership in their communities.

\section{US Civil Society Institutions and CBOs should:}

- Monitor the implementation of Sustainable Development Goal 16 and its corresponding Target 16.9, which provides for legal identify for all, including birth registration.

- Promote awareness of statelessness and the challenges faced by stateless persons in local communities throughout the country.

- Collect anonymized data on stateless persons they encounter in order to strengthen awareness of the causes and consequences of statelessness.

- Screen for statelessness during legal screening of the unauthorized, naturalization workshops, know-you-rights presentations, and targeted outreach efforts to the stateless.

- Provide stateless persons with pro bono and low-cost legal assistance for their asylum cases, immigration benefit applications, removal proceedings, and other legal needs.

- Encourage network building among stateless persons and the organizations that serve them in order to expand best practices to reduce statelessness and to address the challenges of stateless persons.

- Provide fora to allow stateless persons to share their stories, and refer them to organizations such as United Stateless for support and guidance.

- Develop programming to meet the unique needs of stateless persons and to support their integration, including through language assistance to ensure that they can pass the citizenship test. 


\section{Recommendations for the Improved Identification of Stateless Populations in the United States}

A meaningful effort to produce reliable estimates of US stateless persons must include an incentive - like the possibility of verifying nationality and employment authorization - to bring forward these isolated and often invisible residents. For the purposes of this initiative, improved data collection is a pre-condition to better estimates of the US stateless population and, thus, to better-informed strategies to reduce statelessness. To this end:

- The administration should establish statelessness determination procedures (SDPs), and a voluntary procedure to register and offer temporary status and employment authorization to stateless persons.

- DOS, DHS, ORR, and other relevant federal agencies should prioritize the accurate identification of nationality, including statelessness, for every non-citizen they encounter. They should also clarify how nationality data is collected and how determinations of statelessness, "unknown" nationality, and "no" nationality are now made.

- DOS and ORR should record-following a statelessness determination-whether entering refugees are stateless.

- DOS and ORR should extend efforts to conduct longitudinal surveys of refugees, which include questions that enable them to identify stateless persons. ${ }^{72}$

- EOIR and DHS should also track and report on asylum outcomes for stateless individuals.

- DHS should collect and publish data on stateless persons' length of detention, both pre- and post-removal order, along with their year of entry, birthplace, and past countries of habitual residence.

- The US Census Bureau should collect information on the stateless population in either the ACS or the Current Population Survey (CPS). This recommendation can be implemented by modifying the survey questions on citizenship so that stateless persons can be identified.

- The ACS should include questions on foreign-born individuals' countries of residence prior to entering the United States, in addition to their country of birth. This would facilitate the identification of persons who are potentially stateless or potentially at risk of statelessness and who transited through third countries where they may have secured nationality. ${ }^{73}$

- The US government should provide training - in collaboration with UNHCR and outside experts to immigration officials at all levels and in all relevant agencies on how to identify stateless persons.

- DHS, DOS and ORR should compile and share, particularly with researches and academics, all of their relevant data on persons who are potentially stateless or potentially at risk of statelessness in order to facilitate research on these populations and to develop policy

72 Longitudinal surveys will also enable researchers and policymakers to better assess the challenges faced by stateless persons in the United States, and to develop appropriate policy interventions in response.

73 Examples of such a population include Iraqi-born Feyli Kurds emigrating from Iran and Chinese Cambodians emigrating from Vietnam. 
ideas that respond to their needs. These agencies should also make publicly available their data systems manuals for US immigration and refugee datasets.

- DHS should include data in its annual statistical report on stateless persons from its immigration and refugee datasets.

- The Government Accountability Office should review data collection and availability for the stateless population and issue recommendations on ways to improve the methodology for identifying and estimating the number of stateless persons.

- Independent researchers and academics should conduct further research on the size, characteristics and needs of the particular stateless populations described in this report, and should work intensively with federal officials to improve and to gain access to relevant federal data on stateless populations.

\section{References}

Abe, Kohki. 2010. Overview of statelessness: International and Japanese context. Tokyo: UNHCR. https://www.refworld.org/pdfid/4c344c252.pdf.

Aber, Shaina, and May Small. 2013. "Permutations of Belonging in the United States and the Dominican Republic." Journal on Migration and Human Security 1(3): 76-96.https://doi. org/10.1177/233150241300100301.

Adam, Adam Hussein. 2009. "Kenyan Nubians: Standing Up to Statelessness." Forced Migration Review 32:19-20.https://www.fmreview.org/sites/fmr/files/FMRdownloads/en/ statelessness/adam.pdf.

Adjami, Mirna. 2016. "Statelessness and Nationality in Côte d'Ivoire." Geneva: UNHCR. https://www.refworld.org/docid/58594d114.html.

Aikomus, Markku. 2017. "Madagascar's Karana People Still Awaiting Nationality." Geneva: UNHCR. https://www.unhcr.org/news/latest/2017/11/5a018ff44/ madagascars-karanapeople-still-awaiting-nationality.html.

Albarazi, Zahra. 2013. The Stateless Syrians. Tilburg, Netherlands: Statelessness Programme, Tilburg University. https://www.refworld.org/pdfid/52a983124.pdf.

Albert, Eleanor, and Andrew Chatzky. 2018. "The Rohingya Crisis." New York: Council on Foreign Relations. https://www.cfr.org/backgrounder/rohingya-crisis.

Allerton, Catherine. 2014. "Statelessness and the Lives of Children of Migrants in Sabah, East Malaysia." Tilburg Law Review 19: 26-34. http://doi.org/10.1163/22112596-01902004.

Arraiza, Jose Maria, and Olivier Vonk. 2017. Report on Citizenship Law: Myanmar. Country Report 2017/14. San Domenico di Fiesole, Italy: European University Institute.http://cadmus. eui.eu/handle/1814/48284. 
Ashesh, Ashna, and Arun Thiruvengadam. 2017. Report on Citizenship Law: India. Country Report 2017/12. San Domenico di Fiesole, Italy: European University Institute. http://cadmus. eui.eu/bitstream/handle/1814/47124/GLOBALCIT_CR_2017_12.pdf.

Baluarte, David C. 2015. "Life after Limbo: Stateless Persons in the United States and the Role of International Protection in Achieving a Legal Solution." Georgetown Immigration Law Journal 29: 351-89. https://scholarlycommons.law.wlu.edu/cgi/viewcontent.cgi?article= $1508 \&$ context $=$ wlufac.

Batha, Emma. 2014. "International Surrogacy Traps Babies in Stateless Limbo." Reuters, September 18. https://www.reuters.com/article/us-foundation-statelessness-surrogacy/ international-surrogacy-traps-babies-in-stateless-limbo-idUSKBNOHD19T20140918.

BBC (British Broadcasting Corporation). 2018. "Myanmar Rohingya: What You Need to Know about the Crisis." BBC, April 24. https://www.bbc.com/news/world-asia-41566561.

BBC News World. 2019. "Maduro announces the closure of the embassy and consulates of Venezuela in the United States." January 24. https://www.bbc.com/mundo/noticiasamerica-latina-46995916.

Bier, David J. 2019. "Immigration Wait Times from Quotas Have Doubled: Green Card Backlogs Are Long, Growing, and Inequitable." Policy Analysis 873. Washington, DC: Cato Institute. https://www.cato.org/publications/policy-analysis/immigration-wait-times-quotashave-doubled-green-card-backlogs-are-long.

Biswas, Soutik. 2018. "What Happens to India's Four Million 'Stateless' People?" BBC, July 30. https://www.bbc.com/news/world-asia-india-45002670.

Boehm, Deborah A. 2017. "Separated Families: Barriers to Family Reunification After Deportation." Journal on Migration and Human Security 5(2): 401-16. https://doi.org/10.1177/233150 241700500209.

Boyd, Jason, and Greg Chen. 2019. "USCIS Processing Delays Have Reached Crisis Levels Under the Trump Administration." Washington, DC: American Immigration Lawyers Association. https://www.immigrationresearch.org/node/2441.

BLS (US Bureau of Labor Statistics). "U-3 unemployment rate was 4.1 percent in December 2017; U-6 was 8.1 percent." https://www.bls.gov/opub/ted/2018/u-3-unemployment-ratewas-4-1-percent-in-december-2017-u-6-was-8-1-percent.htm.

Budiman, Abby, Anthony Cilluffo, and Neil Ruiz. 2019. "Key Facts about Asian Origin Groups in the U.S." Washington, DC: Pew Research Center. https://www.pewresearch.org/facttank/2019/05/22/key-facts-about-asian-origin-groups-in-the-u-s/

Campbell, Elizabeth. 2010. "The Faili Kurds of Iraq: Thirty Years Without Nationality.” Washington, DC: Refugees International. https://reliefweb.int/report/iraq/faili-kurds-iraq-thirtyyears-without-nationality.

Celorio, Marcela. 2017. "The Role of the Consulate General of Mexico in San Diego: Exercising an Effective Consular Diplomacy." California Western Law Review 53(2): 131-148. 
Chandran, Rina. 2017. "Chakma Refugees to Get Citizenship after 50 Years in India, Not Land." Reuters, September 19. https://www.reuters.com/article/us-indialandrights-refugees/ chakma-refugees-to-get-citizenship-after-50-years-in-india-not-land-idUSKCN1BU1CK.

Chatty, Dawn, Nisrine Mansour, and Nasser Yassin. 2013. "Statelessness and Tribal Identity on Lebanon's Eastern Borders" Mediterranean Politics 18(3): 411-26. https://doi.org/10.10 80/13629395.2013.834566.

CIS Ombudsman (Citizenship and Immigration Services, Office of the Ombudsman). 2018. Annual Report 2018. Washington, DC: DHS (US Department of Homeland Security). https://www. dhs.gov/sites/default/files/publications/DHS\%20Annual\%20Report\%202018.pdf.

Cobb, Robert. 2013. “Meskhetian Turks: Ten Years On.” Eurasian Daily Monitor 10(214). https:// jamestown.org/program/meskhetian-turks-ten-years-on/.

Conklin, William. 2014. Statelessness: The Enigma of the International Community. Oxford: Hart Publishing.

Consulado General de Mexico en Nueva York. 2019. "Registro de Nacimiento para niños mexicanos nacidos en los Estados Unidos." https://www.consulmexny.org/espregistro_nacimiento_ mex.htm

Consulado General de Guatemala en Nueva York. 2019. "Servicios de Documentacion Consular." https://www.consuladoguatemalanuevayork.org/servicios-de-documentacion-consular. html

Coon, Michael. 2017. "Local Immigration Enforcement and Arrests of the Hispanic Population." Journal on Migration and Human Security 5(3): 645-66. https://doi.org/10.1177/233150 241700500305.

Corgan, John. 2012. "The Stateless in the United States." New York: Center for Migration Studies. http://cmsny.org/the-stateless-in-the-united-states/.

CRG (Mahanirban Calcutta Research Group). 2009. "The State of Being Stateless: A Case Study on Chakmas in Arunachal Pradesh." Calcutta, India: CRG. http://www.mcrg.ac.in/ Statelessness/Statelessness_Concept.asp.

. 2011. "Mapping the Stateless in India: 2 Phase." Calcutta, India. http://www.mcrg.ac.in/ Statelessness/Statelessness_Report_2011.pdf.

Development of Human Resources in Rural Areas Malaysia (DHRRA Malaysia), Voice of the Children, Yayasan Chow Kit, Global Campaign for Equal Nationality Rights, Statelessness Network Asia Pacific, and the Institute on Statelessness and Inclusion. 2018. "Joint Submission to the Human Rights Council at the 31st Session of the Universal Periodic Review.: Malaysia." Tilburg, the Netherlands: ISI. https:// uprdoc.ohchr.org/uprweb/downloadfile.aspx?filename=5755\& file=EnglishTranslation

DHS-OIG (US Department of Homeland Security, Office of the Inspector General). 2019. "ICE Faces Barriers in Timely Repatriation of Detained Aliens." OIG-19-28. https://www.oig. dhs.gov/sites/default/files/assets/2019-03/OIG-19-28-Mar19.pdf. 
DIAC (Australian Department of Immigration and Citizenship). 2011. Iran: Country Guidance Note. Canberra: DIAC. https://www.refworld.org/docid/4ec62e0f2.html.

Dodum, Ranju. 2018. "Arunachal Opposition Questions Government Silence on Citizenship Issue." The Citizen, May 10. https://www.thecitizen.in/index.php/en/newsdetail/ index/3/13769/arunachal-opposition-questions-govt-silence-on-citizenship-issue.

DOS (US Department of State). 1994. "Profile Series. Uzbekistan: Political Conditions in the Post-Soviet Era." Washington, DC: DOS. http://hrlibrary.umn.edu/ins/uzbeki95.pdf.

. 2017a. Country Reports on Human Rights Practices for 2017: Bahamas. Washington, DC: Bureau of Democracy, Human Rights and Labor, DOS. http://www.stategov/j/drl/ rls/hrrpt/humanrightsreport/index.htm?year=2017\&dlid=277305.

. 2017b. Country Reports on Human Rights Practices for 2017: Bhutan. Washington, DC: Bureau of Democracy, Human Rights and Labor, DOS. http:// www.state.gov/j/ $\mathrm{drl} / \mathrm{rls} / \mathrm{hrrpt} /$ humanrightsreport/index.htm?year=2017\&dlid=277279.

. 2017c. Country Reports on Human Rights Practices for 2017: Burma. Washington,DC: Bureau of Democracy, Human Rights and Labor, DOS. http://www.state.gov/j/drl/rls/ hrrpt/humanrightsreport/index.htm?year=2017\&dlid=277069.

- 2017d. Country Reports on Human Rights Practices for 2017: Dominican Republic. Washington, DC: Bureau of Democracy, Human Rights and Labor, DOS. http://www. state.gov/j/drl/rls/hrrpt/humanrightsreport/index. htm?year=2017\&dlid=277327.

. 2017e. Country Reports on Human Rights Practices for 2017: Kenya. Washington, DC: Bureau of Democracy, Human Rights and Labor, DOS. http://www.state.gov/j/drl/rls/ hrrpt/humanrightsreport/index.htm?year=2017\&dlid=277011.

.2017f. Country Reports on Human Rights Practices for 2017: Kuwait. Washington, DC: Bureau of Democracy, Human Rights and Labor, DOS. http://www.state.gov/j/drl/rls/ hrrpt/humanrightsreport/index.htm?year=2017\&dlid=277251.

.2017g. Country Reports on Human Rights Practices for 2017: Latvia. Washington, DC: Bureau of Democracy, Human Rights and Labor, DOS. http://www.state.gov/j/drl/rls/ hrrpt/humanrightsreport/index.htm?year=2017\&dlid=277183.

. 2017h. Country Reports on Human Rights Practices for 2017: Nepal. Washington, DC: Bureau of Democracy, Human Rights and Labor, DOS. http://www.state.gov/j/drl/rls/ hrrpt/humanrightsreport/index.htm?year=2017\&dlid=277289.

. 2017i. Country Reports on Human Rights Practices for 2017: Russia. Washington, DC: Bureau of Democracy, Human Rights and Labor, DOS. http://www.state.gov/j/drl/rls/ hrrpt/humanrightsreport/index.htm?year=2017\&dlid=277211.

. 2017j. Country Reports on Human Rights Practices for 2017: Saudi Arabia. Washington, DC: Bureau of Democracy, Human Rights and Labor, DOS. http://www.state.gov/j/drl/ rls/hrrpt/humanrightsreport/index.htm ?year=2017\&dlid=277263.

. 2017k. Country Reports on Human Rights Practices for 2017: United Arab Emirates. 
Washington, DC: Bureau of Democracy, Human Rights and Labor, DOS. http://www.state. gov/j/drl/rls/hrrpt/humanrightsreport/index.htm?year=2017\&dlid=277269.

. 2017l. Country Reports on Human Rights Practices for 2017: Armenia. Washington, DC: Bureau of Democracy, Human Rights and Labor, DOS. http:// www.state.gov/j/drl/ rls/hrrpt/humanrightsreport/index.htm?year=2017\&dlid=277137.

. 2019. "Assisted Reproductive Technology and Surrogacy Abroad." https://travel. state.gov/content/travel/en/legal/travel-legal-considerations/us-citizenship/AssistedReproductive-Technology-ART-Surrogacy-Abroad.html.ENS (European Network on Statelessness). 2015. Ending Childhood Statelessness: A Study on Latvia. Working Paper 07/15, London: ENS. https://www.statelessness.eu/sites/www.statelessness.eu/files/ Latvia_0.pdf.

ENS (European Network on Statelessness). 2015. Ending Childhood Statelessness: A Study on Latvia. Working Paper 07/15, London: ENS. https://www.statelessness.eu/sites/www. statelessness.eu/files/Latvia_0.pdf.

Farquharson, Majorie. 2011. Statelessness in Central Asia. Geneva: UNHCR. https://www.unhcr. org/4dfb592e9.pdf.

Foster, Michelle, Jane McAdam, and Davina Wadley. 2017. "Part one: The protection of stateless persons in Australia law - the rationale for a statelessness determination procedure." Melbourne University Law Review 40(2): 401-55. https://law.unimelb.edu.au/_data/ assets/pdf_file/0008/2369582/01-Foster,-McAdam-and-Wadley-Part-One-402-PostPress.pdf.

Frotan, Najibullah. 2019. "Afghan 'Gypsies' Demand their Rights." Zuerich: ETH Zuerich Center for Security Studies. http://www.css.ethz.ch/en/services/digital-library/articles/article. html/101937/pdf.

Fullerton, Maryellen. 2014. "The Intersection of Statelessness and Refugee Protection in US Asylum Policy." Journal on Migration and Human Security 2(3): 144-64. https://doi.org/1 $0.1177 / 233150241400200301$.

Gelatt, Julia, and Mark Greenberg. 2019. "Health Insurance Test for Green-Card Applicants Could Sharply Cut Future U.S. Legal Immigration." Washington, DC: Migration Policy Institute. https://www.migrationpolicy.org/news/health-insurance-test-green-card-applicantscould-sharply-cut-future-us-legal-immigration.

Global Campaign for Equal Nationality Rights and Institute for Statelessness and Inclusion. 2017. "The Bahamas." Joint submission to the Human Rights Council at the 29th Session of the Universal Periodic Review. Tilburg, the Netherlands: ISI. https://files.institutesi.org/ UPR29_Bahamas.pdf.

González, Werner. 2018. "El Sistema Nacional de Información Social (SNIS) y su Relación con el RENAP." El Siglo, February 28. http://elsiglo.com.gt/2018/02/28/sistema-nacionalinformacion-social-snis-relacion-renap/.

Gordon, Stephanie. 2017. “China's Hidden Children: Denied Documents and At Risk of 
Statelessness." London: ENS. https://www.statelessness.eu/blog/china-s-hiddenchildren-denied-documents-and-risk-statelessness.

Halling, Helene. 2014 . "Constitutional Reform in Mexico Guarantees the Right to Free and Universal Birth Registration." New York: Center for Migration Studies. https://cmsny. org/constitutional-reform-in-mexico-guarantees-the-right-to-free-and-universal-birthregistration/

Helton, Arthur. 1996. "Stalin's Legacy of Statelessness." Christian Science Monitor, June 5. https:// www.csmonitor.com/1996/0605/060596.opin.opin.2.html.

Howard, David M. 2017. "Analyzing the Causes of Statelessness in Syrian Refugee Children." Texas International Law Journal 52: 281-312.

Human Rights Watch. 2010. "Stateless Again: Palestinian-Origin Jordanians Deprived of their Nationality." New York: Human Rights Watch. https://www.hrw.org/ report/2010/02/01/stateless-again/palestinian-origin-jordanians-deprived-their nationality.

Hutt, Michael. 2005. "The Bhutanese Refugees: Between Verification, Repatration, and Realpolitik." Peace and Democracy in South Asia 1:1. http://himalaya.socanth.cam.ac.uk/collections/ journals/pdsa/pdf/pdsa_01_01_05.pdf.

ICE (US Immigration and Customs Enforcement). 2012. "FOIA 12-22205: Currently Detained Population Statistics." Washington, DC: ICE.

ILC (International Law Commission). 2006. Report of the International Law Commission on the work of its fifty-eighth session. "Draft articles on Diplomatic Protection with commentaries." http://legal.un.org/ilc/texts/instruments/english/commentaries/9_8_2006.pdf

ILCM (Immigrant Law Center of Minnesota). 2018. "Alert to Immigrants from Burma and Laos." Saint Paul, MN: ILCM. https://www.ilcm.org/latest-news/alert-to-immigrants-fromburma-and-laos/.

ILO (International Labour Organization). 2017. “Thailand Opens Citizenship Path for 80,000 Stateless People." Bangkok: Regional Office for Asia and the Pacific, ILO. http://apmigration.ilo. org/news/thailand-opens-citizenship-path-for-80-000-stateless-people.

IOS (International Observatory on Statelessness). 2019a. "Germany." Oxford, U.K. Available at http://www.nationalityforall.org/germany.

. 2019b. "Thailand." Oxford: IOS. http://www.nationalityforall.org/thailand.

. 2019c. "Nepal." Oxford: IOS. http://www.nationalityforall.org/nepal.

. 2019d. "Italy." Oxford: IOS. http://www.nationalityforall.org/italy.

IRB (Immigration and Refugee Board of Canada). 2015. "Palestine and Jordan: Passports issued to stateless Palestinians by the government of Jordan, including procedures, entitlements, differences between Jordanian passports issued to Jordanian nationals and those issued to stateless Palestinians; passports issued to Palestinians by the Palestinian Authority, including requirements and procedures, and entitlements." Ottawa: IRB. https://www. 
refworld.org/docid/5652e15c4.html.

. 2014. "Jordan: Rights and obligations of Palestinians living in Jordan without Jordanian citizenship, not including Palestinian refugees fleeing Syria since 2011, including employment, mobility and access to social services (2013-May 2014)." Ottawa. https:// www.refworld.org/docid/53ecc8004.html.

2013. "Haiti: Dual citizenship, including legislation; requirements and procedures for former Haitian citizens to re-acquire citizenship (2012-January 2013.)" Ottawa: IRB. (https://www.refworld.org/docid/51dd18df4.html).

ISI (Institute on Statelessness and Inclusion). 2014. "The World's Stateless." Tilburg, the Netherlands: ISI. http://www.institutesi.org/worldsstateless.pdf .

. 2017. "The World's Stateless: Children." Tilburg, the Netherlands: ISI. http://www. institutesi.org/worldsstateless17.pdf.

. 2018a. "Cameroon." Submission to the Human Rights Council at the 30th Session of the Universal Periodic Review. Tilburg, the Netherlands: ISI. http://www.institutesi.org/ UPR30_Cameroon.pdf.

. 2018b. "Saudi Arabia." Joint submission to the Human Rights Council at the 31st Session of the Universal Periodic Review. Tilburg, the Netherlands: ISI. http://www.institutesi. org/UPR31_SaudiArabia.pdf.

. 2019. "Côte d'Ivoire." Joint submission to the Human Rights Council at the 33rd Session of the Universal Periodic Review. Tilburg, the Netherlands: ISI. http://www.institutesi. org/UPR33_Cote_d'Ivoire.pdf.

Kerwin, Donald. 2018. "From IIRIRA to Trump: Connecting the Dots to the Current US Immigration Policy Crisis." Journal on Migration and Human Security 6(3):192-204. https://doi. org/10.1177/2331502418786718.

Kerwin, Donald, Daniela Alulema, and Siqi Tu. 2015. "Piecing Together the US Immigrant Detention Puzzle One Night at a Time: An Analysis of All Persons in DHS-ICE Custody on September 22, 2012." Journal on Migration and Human Security 3(4): 330-76. https://doi.org/10.11 77/233150241500300402.

Kerwin, Donald, and Serena Yi-Ying Lin. 2009. "Can ICE Meet Its Legal Imperatives and Case Management Responsibilities." Washington, DC: Migration Policy Institute. https://www. migrationpolicy.org/research/immigrant-detention-can-ice-meet-its-legal-imperativesand-case-management-responsibilities.

Kerwin, Donald, and Robert Warren. 2017. "National Interests and Common Ground in the US Immigration Debate: How to Legalize the US Immigration System and Permanently Reduce Its Undocumented Population." Journal on Migration and Human Security 5(2): 297-330. https://journals.sagepub.com/doi/abs/10.1177/233150241700500205

. 2019a. "Fixing What's Most Broken in the US Immigration System: A Profile of the Family Members of US Citizens and Lawful Permanent Residents Mired in Multiyear Backlogs." 
Journal on Migration and Human Security 7(2): 36-41. https://journals.sagepub.com/ doi/pdf/10.1177/2331502419852925

. 2019b. "Putting Americans First: A Statistical Case for Encouraging, Rather Than Impeding and Devaluing US Citizenship." Journal on Migration and Human Security. https://journals. sagepub.com/doi/full/10.1177/2331502419894286.

Kerwin, Donald, Robert Warren, and Mike Nicholson. 2018. “Proposed Public Charge Rule Would Significantly Reduce Legal Admissions and Adjustment to Lawful Permanent Resident Status of Working Class Persons." New York: Center for Migration Studies. https:// cmsny.org/publications/2018-proposed-public-charge-rule/.

Khalil, Asem. 2007. "Palestinian Nationality and Citizenship: Current Challenges and Future Perspectives." CARIM Research Report 2007/7. San Domenico di Fiesole, Italy: European University Institute. https://cadmus.eui.eu/bitstream/handle/1814/8162/ CARIM?sequence=1

Kohn, Sebastian. 2011. "Fear and Statelessness in Mauritania." New York: Open Society Foundations. https://www.opensocietyfoundations.org/voices/fear-and-statelessnessmauritania.

Lee, Mai Na M. 2016. "Hmong and Hmong Americans in Minnesota." St. Paul, MN: MNopedia, Minnesota Historical Society. http://www.mnopedia.org/hmong-andhmong-americans-minnesota.

Linthicum, Kate. January 15, 2015. "Mexican consulates begin issuing copies of birth certificates." Los Angeles Times. https://www.latimes.com/local/lanow/la-me-In- mexicodocuments-20150115-story.html

Lochery, Emma. 2012. "Rendering Differences Visible: The Kenyan State and Its Somali Citizens." African Affairs 111(445): 615-39.

Longva, Anh Nga. Walls Built on Sand. Oxford: Westview Press, 1997.

Lynch, M. 2005. "Lives on Hold: The Human Cost of Statelessness." Washington, DC: Refugees International. https://www.refworld.org/pdfid/47a6eba00.pdf.

Macedonian Young Lawyers Association, Institute on Statelessness and Inclusion, European Network on Statelessness, European Roma Rights Center, and Minority Rights Group International. 2018. "Macedonia." Joint submission to the Human Rights Council at the 32nd Session of the Universal Periodic Review. http://www.institutesi.org/UPR32 Macedonia.pdf.

Magner, Tara. 2016. "Refugee, Asylum, and Related Legislation in the US Congress 2013-2016." Journal on Migration and Human Security 4(4): 166-89. https://doi. org/10.1177/233150241600400401.

Majumder, Azad. 2008. "Bangladeshi Citizenship Right Divides Biharis." Reuters, May 20. https:// www.reuters.com/article/idINIndia-33670320080520.

Manby, Bronwen. 2009. Struggles for Citizenship in Africa. New York: Open Society Institute. 
. 2015. "Citizenship and Statelessness in Africa: The Law and Politics of Belonging." PhD diss., Maastricht University. https://cris.maastrichtuniversity.nl/portal/files/1560984/ guid-f91d9081-73da-4125-9a7a-887ceb4acca7-ASSET1.0.pdf .

Massey, Hugh. 2010. "UNHCR and De Facto Statelessness." UNHCR Legal and Protection Policy Research Series. Geneva: UNHCR. https://www.unhcr.org/4bc2ddeb9.pdf.

McGranahan, Carole. 2018. "Refusal as Political Practice: Citizenship, Sovereignty, and Tibetan Refugee Status." American Ethnologist 45(3): 367-79. https://doi.org/10.1111/ amet.12671.

McInerney, Caroline. 2014. "Accessing Malagasy Citizenship: The Nationality Code and Its Impact on the Karana." Tilburg Law Review 19: 182-93. https://doi.org/10.1163/2211259601902018.

Meho, Lokman I., and Farah W. Kawtharani. 2005. The Kurdish community in Lebanon and their future prospects. In The Kurdish question and the 2003 Iraqi war, edited by Mohammed M. A. Ahmed and Michael M. Gunter, 248-75. Costa Mesa, CA: Mazda Publishers. https:// staff.aub.edu.Ib/ Imeho/meho-kawtharani-kurdish-community-in-lebanon.pdf.

Meissner, Doris, Donald Kerwin, Muzaffar Chishti, and Claire Bergeron. 2013. "Immigration Enforcement in the United States: The Rise of a Formidable Machinery." Washington, DC: Migration Policy Institute. https://www.migrationpolicy.org/research/immigrationenforcement-united-states-rise-formidable-machinery.

Mercado Asencio, Karen. 2012. "The Under-Registration of Births in Mexico: Consequences for Children, Adults, and Migrants." Washington, DC: Migration Policy Institute. https:// www.migrationpolicy.org/article/under-registration- births-mexico-consequenceschildren-adults-and-migrants/.

Migration Policy Centre. 2013. "Migration Facts Palestine." San Domenico di Fiesole, Italy: European University Institute. http://www.migrationpolicycentre.eu/docs/fact_sheets/ Factsheet\%20Palestine.pdf.

Minority Rights Organization (Cambodia), Khmer Kampuchea Krom for Human Rights and Development Association, Institute on Statelessness and Inclusion, Statelessness Network Asia Pacific, and Minority Rights Group International.2019. "Cambodia." Joint Submission to the Human Rights Council at the 32nd Session of the Universal Periodic Review. http:// www.institutesi.org/UPR32_Cambodia.pdf.

MRS/USCCB and CMS (Migration Refugee Services/US Conference of Catholic Bishops, and Center for Migration Studies). 2015. "Unlocking Human Dignity: A Plan to Transform the US Immigrant Detention System." Journal on Migration and Human Security 3(2):159-204. https://doi.org/10.1177/233150241500300203.

Mughal, Bilal Karim, and Saher Baloch. 2017. "The Woes of Bengalis, Burmese, and Iranians of Karachi." Herald Pakistan, September 14. https://herald.dawn.com/ news/1153771.

Navarro, Waleed. 2018. “Annual Flow Report: Nonimmigrant Admissions.” Washington, DC: Office 
of Immigration Statistics, DHS. https://www.dhs.gov/sites/default/files/publications/ Nonimmigrant_Admissions_2017.pdf .

Ndubi, Modesta. 2017. "The Makonde: From Statelessness to Citizenship in Kenya." Kwale, Kenya: UNHCR. https://www.unhcr.org/ke/10581-stateless-becoming-kenyan-citizens.html.

Nyhan, Paul. July 28, 2016. "America's Stateless Hmong." Asia Sentinel. https://www.asiasentinel. com/society/america-stateless-hmong/.

Odinkalu, Chidi. 2012. "Stateless in Bakassi: How a Changed Border Left Inhabitants Adrift." New York: Open Society Foundations. https://www.opensocietyfoundations.org/voices/ stateless-bakassi-how-changed-border-left-inhabitants-adrift.

Pentikainen, Oskari, and Tom Trier. 2004. "Between Integration and Resettlement: The Meskhetian Turks." ECMI Working Paper 21. Flensburg, Germany: European Centre for Minority Issues.

Plachta, Ari. 2017. "This Ethnic Minority in Israel Still Swears Allegiance to Syria. But for Many Young People That's Changing." Haaretz. October 2, https://www.haaretz.com/israel-news/anisraeli-ethnic-minority-swears-allegiance-to-syria-but-that-s-changing- 1.5453460

Poleschuk, Vadim. 2004. Non-citizens in Estonia. Tallinn, Estonia: Legal Information Center for Human Rights. http://www.lichr.ee/home/wp-content/uploads/2014/05/non-citizens. pdf.

Price, Polly J. 2013. "Stateless in the United States: Current reality and a future prediction." Vanderbilt Journal of Transnational Law 46: 443-514.

Razali, Rodziana Mohamed. 2017. “Addressing Statelessness in Malaysia: New Hope and Remaining Challenges." Statelessness Working Paper Series 2017/9. Tilburg, the Netherlands: ISI.

Ridderbos, Katinka. 2009. "Stateless Former Farm Workers in Zimbabwe." Forced Migration Review 32: 73. https://www.fmreview.org/sites/fmr/files/FMRdownloads/en/statelessness/ ridderbos.pdf.

Rijken, Conny, Laura van Waas, Martin Gramatikov, and Deirdre Brennan. 2015. The Nexus Between Statelessness and Human Trafficking in Thailand. Oisterwijk, the Netherlands: Wolf Legal Publishers. http://www.institutesi.org/Stateless-Trafficking_Thailand.pdf.

Robertson, Cassandra B., and Irina D. Manta. 2018. "President Trump's Expansion of Immigration Fraud Investigations Comes with Significant Risks." Pacific Standard. Dec. 11. https:// psmag.com/social-justice/trump-is-expaning-immigration-fraudinvestigations

Robertson, Cassandra Burke, and Irina D. Manta. 2019. “(Un)Civil Denaturalization.” New York University Law Review 94: 402-471.

RPC (Refugee Processing Center). n.d. "About Us.” http://www.wrapsnet.org/about-us/about. . 2019. "Interactive Reporting." http://ireports.wrapsnet.org/.

Russian Federation Office of the President. 2018. "New Simplified Procedure for Obtaining Russian Citizenship Approved." http://en.kremlin.ru/acts/news/59598. 
Samuel Hall Consulting. 2011. "Jogi and Chori Frosh Communities: A Story of Marginalization." Kabul, Afghanistan: Samuel Hall Consulting. https://reliefweb.int/sites/reliefweb.int/ files/resources/Assessment-of-Out-of-School-Children-and-JOGI-Communities.pdf.

Sanderson, Mike. 2014. "Statelessness and Mass Expulsion in Sudan: A Reassessment of International Law." Northwestern Journal of International Human Rights 12(1): 74-114. http://hdl.handle.net/10871/16497.

Shiblak, Abbas.. 2006. "Stateless Palestinians." Forced Migration Review 26: 8-10.

. 2009. "The Lost Tribes of Arabia." Forced Migration Review 32: 37-40. Southwick, Katherine. 2009. "Ethiopia-Eritrea: Statelessness and State Succession." Forced Migration Review 32: 15-17.

Statelessness Network Asia Pacific, Global Campaign for Equal Nationality Rights, Brunei Project, and Institute on Statelessness and Inclusion. 2018. "Brunei Darussalam." Joint Submission to the Human Rights Council at the 33rd Session of the Universal Periodic Review. http://www.institutesi.org/UPR33_Brunei_Darussalam.pdf.

Stubley, Peter, and Chris Baynes. 2018. "Imran Khan Vows to Grant Pakistan Citizenship to 1.5 Million Afghan Refugees." The Independent, September 18. https://www.independent. co.uk/news/world/asia/pakistan-afghan-refugees-imran-khan-citizenship-grant-primeminister-a8543131.html.

Tabachnik, Maxim. 2019. Report on Citizenship Law: Azerbaijan. San Domenico diFiesole, Italy: European University Institute. http://cadmus.eui.eu/bitstream/ handle/1814/60437/ RSCAS_GLOBALCIT_CR_2019_02.pdf?sequence=1\&isAllowed=y.

Tibet Justice Center. 2003. “Tibet's Stateless Nationals: Tibetan Refugees in Nepal." Berkeley, California: Tibet Justice Center. http://www.tibetjustice.org/reports/nepal.pdf.

. 2016. "Tibet's Stateless Nationals III: The Status of Tibetan Refugees in India." Berkeley, California: Tibet Justice Center. https://www.bu.edu/law/files/2016/09/Tibets-StatelessNationals-II-FINAL-report.pdf.

Times of India. 2015. "16,000 Sri Lanka Refugee Kids Born in India Stateless." Times of India, February 2. https://timesofindia.indiatimes.com/india/16000-SL-refugee-kids-born-inIndia-stateless/articleshow/46094412.cms.

TRAC (Transactional Records Access Clearinghouse, Inc.). 2019a. "Details on Deportation Proceedings in Immigration Court by Custody, Representation, Nationality, Entry Year, Location, Month and Year of NTA, Outcome, and Current Status." Syracuse, NY: TRAC. https://trac.syr.edu/phptools/immigration/nta/.

- 2019b. "Asylum Decisions by Custody, Representation, Nationality, Location, Month and Year, Outcome and more." Syracuse, NY: TRAC. https://trac.syr.edu/phptools/ immigration/asylum/.

. 2019c. "Immigration Court Backlog Surpasses One Million Cases." Syracuse, NY: TRAC. https://trac.syr.edu/immigration/reports/536/. 
. 2019d. "Immigration and Customs Enforcement Detainees: ICE Data Snapshot as of June 2018 - see About the Data." Syracuse, NY: TRAC. https://trac.syr.edu/phptools/ immigration/detention/.

Trimbach, David, and Nicole Reiz. 2018. "Unmaking Citizens: The Expansion of Citizenship Revocation in Response to Terrorism." New York: Center for Migration Studies. http:// doi.org/10.14240/cmsesy013018.

UNGA (United Nations General Assembly). 2013. "Human Rights and Arbitrary Deprivation of Nationality: Report of the Secretary General." Geneva: Human Rights Council, UNGA.

UNICEF (United Nations Children's Fund). 2013. “Every Child's Birth Right: Inequities and trends in birth registration." New York: UNICEF. https://www.unicef.org/publications/files/Birth_ Registration_11_Dec_13.pdf.

. 2017. "Birth Registration: The births of around one fourth of the global population of children under five have never been registered." https://data.unicef.org/topic/childprotection/birth-registration/.

UNHCR (United Nations High Commissioner for Refugees). 1993. Nationality laws of the former Soviet republics. Geneva: UNHCR. http://www.refworld.org/docid/3ae6b31db3.html.

. 2003. International Protections Considerations Regarding Azerbaijani Asylum Seekers and Refugees. Geneva: UNHCR.

. 2011a. Mapping statelessness in the Netherlands. The Hague: UNHCR. https://www. refworld.org/docid/4eef65da2.html.

. 2011b. Report on Statelessness in South Eastern Europe. Geneva: UNHCR. https://www. refworld.org/docid/514d715f2.html.

. 2012. Mapping statelessness in Belgium. Brussels: UNHCR. https://www.refworld.org/ docid/5100f4b22.html.

. 2013. Questions of Statelessness and Nationality in Armenia. Yerevan: UNHCR Armenia. https://www.refworld.org/pdfid/54817cb44.pdf.

. 2014a. Mapping statelessness in Finland. Stockholm: UNHCR. https://www.refworld. org/docid/546da8744.html.

. 2014b. Mapping statelessness in Iceland. Stockholm: UNHCR. https://www.refworld. org/docid/54c775dd4.html.

. 2014c. Mapping statelessness in Malta. Floriana, Malta: UNHCR. https://www.refworld. org/docid/546dae5d4.html.

. 2014d. Global Action Plan to End Statelessness, 2014-2024. Geneva: UNHCR. https:// www.unhcr.org/protection/statelessness/54621bf49/global-action-plan-endstatelessness-2014-2024.html.

. 2014e. "Zimbabwe." Submission by the UNHCR for the Office of the High Commissioner for Human Rights' Compilation Report Universal Periodic Review, 26th Session. 
2014f. Submission by the United Nations High Commissioner for Refugees for the Office of the High Commissioner for Human Rights' Compilation Report - Universal Periodic Review: Croatia. Geneva: UNHCR.

. 2014g. Handbook on Protection of Stateless Persons. https://www.refworld.org/ docid/53b676aa4.html .

. 2015a. "Statement of Jana Mason Senior Advisor, External Relations and Government Affairs United Nations High Commissioner for Refugees Regarding The Human Rights of Stateless People Before the Tom Lantos Human Rights Commission." https:// humanrightscommission.house.gov.siteshumanrightscommission.house.gov/files/ documents/UNHCR\%20Testimony.\%20TLHRC\%20Statelessness\%20Hearing\%20 3.23.15_0.pdf.

. 2015b. Mapping statelessness in Norway. Stockholm: UNHCR. https://www.refworld. org/pdfid/5653140d4.pdf.

. 2015c. Good Practices Paper - Action 1. Resolving Existing Major Situations of Statelessness. Geneva: UNHCR.

. 2016a. Mapping statelessness in Lithuania. Stockholm: UNHCR. https://www.refworld. org/docid/580f649c4.html.

. 2016b. Mapping statelessness in Sweden (2nd ed.). Stockholm: UNHCR. https:// www. refworld.org/docid/58526c577.html.

. 2016c. Mapping statelessness in Estonia. Stockholm: UNHCR. https://www.refworld. org/pdfid/5a338b5c4.pdf.

. 2017a. Mapping statelessness in Austria. Vienna: UNHCR. https://www.refworld.org/ docid/58b6e5b14.html.

. 2017b. "A Study on Statelessness in South Sudan." Juba, South Sudan: UNHCR. https:// data2.unhcr.org/en/documents/download/63857.

. 2017c. "Global Trends: Forced Displacement in 2017." Geneva: UNHCR. https://www. unhcr.org/5b27be547.pdf.

. 2018. "UNHCR welcomes move by Malaysia to grant citizenship to stateless persons." UNHCR. $\quad$ https://www.unhcr.org/en-my/news/press/2018/8/5b73e54d4/unhcrwelcomes-move-by-malaysia-to-grant-citizenship-to-stateless-persons.html

. 2019. "Background Note on Gender Equality, Nationality Laws, and Statelessness." Geneva: UNHCR. https://www.refworld.org/pdfid/5aa10fd94.pdf.

. 2019b. "Global Trends: Forced Displacement in 2018." Geneva: UNHCR. https://www. unhcr.org/en-us/statistics/unhcrstats/5d08d7ee7/unhcr-global-trends-2018.html.

UNHCR and Asylum Aid. 2011. Mapping statelessness in The United Kingdom. London: UNHCR. https://www.refworld.org/docid/4ecb6a192.html.

UNHCR and OSJI (Open Society Justice Initiative). 2012. Citizens of nowhere: Solutions for the 
stateless in the U.S. New York and Washington, DC: OSJI and UNHCR. http://www.unhcr. org/en-us/about-us/background/56fbfcea4/citizens-of-nowhere-solutions-for-thestateless-in-the-us.html.

United Nations News. 2010. “U.N. Hails Viet Nam's Moves to End Statelessness of Cambodian Refugees." Geneva: United Nations. https://news.un.org/en/story/2010/07/345232.

. 2011. "Guidance Note of the Secretary-General: The United Nations and Statelessness." https://www.un.org/ruleoflaw/files/FINAL\%20Guidance\%20Note\%20of\%20the\%20 Secretary-General\%20on\%20the\%20United\%20Nations\%20and\%20Statelessness.pdf

US Census Bureau. 2014, “American Community Survey Design and Methodology (January 2014)." Washington, DC. https://www2.census.gov/programs-surveys/acs/methodology/ design_and_methodology/acs_design_methodology_report_2014.pdf.

. 2017. "American Community Survey Group Quarters Data Collection." Washington, DC.https://www.census.gov/content/dam/Census/programs-surveys/acs/Library/ OutreachMaterials/ACSFlyers/2017\%20Group\%20 Quarters\%20flyer_508.pdf.

.2018a. "American Community Survey: Response Rates." Washington, D.C. https://www. census.gov/acs/www/methodology/sample-size-and-data-quality/response-rates/.

.2018b. "2017 American Community Survey 1-Year Estimates.

.2019. "2013-2017 ACS 5-year Public Use Microdata Samples (PUMS)." https://factfinder. census.gov/faces/nav/jsf/pages/searchresults.xhtml?refresh=t\#.

. 2019b. "2013-2017 ACS 5-year Public Use Microdata Samples (PUMS): Selected Economic Characteristics."https://factfinder.census.gov/bkmk/table/1.0/en/ACS/17_5YR/ DP03/0100000US

. 2019e. "American Community Survey: Response Rates." Washington, D.C https://www. census.gov/acs/www/methodology/sample-size-and-data-quality/response-rates/

USCIS (US Citizenship and Immigration Services). 2011. "Refugees, Asylum and Parole System G23 Workload Statistics Report." File with authors.

.2012. "Refugees, Asylum and Parole System G23 Workload Statistics Report." On file with authors.

. 2013. "Refugees, Asylum and Parole System G23 Workload Statistics Report." On file with authors.

. 2014. "Refugees, Asylum and Parole System G23 Workload Statistics Report." On file with authors.

. 2015. "Refugees, Asylum and Parole System G23 Workload Statistics Report." On file with authors.

. 2016. "Refugees, Asylum and Parole System G23 Workload Statistics Report." On file with authors. 
US GAO (United States Government Accountability Office). 2004. "Border Security: Consular Identification Cards Accepted within United States, but Consistent Federal Guidance Needed." Washington, DC: USGAO, GAO-04-881. https://www.gao.gov/new.items/ d04881.pdf

Van Waas, Laura. 2010. "The Situation of Stateless Persons in the Middle East and North Africa." Geneva: UNHCR.

. 2013. "The Stateless Tebu of Libya: Report of the Middle East and North Africa Nationality and Statelessness Research Project." Tilburg Law School Legal Studies Research Paper Number 10. Tilburg, the Netherlands: Tilburg University.

Wallace, Julia. 2010. "Stateless Cambodians in Vietnam to Become Citizens." The Cambodia Daily, July 21. https://www.cambodiadaily.com/news/stateless-cambodians-in-vietnam-tobecome-citizens-100439/.

Wheeler, Charles. 2019. "Backlogs in Family-Based Immigration: Shedding Light on the Numbers." Washington, DC: Catholic Legal Immigration Network, Inc. https://cliniclegal.org/ resources/backlogs-family-based-immigration-shedding-light-numbers.

Wong, Tom K., Donald Kerwin, Jeanne M. Atkinson, and Mary Meg McCarthy. 2014. "Paths to Lawful Immigration Status: Results and Implications from the PERSON Survey." Journal on Migration and Human Security 2(4): 287-304. http://doi.org/10.1177/23315024140 0200402.

Yau, Jennifer. 2005. "The Foreign-Born Hmong in the United States." Washington, DC: Migration Policy Institute. https://www.migrationpolicy.org/article/foreign-born-hmong-unitedstates. 


\section{Appendices}

\section{Attachment A: Online Survey}

Please share some contact information for you and your organization:

Your Name

Name of Your Organization

Phone number

Email

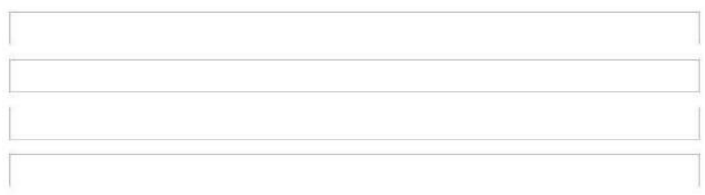

I am 18 years of age or older, and I wish to participate in this study.

By continuing I agree to participate in this research study.

Proceed to the survey.

I decline to participate.

Block 2

In this section of the survey, we will ask you to share non-identifying details about stateless individuals that you or your organization has helped.

Please think about a specific stateless individual that you or your organization has helped or encountered. We will ask you questions that will help us build an anonymous profile of that person, so we can understand the lived experiences of stateless people in the United States. Please do not share the names or other personally identifying information about the individual(s) you are describing.

If you would like to share information about multiple people, there will be an option at the bottom of this page that will allow you to fill out multiple profiles. 
Does this person have national identity documents? If so, from which country?
Yes (please list country if applicable)
No
Don't know or prefer not to answer

Was the person registered at birth in his/her home country?

Yes
No

Don't know or prefer not to answer

Is this person the sole stateless person in his/her immediate family, or part of a stateless household?

Please describe this person's...

Approximate age

Place of birth

Ethnicity

Race

Religion

Languages spoken

To your knowledge, would this person be willing to participate in a longer, in-person interview with a member of our research team? If so, do you have a way to contact this person? 


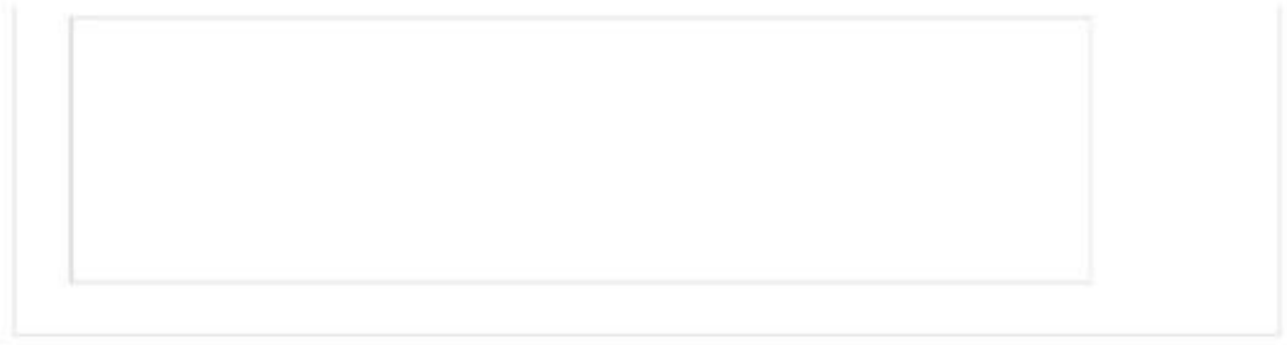

Is there any other information you would like to share about this person?

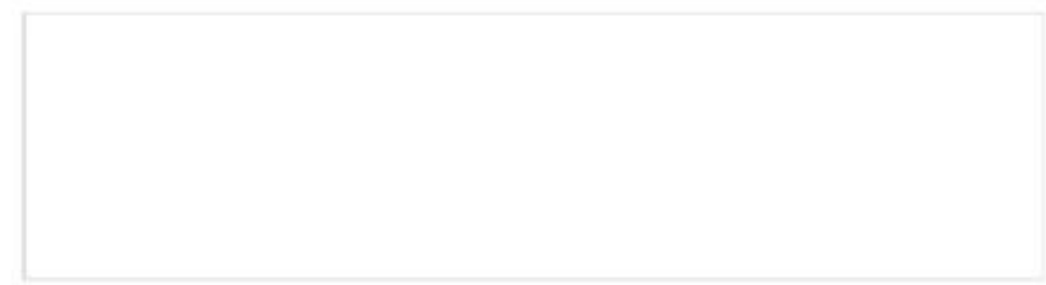

Would you like to fill out another stateless person profile for this portion of the survey?

$$
\begin{aligned}
& \text { Yes } \\
& \text { No }
\end{aligned}
$$

Block 3

\begin{tabular}{|c|c|c|c|c|c|c|}
\hline Daily & Every week & $\begin{array}{l}\text { About once a } \\
\text { month }\end{array}$ & $\begin{array}{c}\text { A few times a } \\
\text { year }\end{array}$ & $\begin{array}{c}\text { Loss than once a } \\
\text { year }\end{array}$ & Never & $\begin{array}{l}\text { Dont know or } \\
\text { prefer not to } \\
\text { answer }\end{array}$ \\
\hline 0 & 0 & 0 & 0 & 0 & 0 & 0 \\
\hline
\end{tabular}

How frequently does your organization encounter stateless people?

Do you have any further comments that you would like to share about your work with stateless people or the particular stateless person(s) described in this survey? 
Would you allow members of our research team to follow up with you about your work with stateless people?

Yes

No 


\section{Attachment B: Description of Survey Results}

The largest share of stateless persons described in the CMS survey, 28 percent or 13 in total, had become stateless through gaps in citizenship laws. Most were born in states without birthright citizenship and either had stateless parents or could not attain their parents' citizenship. Nine persons (19.6 percent) were stateless due to discriminatory laws that denied nationality to or denationalized members of their ethnic or religious groups. An additional nine persons were stateless due to state succession. Most in this latter category came to the United States on passports from states, such as the Soviet Union, that no longer exist, and had not been able to gain recognition from those successor states.

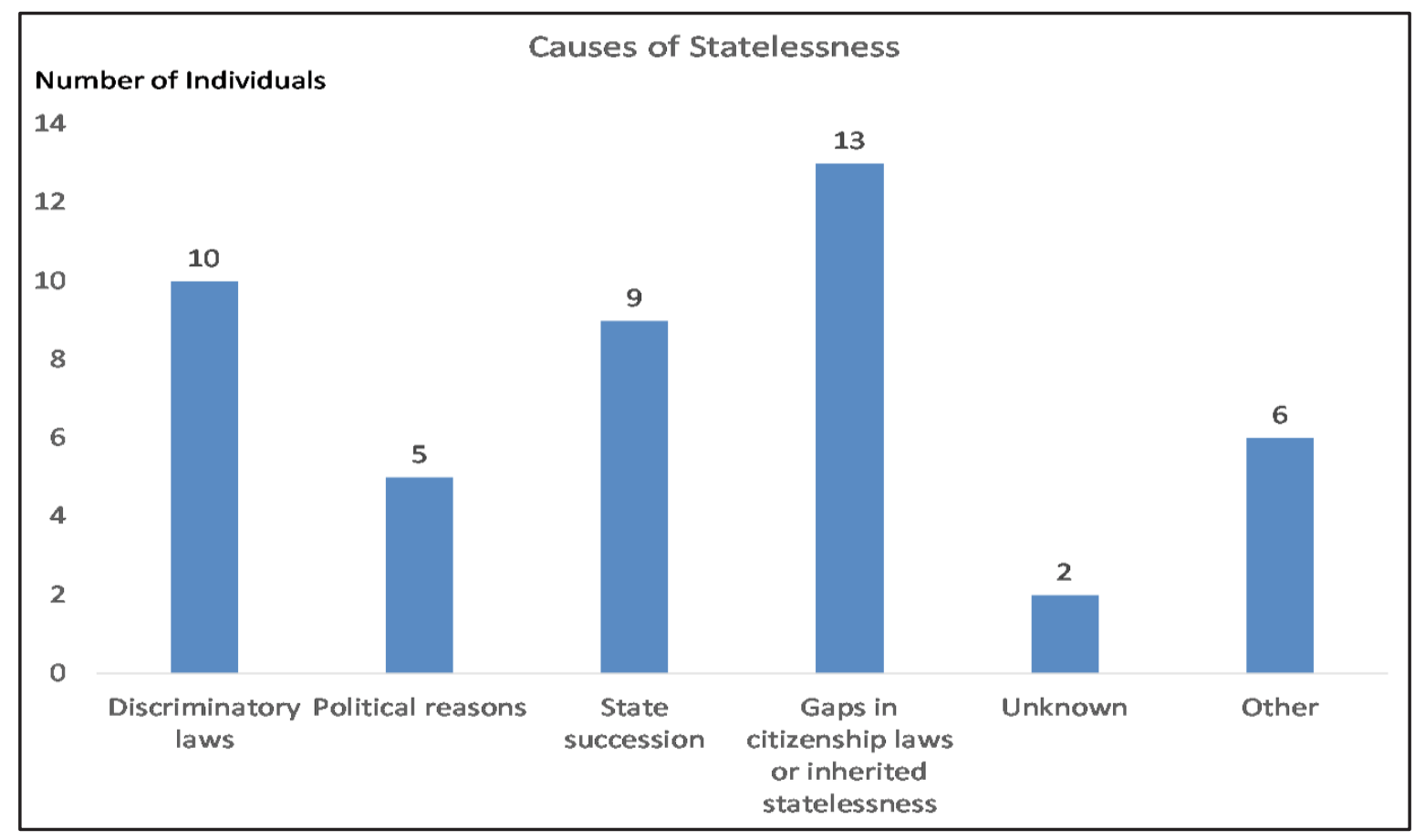

Sixteen had been granted the right to stay in the United States legally, either by an affirmative asylum decision or through family sponsorship, but 26 (57.8 percent) lacked legal status. Of the latter group, six had been denied asylum, two were living under orders of supervision, and one had been granted withholding of removal. The survey highlighted both the heterogeneity of stateless persons in the United States and the common challenges faced by them. 


\section{Attachment C: Interview Questionnaire}

\section{Semi-Structured Interview Protocol}

\section{Background}

Where were you born?

Where were you just before you arrived in the US?

Where did you grow up? Was it an urban or rural environment?

Where were your parents born? What nationality do they hold?

Do you have any siblings? If so, where are they? What nationality do they hold?

Who did you live with growing up?

Could you describe your educational background?

Did you work in your home country?

What was your occupation?

Are you married? (If yes, what is spouse's nationality, ethnicity, religion, place of birth?)

Do you have children? (If yes, where were they born? Where are they currently?)

What is your religion?

\section{Origins of Statelessness}

Are you familiar with the term "stateless"? [If not, mention that stateless is a person who does not have any nationality at all]. Do you consider yourself stateless? If so, why?

When did you become stateless?

How did you become stateless?

How did you find out that you were stateless?

Have you ever approached the authorities of the country in which you were born or used to hold a passport to see if they will recognize you as a citizen? If so, what was their response? If not, why not?

If these questions did not come out of conversation from the above questions: When did you become stateless?

Why did you come to the U.S.?

How did you get to the U.S.?

What type of visa, if any, did you use to enter the U.S? 


\section{Stateless status \& migration}

Have you ever applied for citizenship in the U.S.? Did you ever apply for citizenship in any country?

If so, what happened?

Have you ever had citizenship and lost it?

What is your residency status in the United States?

Have you ever had a passport, birth certificate, or other identity document stating nationality, from any country? Do you still have them? (If no, how did you come to lose them?)

Do you currently have a Refugee Travel Document from the U.S. or any other country?

\section{Conditions of life before coming to the U.S.}

What was your life like before coming to the United States? Where did you live?

When did you leave your home country?

Why?

Where did you go? (trace path to the United States)

Could you go back to (former place of residence) or (country of birth) if you wanted to? Why or why not?

How did being stateless affect your life there?

\section{Conditions of life in the U.S.}

Where do you currently live?

What are the biggest issues you face as a stateless person in the US?

How has your stateless situation affected your family?

How has your stateless situation affected your friendships or other relations?

How do you support yourself? Do you have work authorization?

Have you ever worked or studied here?

Have you ever received any government assistance or benefits?

Can you travel?

What restrictions do you have in your life on account of your statelessness?

How else does your condition of statelessness impact your life? 


\section{Experience with US immigration authorities}

What is your current immigration status in the U.S.?

Have you had any experiences with US immigration authorities? What were they like?

Have you ever made any applications to immigration authorities?

If so, what type of application, and what did you enter as your country of citizenship/ nationality on those forms?

\section{Social support}

Do you know other people who are stateless?

Would you say you are part of a community of stateless people?

If so, how often do you interact with other stateless people?

How do you interact with these other stateless people (for example, online, in person, etc.)?

Are there particular social media pages for different groups of stateless people?

If you know other stateless people, how are their situations similar to yours?

Different from yours?

What additional kinds of supports would you like?

Are you still in touch with the stateless people you know?

If so, would you be willing to ask them if they would agree to be interviewed by us?

\section{Preferences/voice}

In what country would you ideally like to live? to hold citizenship?

What should the U.S. government/immigration authorities understand about your situation?

Is there anything else you would like me to know about you or your situation? 
Attachment D: Annual numbers of persons in deportation proceedings of selected nationalities by outcome and custody status

Annual Figures of Deportation Proceedings for Selected Nationalities by Outcome

Stateless: Alien unable to name a country

\section{Outcome}

FY

\begin{tabular}{|c|c|c|c|c|c|}
\hline $\begin{array}{l}\text { Case } \\
\text { Began Terminate }\end{array}$ & $\begin{array}{c}\text { Removal } \\
\text { Order }\end{array}$ & $\begin{array}{l}\text { Grant } \\
\text { Relief }\end{array}$ & Voluntary & $\begin{array}{l}\text { Other } \\
\text { Closure }\end{array}$ & $\begin{array}{c}\text { Prosecutorial } \\
\text { Discretion }\end{array}$ \\
\hline
\end{tabular}

\begin{tabular}{|c|c|c|c|c|c|c|c|c|}
\hline 2001 & 7 & 29 & 26 & 6 & 2 & & & 70 \\
\hline 2002 & 12 & 51 & 55 & 11 & 3 & & & 132 \\
\hline 2003 & 14 & 60 & 73 & 11 & 5 & 1 & & 164 \\
\hline 2004 & 15 & 39 & 92 & 12 & 2 & & & 160 \\
\hline 2005 & 6 & 32 & 108 & 10 & 5 & & 1 & 162 \\
\hline 2006 & 17 & 25 & 53 & 4 & 5 & 4 & 1 & 109 \\
\hline 2007 & 13 & 52 & 84 & 3 & & 1 & 1 & 154 \\
\hline 2008 & 17 & 36 & 146 & 6 & 5 & 3 & 4 & 217 \\
\hline 2009 & 29 & 39 & 125 & 2 & 3 & 2 & 5 & 205 \\
\hline 2010 & 9 & 22 & 78 & 2 & 7 & 4 & 5 & 127 \\
\hline 2011 & 7 & 12 & 63 & & 5 & 12 & 2 & 101 \\
\hline 2012 & 10 & 9 & 24 & & 2 & 3 & 17 & 65 \\
\hline 2013 & 4 & 4 & 22 & 1 & 2 & 3 & 7 & 43 \\
\hline 2014 & 10 & 6 & 7 & 1 & 1 & 1 & 12 & 38 \\
\hline 2015 & 5 & 10 & 2 & 2 & & 5 & 21 & 45 \\
\hline 2016 & & 12 & 5 & & & 1 & 21 & 39 \\
\hline 2017 & 2 & 3 & 2 & 2 & & & 38 & 47 \\
\hline 2018 & 1 & 6 & 9 & 2 & & & 89 & 107 \\
\hline \\
\hline \multicolumn{9}{|l|}{ 2001- } \\
\hline \multirow[t]{2}{*}{2018} & 178 & 447 & 974 & 75 & 47 & 40 & 224 & 1985 \\
\hline & 9\% & $23 \%$ & $49 \%$ & $4 \%$ & $2 \%$ & $2 \%$ & $11 \%$ & $100 \%$ \\
\hline
\end{tabular}

Source: Data accessed through the data tool based upon analyses by TRAC at Syracuse University of court records detained from EOIR using the Freedom of Information Act. Retrieved on March 23, 2019. 


\section{Unknown Nationality}

\section{Outcome}

\begin{tabular}{|c|c|c|c|c|c|c|c|c|}
\hline $\begin{array}{l}\text { FY Case } \\
\text { Began }\end{array}$ & & $\begin{array}{l}\text { Removal } \\
\text { C rder }\end{array}$ & $\begin{array}{l}\text { Grant } \\
\text { Relief }\end{array}$ & & & $\begin{array}{c}\text { Prosecutorial } \\
\text { Discretion }\end{array}$ & Pending $A$ & Annual Total \\
\hline 2001 & 1 & 18 & 1 & 1 & 1 & & & 22 \\
\hline 2002 & & 18 & 3 & 1 & & & & 22 \\
\hline 2003 & 1 & 9 & 2 & 6 & & & & 18 \\
\hline 2004 & 1 & 8 & 2 & & 2 & & & 13 \\
\hline 2005 & 1 & 6 & 2 & 5 & 3 & & & 17 \\
\hline 2006 & 10 & 11 & 1 & 5 & & & & 27 \\
\hline 2007 & 11 & 18 & 9 & 14 & 6 & & & 58 \\
\hline 2008 & 17 & 34 & 12 & 26 & 3 & & & 92 \\
\hline 2009 & 28 & 32 & 13 & 13 & 3 & 2 & 2 & 93 \\
\hline 2010 & 12 & 14 & 5 & 12 & 2 & 1 & 5 & 51 \\
\hline 2011 & 16 & 14 & 5 & 6 & 5 & 3 & 2 & 51 \\
\hline 2012 & 13 & 16 & 5 & 14 & 11 & 7 & 10 & 76 \\
\hline 2013 & 12 & 27 & 2 & 13 & 7 & 3 & 21 & 85 \\
\hline 2014 & 7 & 14 & 3 & 3 & 4 & & 45 & 76 \\
\hline 2015 & 9 & 14 & 4 & & 3 & 2 & 19 & 51 \\
\hline 2016 & 8 & 8 & 1 & 3 & 3 & & 19 & 42 \\
\hline 2017 & 6 & 15 & & 4 & & 1 & 30 & 56 \\
\hline 2018 & 2 & 10 & 2 & 3 & 5 & & 89 & 111 \\
\hline & 2001- \\
\hline \multirow[t]{2}{*}{2018} & 155 & 286 & 72 & 129 & 58 & 19 & 242 & 961 \\
\hline & $16 \%$ & $30 \%$ & $7 \%$ & $13 \%$ & $6 \%$ & $2 \%$ & $25 \%$ & $100 \%$ \\
\hline
\end{tabular}

Source: Data accessed through the data tool based upon analyses by TRAC at Syracuse University of court records detained from EOIR using the Freedom of Information Act. Retrieved on March 23, 2019. 
No Nationality

\section{Outcome}

\begin{tabular}{|c|c|c|c|c|c|c|c|}
\hline $\begin{array}{l}\text { FY Case } \\
\text { Began }\end{array}$ & $\begin{array}{c}\text { Terminate } \\
\text { Proceedings }\end{array}$ & $\begin{array}{c}\text { Removal } \\
\text { Order }\end{array}$ & Grant Relief & $\begin{array}{l}\text { Voluntary } \\
\text { Departure }\end{array}$ & $\begin{array}{l}\text { Other } \\
\text { Closure }\end{array}$ & Pending & Total \\
\hline 2001 & 3 & 3 & 3 & 2 & & & 8 \\
\hline 2002 & 3 & 2 & 3 & 3 & 3 & & 14 \\
\hline 2003 & 7 & 5 & 2 & 1 & & & 15 \\
\hline 2004 & 3 & 4 & 4 & 1 & & & 12 \\
\hline 2005 & 9 & 3 & 2 & 1 & 2 & & 17 \\
\hline 2006 & 3 & 1 & 1 & 1 & & & 6 \\
\hline 2007 & 3 & 1 & 2 & & 1 & & 7 \\
\hline 2008 & 1 & & & & & & 1 \\
\hline 2009 & & & & & & & 0 \\
\hline 2010 & & & & & & & 0 \\
\hline 2011 & & & & & & & 0 \\
\hline 2012 & 1 & & & & & & 1 \\
\hline 2013 & & & & & & & 0 \\
\hline 2014 & & & & & & & 0 \\
\hline 2015 & & & & & & & 0 \\
\hline 2016 & & & & & & & 0 \\
\hline 2017 & & & & & & & 0 \\
\hline 2018 & & & & & & 3 & 3 \\
\hline \multicolumn{8}{|l|}{ Total 2001- } \\
\hline \multirow[t]{2}{*}{2018} & 33 & 19 & 14 & 9 & 6 & 3 & 84 \\
\hline & $39 \%$ & $23 \%$ & $17 \%$ & $11 \%$ & $7 \%$ & $4 \%$ & $100 \%$ \\
\hline
\end{tabular}

Source: Data accessed through the data tool based upon analyses by TRAC at Syracuse University of court records detained from EOIR using the Freedom of Information Act. Retrieved on March 23, 2019. 


\section{Soviet Union}

\section{Outcome}

\begin{tabular}{|c|c|c|c|c|c|c|c|c|}
\hline $\begin{array}{l}\text { FY Case } \\
\text { Began }\end{array}$ & & $\begin{array}{c}\text { Removal } \\
\text { Order }\end{array}$ & $\begin{array}{l}\text { Grant } \\
\text { Relief }\end{array}$ & & $\begin{array}{l}\text { Other } \\
\text { Closure }\end{array}$ & $\begin{array}{l}\text { Prosecutorial } \\
\text { Discretion }\end{array}$ & Pending & Annual Total \\
\hline 2001 & 2 & 3 & 1 & 1 & & & & 7 \\
\hline 2002 & 1 & 7 & 2 & 2 & & & 1 & 13 \\
\hline 2003 & 15 & 108 & 100 & 16 & 10 & & 1 & 250 \\
\hline 2004 & 63 & 126 & 298 & 33 & 15 & 2 & 8 & 545 \\
\hline 2005 & 43 & 122 & 295 & 37 & 9 & 2 & 3 & 511 \\
\hline 2006 & 54 & 64 & 189 & 15 & 24 & 2 & 4 & 352 \\
\hline 2007 & 52 & 75 & 211 & 16 & 22 & 6 & 7 & 389 \\
\hline 2008 & 31 & 49 & 149 & 5 & 2 & 3 & 3 & 242 \\
\hline 2009 & 35 & 43 & 252 & 5 & 6 & 2 & 1 & 344 \\
\hline 2010 & 46 & 32 & 315 & 4 & 11 & 3 & 10 & 421 \\
\hline 2011 & 42 & 28 & 295 & 6 & 13 & 6 & 26 & 416 \\
\hline 2012 & 26 & 41 & 240 & 2 & 9 & 8 & 30 & 356 \\
\hline 2013 & 29 & 26 & 200 & 3 & 11 & 7 & 55 & 331 \\
\hline 2014 & 10 & 29 & 94 & 2 & 3 & 8 & 73 & 219 \\
\hline 2015 & 13 & 19 & 59 & & 4 & 1 & 106 & 202 \\
\hline 2016 & 7 & 27 & 64 & 3 & 6 & 4 & 120 & 231 \\
\hline 2017 & 4 & 15 & 34 & 4 & 2 & 1 & 366 & 426 \\
\hline 2018 & 4 & 20 & 10 & 3 & 6 & & 815 & 858 \\
\hline \multicolumn{9}{|l|}{ Total } \\
\hline \multirow{2}{*}{$\begin{array}{l}2001- \\
2018\end{array}$} & 477 & 834 & 2808 & 157 & 153 & 55 & 1629 & 6113 \\
\hline & $8 \%$ & $14 \%$ & $46 \%$ & $3 \%$ & $3 \%$ & $1 \%$ & $27 \%$ & $100 \%$ \\
\hline
\end{tabular}

Source: Data accessed through the data tool based upon analyses by TRAC at Syracuse University of court records detained from EOIR using the Freedom of Information Act. Retrieved on March 23, 2019. 
Palestine

Outcome

\begin{tabular}{|c|c|c|c|c|c|c|c|c|}
\hline $\begin{array}{l}\text { FY Case } \\
\text { Began }\end{array}$ & & $\begin{array}{c}\text { Removal } \\
\text { Order }\end{array}$ & $\begin{array}{l}\text { Grant } \\
\text { Relief }\end{array}$ & & $\begin{array}{l}\text { Other } \\
\text { Closure }\end{array}$ & $\begin{array}{l}\text { Prosecutorial } \\
\text { Discretion }\end{array}$ & Pending & $\begin{array}{c}\text { Annual } \\
\text { Total }\end{array}$ \\
\hline 2001 & 5 & 12 & 4 & 6 & & 1 & 1 & 29 \\
\hline 2002 & 7 & 15 & 8 & 6 & 2 & & & 38 \\
\hline 2003 & 10 & 10 & 9 & 9 & 1 & & & 39 \\
\hline 2004 & 7 & 10 & & 2 & 2 & 1 & & 22 \\
\hline 2005 & 7 & 19 & 4 & 3 & 1 & & & 34 \\
\hline 2006 & 8 & 10 & 10 & 10 & 1 & & 1 & 40 \\
\hline 2007 & 12 & 10 & 13 & 16 & 4 & & & 55 \\
\hline 2008 & 16 & 19 & 15 & 6 & 3 & 1 & 1 & 61 \\
\hline 2009 & 17 & 19 & 7 & 9 & 2 & 1 & 4 & 59 \\
\hline 2010 & 3 & 17 & 3 & 1 & & & 2 & 26 \\
\hline 2011 & 7 & 19 & 8 & 2 & & & 2 & 38 \\
\hline 2012 & 9 & 3 & 5 & & & 3 & 4 & 24 \\
\hline 2013 & 6 & 13 & 1 & & 4 & 1 & 3 & 28 \\
\hline 2014 & 5 & 12 & 6 & 1 & & & 6 & 30 \\
\hline 2015 & 4 & 4 & 2 & 2 & 1 & & 10 & 23 \\
\hline 2016 & 2 & 14 & 3 & & 1 & & 14 & 34 \\
\hline 2017 & 1 & 9 & 2 & 4 & & & 20 & 36 \\
\hline 2018 & 1 & 10 & 1 & 2 & & & 52 & 66 \\
\hline \multicolumn{9}{|l|}{$\begin{array}{l}\text { Total } \\
2001-\end{array}$} \\
\hline \multirow[t]{2}{*}{2018} & 127 & 225 & 101 & 79 & 22 & 8 & 120 & 682 \\
\hline & $19 \%$ & $33 \%$ & $15 \%$ & $12 \%$ & $3 \%$ & $1 \%$ & $18 \%$ & $100 \%$ \\
\hline
\end{tabular}

Source: Data accessed through the data tool based upon analyses by TRAC at Syracuse University of court records detained from EOIR using the Freedom of Information Act. Retrieved on March 23, 2019. 


\section{Yugoslavia}

\begin{tabular}{|c|c|c|c|c|c|c|c|c|c|}
\hline \multirow[b]{2}{*}{$\begin{array}{l}\text { FY Case } \\
\text { Began }\end{array}$} & \multicolumn{7}{|c|}{ Outcome } & \multirow[b]{2}{*}{$\begin{array}{c}\text { Not } \\
\text { Known }\end{array}$} & \multirow{3}{*}{$\begin{array}{c}\begin{array}{c}\text { Annual } \\
\text { Total }\end{array} \\
672\end{array}$} \\
\hline & & $\begin{array}{l}\text { Rı moval } \\
\text { । rder }\end{array}$ & $\begin{array}{l}\text { Grant } \\
\text { Relief }\end{array}$ & & $\begin{array}{l}\text { her } \\
\text { sure }\end{array}$ & $\begin{array}{c}\text { Prosecutorial } \\
\text { Discretion }\end{array}$ & Pending & & \\
\hline 2001 & 80 & 286 & 229 & 57 & 14 & & 5 & & \\
\hline 2002 & 64 & 200 & 199 & 41 & 12 & & 1 & & 517 \\
\hline 2003 & 48 & 153 & 171 & 14 & 13 & & 2 & & 401 \\
\hline 2004 & 29 & 111 & 197 & 15 & 5 & & 2 & 1 & 360 \\
\hline 2005 & 18 & 67 & 119 & 14 & 5 & & 1 & & 224 \\
\hline 2006 & 24 & 43 & 86 & 4 & 4 & & 1 & & 162 \\
\hline 2007 & 28 & 70 & 125 & 10 & 18 & & 2 & & 253 \\
\hline 2008 & 30 & 48 & 112 & 8 & 7 & & 2 & & 208 \\
\hline 2009 & 21 & 37 & 105 & 5 & 4 & & 4 & & 177 \\
\hline 2010 & 23 & 27 & 63 & 5 & 4 & & 3 & & 127 \\
\hline 2011 & 23 & 29 & 36 & 2 & 5 & & 10 & & 108 \\
\hline 2012 & 11 & 16 & 31 & 2 & 7 & & 5 & & 72 \\
\hline 2013 & 11 & 10 & 32 & & 7 & & 8 & & 68 \\
\hline 2014 & 8 & 12 & 24 & 1 & 4 & & 11 & & 63 \\
\hline 2015 & 1 & 8 & 10 & 1 & 2 & & 18 & & 40 \\
\hline 2016 & 2 & 10 & 4 & & 2 & & 10 & & 30 \\
\hline 2017 & & 7 & & 2 & 5 & & 34 & & 48 \\
\hline 2018 & 2 & 3 & & & 1 & & 59 & & 65 \\
\hline \multicolumn{10}{|l|}{$\begin{array}{l}\text { Total } \\
\text { 2001- }\end{array}$} \\
\hline \multirow[t]{2}{*}{2018} & 423 & 1137 & 1543 & 181 & 119 & 14 & 177 & 1 & 3595 \\
\hline & $12 \%$ & $32 \%$ & $43 \%$ & $5 \%$ & $3 \%$ & $0 \%$ & $5 \%$ & $0 \%$ & $100 \%$ \\
\hline
\end{tabular}

Source: Data accessed through the data tool based upon analyses by TRAC at Syracuse University of court records detained from EOIR using the Freedom of Information Act. Retrieved on March 23, 2019. 
Annual Figures of Deportation Proceedings for Selected Nationalities by Custody Status

Stateless- Alien Unable to Name a Country

\section{Custody}

\begin{tabular}{|c|c|c|c|c|}
\hline $\begin{array}{l}\text { Fiscal Year Case } \\
\text { Began }\end{array}$ & Detained & Never Detained & Released & Yearly Total \\
\hline 2001 & 7 & 62 & 1 & 70 \\
\hline 2002 & 9 & 121 & 2 & 132 \\
\hline 2003 & 12 & 146 & 6 & 164 \\
\hline 2004 & 10 & 148 & 2 & 160 \\
\hline 2005 & 11 & 147 & 4 & 162 \\
\hline 2006 & 11 & 92 & 6 & 109 \\
\hline 2007 & 8 & 139 & 7 & 154 \\
\hline 2008 & 4 & 204 & 9 & 217 \\
\hline 2009 & 9 & 189 & 7 & 205 \\
\hline 2010 & 6 & 118 & 3 & 127 \\
\hline 2011 & 4 & 95 & 2 & 101 \\
\hline 2012 & 4 & 60 & 1 & 65 \\
\hline 2013 & 6 & 37 & & 43 \\
\hline 2014 & 6 & 29 & 3 & 38 \\
\hline 2015 & 5 & 39 & 1 & 45 \\
\hline 2016 & 4 & 30 & 5 & 39 \\
\hline 2017 & 3 & 41 & 3 & 47 \\
\hline 2018 & 6 & 96 & 5 & 107 \\
\hline \multirow[t]{2}{*}{ Total 2001-2018 } & 125 & 1793 & 67 & 1985 \\
\hline & $6 \%$ & $90 \%$ & $3 \%$ & $100 \%$ \\
\hline
\end{tabular}

Source: Data accessed through the data tool based upon analyses by TRAC at Syracuse University of court records detained from EOIR using the Freedom of Information Act. Retrieved on March 23, 2019. 


\section{No Nationality}

\begin{tabular}{|c|c|c|c|c|}
\hline & & Custody & & \\
\hline \multicolumn{5}{|l|}{ Fiscal Year Case } \\
\hline Began & Detained & Never Detained & Released & Yearly Total \\
\hline 2001 & 4 & 3 & 1 & 8 \\
\hline 2002 & 4 & 6 & 4 & 14 \\
\hline 2003 & 5 & 4 & 6 & 15 \\
\hline 2004 & 6 & 2 & 4 & 12 \\
\hline 2005 & 3 & 10 & 4 & 17 \\
\hline 2006 & 1 & 4 & 1 & 6 \\
\hline 2007 & 1 & 6 & & 7 \\
\hline 2008 & & 1 & & 1 \\
\hline 2009 & & & & 0 \\
\hline 2010 & & & & 0 \\
\hline 2011 & & & & 0 \\
\hline 2012 & & 1 & & 1 \\
\hline 2013 & & & & 0 \\
\hline 2014 & & & & 0 \\
\hline 2015 & & & & 0 \\
\hline 2016 & & & & 0 \\
\hline 2017 & & & & 0 \\
\hline 2018 & 1 & 2 & & 3 \\
\hline \multirow[t]{2}{*}{ Total 2001-2018 } & 25 & 39 & 20 & 84 \\
\hline & $30 \%$ & $46 \%$ & $24 \%$ & $100 \%$ \\
\hline
\end{tabular}

Source: Data accessed through the data tool based upon analyses by TRAC at Syracuse University of court records detained from EOIR using the Freedom of Information Act. Retrieved on March 23, 2019. 
Unknown Nationality

\section{Fiscal Year Case Began}

2001

2002

2003

2004

2005

2006

2007

2008

2009

2010

2011

2012

2013

2014

2015

2016

2017

2018

Total 2001-2018

\begin{tabular}{|c|c|c|c|}
\hline \multirow[b]{2}{*}{ Detained } & Custody & \multirow[b]{2}{*}{ Released } & \\
\hline & Never Detained & & \\
\hline 7 & 7 & 8 & 22 \\
\hline 3 & 18 & 1 & 22 \\
\hline 2 & 16 & & 18 \\
\hline 8 & 4 & 1 & 13 \\
\hline 4 & 10 & 3 & 17 \\
\hline 8 & 5 & 14 & 27 \\
\hline 34 & 12 & 12 & 58 \\
\hline 48 & 18 & 26 & 92 \\
\hline 41 & 28 & 24 & 93 \\
\hline 22 & 13 & 16 & 51 \\
\hline 19 & 19 & 13 & 51 \\
\hline 27 & 15 & 34 & 76 \\
\hline 34 & 23 & 28 & 85 \\
\hline 16 & 19 & 41 & 76 \\
\hline 15 & 19 & 17 & 51 \\
\hline 6 & 20 & 16 & 42 \\
\hline 16 & 26 & 14 & 56 \\
\hline 12 & 69 & 30 & 111 \\
\hline 322 & 341 & 298 & 961 \\
\hline $34 \%$ & $35 \%$ & $31 \%$ & $100 \%$ \\
\hline
\end{tabular}

Source: Data accessed through the data tool based upon analyses by TRAC at Syracuse University of court records detained from EOIR using the Freedom of Information Act. Retrieved on March 23, 2019. 
Palestine

\section{Custody}

\begin{tabular}{|c|c|c|c|c|c|}
\hline Fiscal Year Case & Began & Detained & Never Detained & Released & Yearly Total \\
\hline & 2001 & 5 & 12 & 12 & 29 \\
\hline & 2002 & 7 & 16 & 15 & 38 \\
\hline & 2003 & 9 & 25 & 5 & 39 \\
\hline & 2004 & 4 & 14 & 4 & 22 \\
\hline & 2005 & 7 & 25 & 2 & 34 \\
\hline & 2006 & 10 & 22 & 8 & 40 \\
\hline & 2007 & 12 & 30 & 13 & 55 \\
\hline & 2008 & 6 & 42 & 13 & 61 \\
\hline & 2009 & 11 & 42 & 6 & 59 \\
\hline & 2010 & 7 & 14 & 5 & 26 \\
\hline & 2011 & 4 & 26 & 8 & 38 \\
\hline & 2012 & & 16 & 8 & 24 \\
\hline & 2013 & 2 & 23 & 3 & 28 \\
\hline & 2014 & 3 & 23 & 4 & 30 \\
\hline & 2015 & & 19 & 4 & 23 \\
\hline & 2016 & 5 & 20 & 9 & 34 \\
\hline & 2017 & 9 & 21 & 6 & 36 \\
\hline & 2018 & 6 & 56 & 4 & 66 \\
\hline \multirow{2}{*}{\multicolumn{2}{|c|}{ Total 2001-2018 }} & 107 & 446 & 129 & 682 \\
\hline & & $11 \%$ & $46 \%$ & $13 \%$ & $71 \%$ \\
\hline
\end{tabular}

Source: Data accessed through the data tool based upon analyses by TRAC at Syracuse University of court records detained from EOIR using the Freedom of Information Act. Retrieved on March 23, 2019. 


\section{Soviet Union}

\begin{tabular}{|c|c|c|c|c|}
\hline & \multirow{2}{*}{\multicolumn{2}{|c|}{ Custody }} & \\
\hline & & & & \\
\hline \multicolumn{5}{|l|}{ Fiscal Year Case } \\
\hline Began & Detained & Never Detained & Released & Yearly Total \\
\hline 2001 & 3 & 4 & & 7 \\
\hline 2002 & 4 & 7 & 2 & 13 \\
\hline 2003 & 9 & 235 & 6 & 250 \\
\hline 2004 & 2 & 533 & 10 & 545 \\
\hline 2005 & 6 & 498 & 7 & 511 \\
\hline 2006 & 13 & 333 & 6 & 352 \\
\hline 2007 & 7 & 377 & 5 & 389 \\
\hline 2008 & 6 & 233 & 3 & 242 \\
\hline 2009 & 4 & 338 & 2 & 344 \\
\hline 2010 & 7 & 413 & 1 & 421 \\
\hline 2011 & 5 & 409 & 2 & 416 \\
\hline 2012 & 8 & 344 & 4 & 356 \\
\hline 2013 & 8 & 323 & & 331 \\
\hline 2014 & 10 & 207 & 2 & 219 \\
\hline 2015 & 4 & 197 & 1 & 202 \\
\hline 2016 & 2 & 228 & 1 & 231 \\
\hline 2017 & 6 & 417 & 3 & 426 \\
\hline 2018 & 5 & 851 & 2 & 858 \\
\hline \multirow[t]{2}{*}{ Total 2001-2018 } & 109 & 5947 & 57 & 6113 \\
\hline & $2 \%$ & $97 \%$ & $1 \%$ & $100 \%$ \\
\hline
\end{tabular}

Source: Data accessed through the data tool based upon analyses by TRAC at Syracuse University of court records detained from EOIR using the Freedom of Information Act. Retrieved on March 23, 2019. 
Yugoslavia

\section{Custody}

\begin{tabular}{|c|c|c|c|c|}
\hline $\begin{array}{l}\text { Fiscal Year Case } \\
\text { Began }\end{array}$ & Detained & Never Detained & Released & Yearly Total \\
\hline 2001 & 37 & 582 & 53 & 672 \\
\hline 2002 & 41 & 451 & 25 & 517 \\
\hline 2003 & 51 & 316 & 34 & 401 \\
\hline 2004 & 28 & 292 & 40 & 360 \\
\hline 2005 & 24 & 190 & 10 & 224 \\
\hline 2006 & 21 & 134 & 7 & 162 \\
\hline 2007 & 33 & 199 & 21 & 253 \\
\hline 2008 & 22 & 173 & 13 & 208 \\
\hline 2009 & 22 & 148 & 7 & 177 \\
\hline 2010 & 17 & 107 & 3 & 127 \\
\hline 2011 & 20 & 85 & 3 & 108 \\
\hline 2012 & 14 & 54 & 4 & 72 \\
\hline 2013 & 6 & 58 & 4 & 68 \\
\hline 2014 & 14 & 43 & 6 & 63 \\
\hline 2015 & 6 & 31 & 3 & 40 \\
\hline 2016 & 5 & 25 & & 30 \\
\hline 2017 & 7 & 39 & 2 & 48 \\
\hline 2018 & 3 & 61 & 1 & 65 \\
\hline \multirow[t]{2}{*}{ Total 2001-2018 } & 371 & 2988 & 236 & 3595 \\
\hline & $6 \%$ & $49 \%$ & $4 \%$ & $59 \%$ \\
\hline
\end{tabular}

Source: Data accessed through the data tool based upon analyses by TRAC at Syracuse University of court records detained from EOIR using the Freedom of Information Act. Retrieved on March 23, 2019. 
Attachment E: Annual numbers of asylum decisions by nationality and court decision

No Nationality

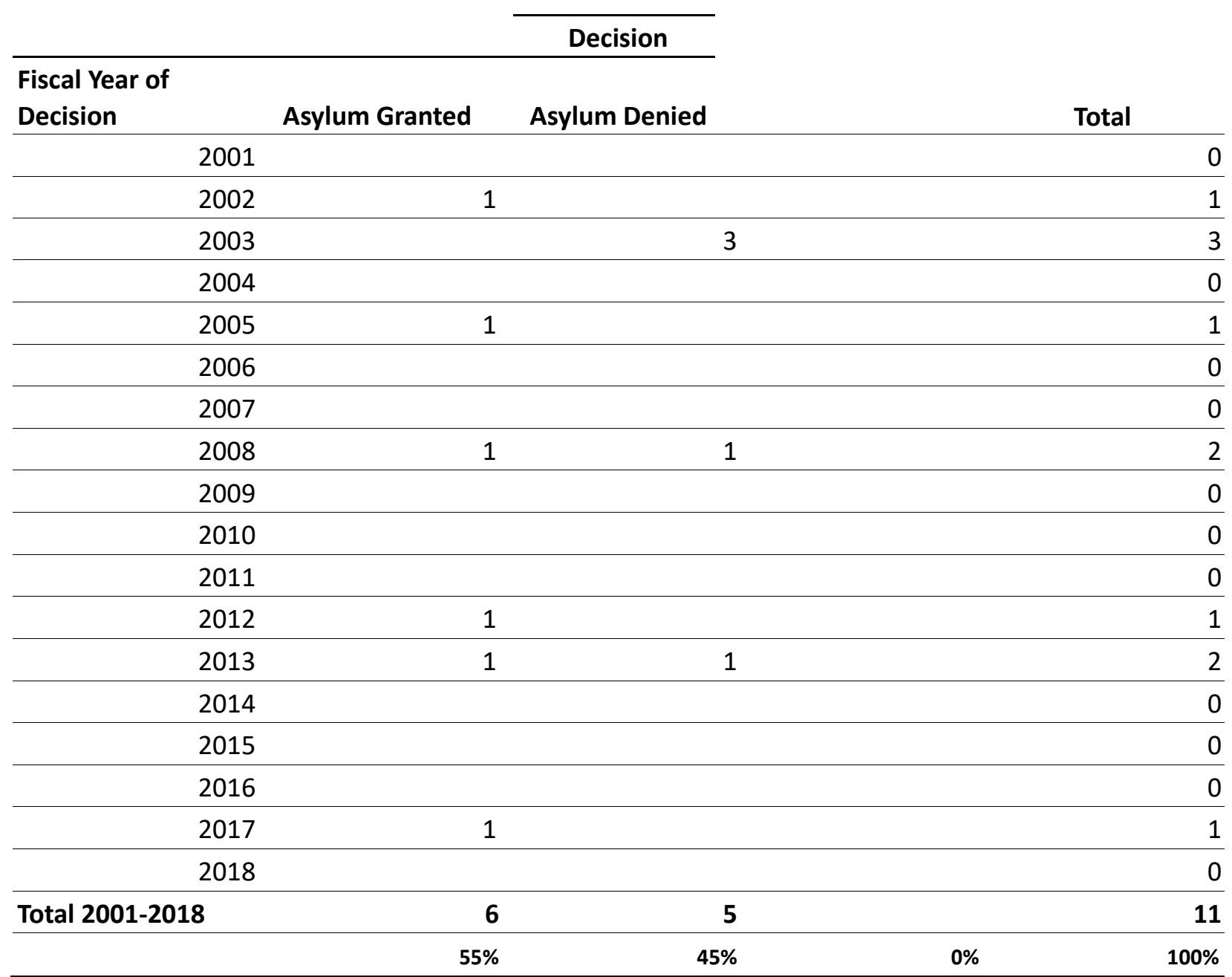

Source: Data accessed through the data tool based upon analyses by TRAC at Syracuse University of court records detained from EOIR using the Freedom of Information Act. Retrieved on March 23, 2019. 
Stateless - Alien Unable to Name a Country

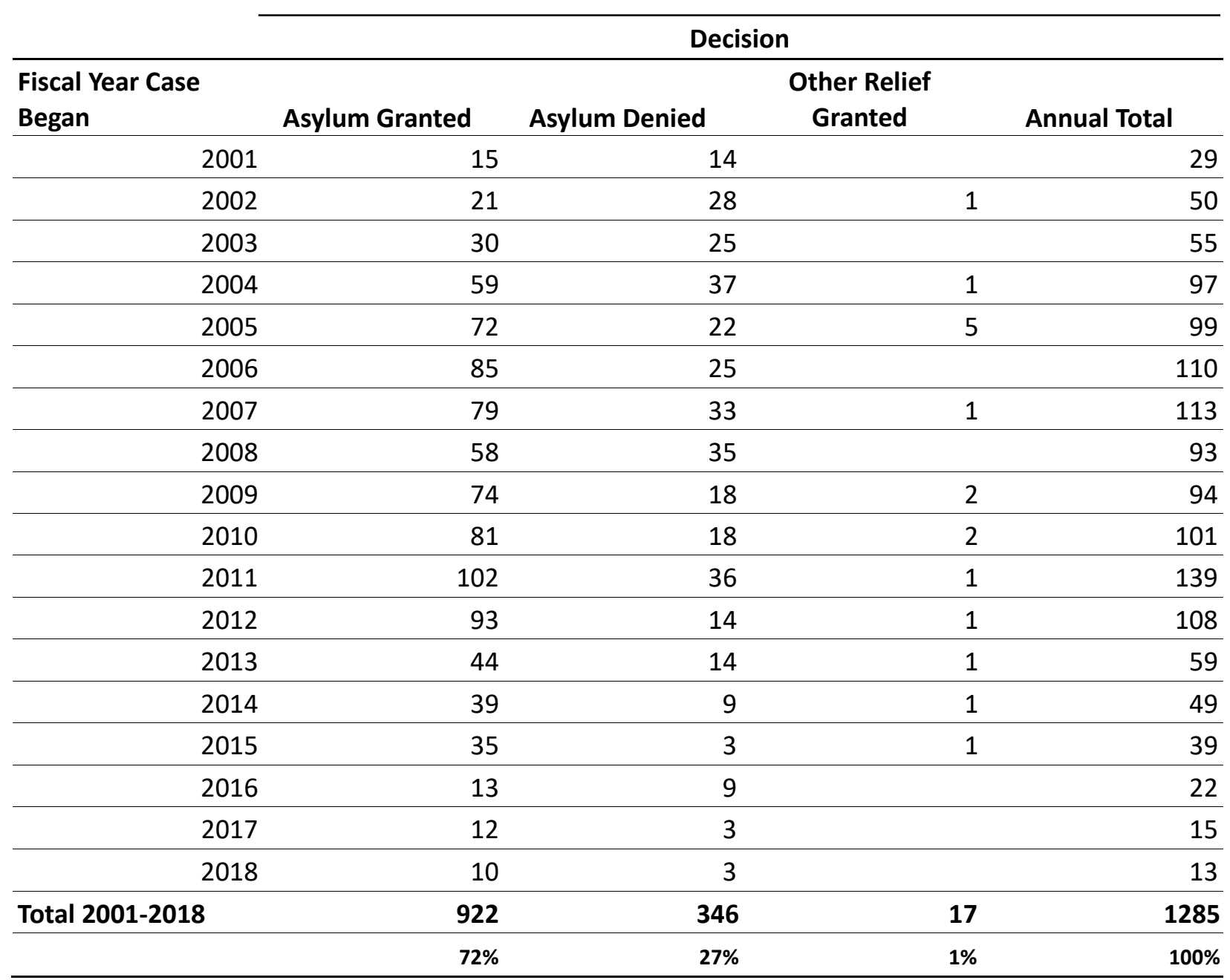

Source: Data accessed through the data tool based upon analyses by TRAC at Syracuse University of court records detained from EOIR using the Freedom of Information Act. Retrieved on March 23, 2019. 
Unknown Nationality

Decision

Fiscal Year Case

Other Relief

\begin{tabular}{|c|c|c|c|c|}
\hline Began & Asylum Granted & Asylum Denied & Granted & Annual Total \\
\hline 2001 & & 3 & & 3 \\
\hline 2002 & 1 & 11 & & 12 \\
\hline 2003 & 1 & 19 & & 20 \\
\hline 2004 & & 10 & & 10 \\
\hline 2005 & 2 & 12 & 1 & 15 \\
\hline 2006 & 2 & & & 2 \\
\hline 2007 & 1 & 1 & & 2 \\
\hline 2008 & 1 & 3 & 1 & 5 \\
\hline 2009 & 3 & 4 & & 7 \\
\hline 2010 & 2 & 1 & & 3 \\
\hline 2011 & 4 & 3 & & 7 \\
\hline 2012 & 2 & & & 2 \\
\hline 2013 & 4 & 1 & & 5 \\
\hline 2014 & 2 & 2 & & 4 \\
\hline 2015 & & & & 0 \\
\hline 2016 & 1 & & & 1 \\
\hline 2017 & 3 & & & 3 \\
\hline 2018 & 1 & & & 1 \\
\hline \multirow[t]{2}{*}{ Total 2001-2018 } & 30 & 70 & 2 & 102 \\
\hline & $29 \%$ & $69 \%$ & $2 \%$ & $100 \%$ \\
\hline
\end{tabular}

Source: Data accessed through the data tool based upon analyses by TRAC at Syracuse University of court records detained from EOIR using the Freedom of Information Act. Retrieved on March 23, 2019. 
Palestine

\section{Decision}

\section{Fiscal Year Case}

\section{Other Relief}

\begin{tabular}{|c|c|c|c|c|}
\hline Began & Asylum Granted & Asylum Denied & Granted & Annual Total \\
\hline 2001 & 1 & 4 & & 5 \\
\hline 2002 & & 7 & & 7 \\
\hline 2003 & & 5 & & 5 \\
\hline 2004 & 1 & 9 & & 10 \\
\hline 2005 & & 5 & & 5 \\
\hline 2006 & & 7 & & 7 \\
\hline 2007 & 3 & 8 & & 11 \\
\hline 2008 & 2 & 4 & & 6 \\
\hline 2009 & 5 & 5 & & 10 \\
\hline 2010 & 1 & 4 & & 5 \\
\hline 2011 & 3 & 1 & & 4 \\
\hline 2012 & 6 & 8 & & 14 \\
\hline 2013 & 1 & 4 & & 5 \\
\hline 2014 & & 2 & & 2 \\
\hline 2015 & 1 & 1 & & 2 \\
\hline 2016 & 1 & 2 & & 3 \\
\hline 2017 & 4 & 1 & & 5 \\
\hline 2018 & 2 & 6 & & 8 \\
\hline \multirow[t]{2}{*}{ Total 2001-2018 } & 31 & 83 & 0 & 114 \\
\hline & $27 \%$ & $73 \%$ & $0 \%$ & $100 \%$ \\
\hline
\end{tabular}

Source: Data accessed through the data tool based upon analyses by TRAC at Syracuse University of court records detained from EOIR using the Freedom of Information Act. Retrieved on March 23, 2019. 


\section{Soviet Union}

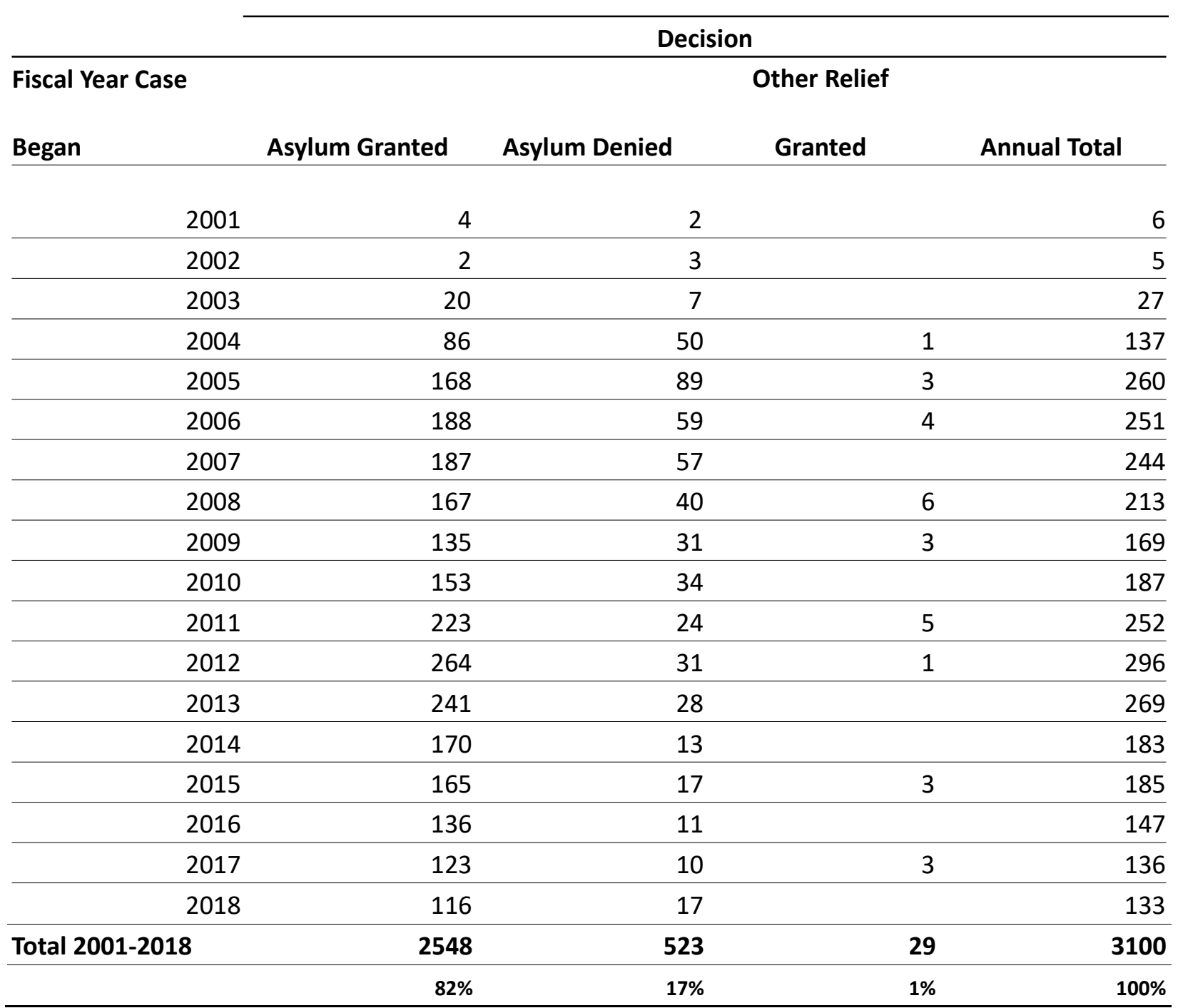

Source: Data accessed through the data tool based upon analyses by TRAC at Syracuse University of court records detained from EOIR using the Freedom of Information Act. Retrieved on March 23, 2019. 
Yugoslavia

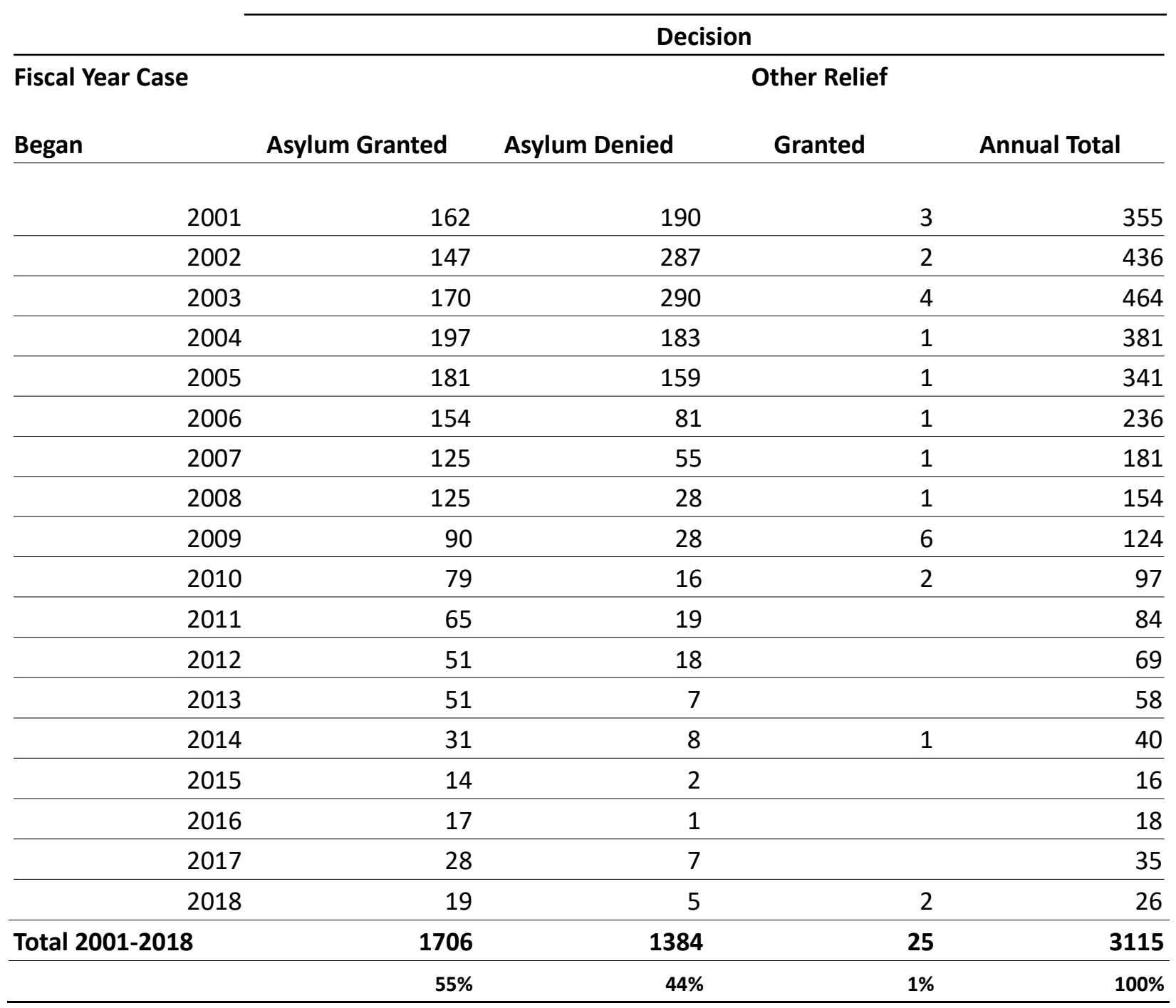

Source: Data accessed through the data tool based upon analyses by TRAC at Syracuse University of court records detained from EOIR using the Freedom of Information Act. Retrieved on March 23, 2019. 


\section{Attachment F: Annual figures of affirmative asylum applications filed and} cases completed from 2011 to 2016

\begin{tabular}{|c|c|c|c|c|c|c|c|c|c|}
\hline Nationality & $\begin{array}{c}\text { Calendar } \\
\text { Year }\end{array}$ & Received & Reopened & Approvals & Denials & $\begin{array}{c}\text { Referrals } \\
\text { (interviewed } \\
\text { cases) }\end{array}$ & $\begin{array}{c}\text { Filing } \\
\text { Deadline } \\
\text { Referrals }\end{array}$ & $\begin{array}{c}\text { Referrals } \\
\text { (uninterviewed } \\
\text { cases) }\end{array}$ & $\begin{array}{c}\text { Administratively } \\
\text { Closed/no-show } \\
\text { denials }\end{array}$ \\
\hline Stateless & CY 2011 & 95 & 2 & 31 & 4 & 25 & 13 & 4 & 3 \\
\hline Stateless & CY 2012 & 68 & 2 & 38 & 3 & 25 & 5 & 1 & 2 \\
\hline Stateless & CY 2013 & 86 & 4 & 33 & 3 & 8 & 3 & 4 & 2 \\
\hline Stateless & CY 2014 & 107 & d & 32 & 5 & 10 & 3 & 2 & 1 \\
\hline Stateless & CY 2015 & 202 & 1 & 30 & 1 & 27 & 3 & 2 & 8 \\
\hline Stateless & CY 2016 & 260 & 1 & 32 & 1 & 19 & 0 & 4 & 13 \\
\hline $\begin{array}{l}\text { SIX-YEAR } \\
\text { TOTALS }\end{array}$ & & 818 & 10 & 196 & 17 & 114 & 27 & 17 & 29 \\
\hline
\end{tabular}

Source: Bureau of Citizenship and Immigration Services, Refugees, Asylum, and Parole System (RAPS)

\begin{tabular}{|c|c|c|c|c|c|c|c|c|c|}
\hline \multirow[b]{2}{*}{ Nationality } & \multirow[b]{2}{*}{$\begin{array}{c}\text { Calendar } \\
\text { Year }\end{array}$} & \multicolumn{2}{|c|}{ Applications Filed } & \multicolumn{2}{|l|}{ Cases } & \multirow[b]{2}{*}{$\begin{array}{c}\text { Referrals } \\
\text { (interviewed } \\
\text { cases) }\end{array}$} & \multirow[b]{2}{*}{\begin{tabular}{|c|} 
Filing \\
Deadline \\
Referrals
\end{tabular}} & \multirow[b]{2}{*}{$\begin{array}{c}\text { Referrals } \\
\text { (uninterviewed } \\
\text { cases) }\end{array}$} & \multirow[b]{2}{*}{$\begin{array}{c}\text { Administratively } \\
\text { Closed/no-show } \\
\text { denials }\end{array}$} \\
\hline & & Received & Reopened & Approvals & Denials & & & & \\
\hline Yugoslavia & CY 2011 & 22 & 2 & 6 & 0 & 5 & 0 & d & $\theta$ \\
\hline Yugoslavia & CY 2012 & 27 & 7 & 10 & 0 & 2 & 1 & d & d \\
\hline Yugoslavia & CY 2013 & 28 & 8 & 1 & 0 & 2 & 3 & d & 1 \\
\hline Yugoslavia & CY 2014 & 21 & 1 & 2 & 0 & 3 & 0 & 1 & g \\
\hline Yugoslavia & CY 2015 & 21 & 1 & 8 & 1 & 1 & 1 & d & 2 \\
\hline Yugoslavia & CY 2016 & 8 & 8 & 4 & 0 & 1 & 1 & 1 & 2 \\
\hline $\begin{array}{l}\text { SIX-YEAR } \\
\text { TOTALS }\end{array}$ & & 127 & 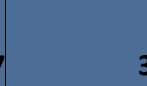 & 31 & 1 & 14 & 6 & 2 & 11 \\
\hline
\end{tabular}

Source: Bureau of Citizenship and Immigration Services, Refugees, Asylum, and Parole System (RAPS) 


\section{Affirmative Asylum Report Key (source: Affirmative Asylum Application Statistics and Decisions Annual Report)}

Applications Filed: The total number of new asylum cases received and reopened cases.

Applications Received: The number of new asylum cases USCIS received during the fiscal year.

Applications Reopened: The total number of previously administratively closed asylum cases that were reopened.

Cases Completed: The total number of cases approved, denied, interviewed referred, uninterviewed referred, and administratively closed.

Approved: The number of cases that USCIS approved for asylum status during the fiscal year.

Denied: The number of cases USCIS interviewed and found ineligible for asylum status while in lawful immigration status.

Interviewed Referred: The number of cases USCIS interviewed, found ineligible for asylum status, and referred to the Immigration Judge because the applicant was not in lawful immigration status. Included is the number of referrals following termination of approved asylum applications.

Filing Deadline Referrals: The number of cases USCIS interviewed and found ineligible for asylum status and referred to the Immigration Judge because the applicant failed to establish that they met the one year filing deadline or exceptions

Un-interviewed Referred: The number of cases USCIS referred to the Immigration Judge because the applicant failed to appear for interview or withdrew his or her asylum application and were not in lawful immigration status.

Administratively Closed: The number of cases USCIS administratively closed for lack of jurisdiction, withdrawn by an applicant who is a lawful permanent resident, or found ineligible due to status as a US Citizen, outside the US/abandoned, or denied for failure to appear.

NOTE: Cases completed in any fiscal year could have been filed, received, or reopened in previous fiscal years. Cases may include more than one individual (e.g., an applicant and a spouse and/or children). 